\title{
Advancing the Science of Natural and Enhanced Attenuation for Chlorinated Solvents
}

\begin{abstract}
Final Technical Document for the Monitored Natural Attenuation and Enhanced Attenuation for Chlorinated

Solvents Project
\end{abstract}

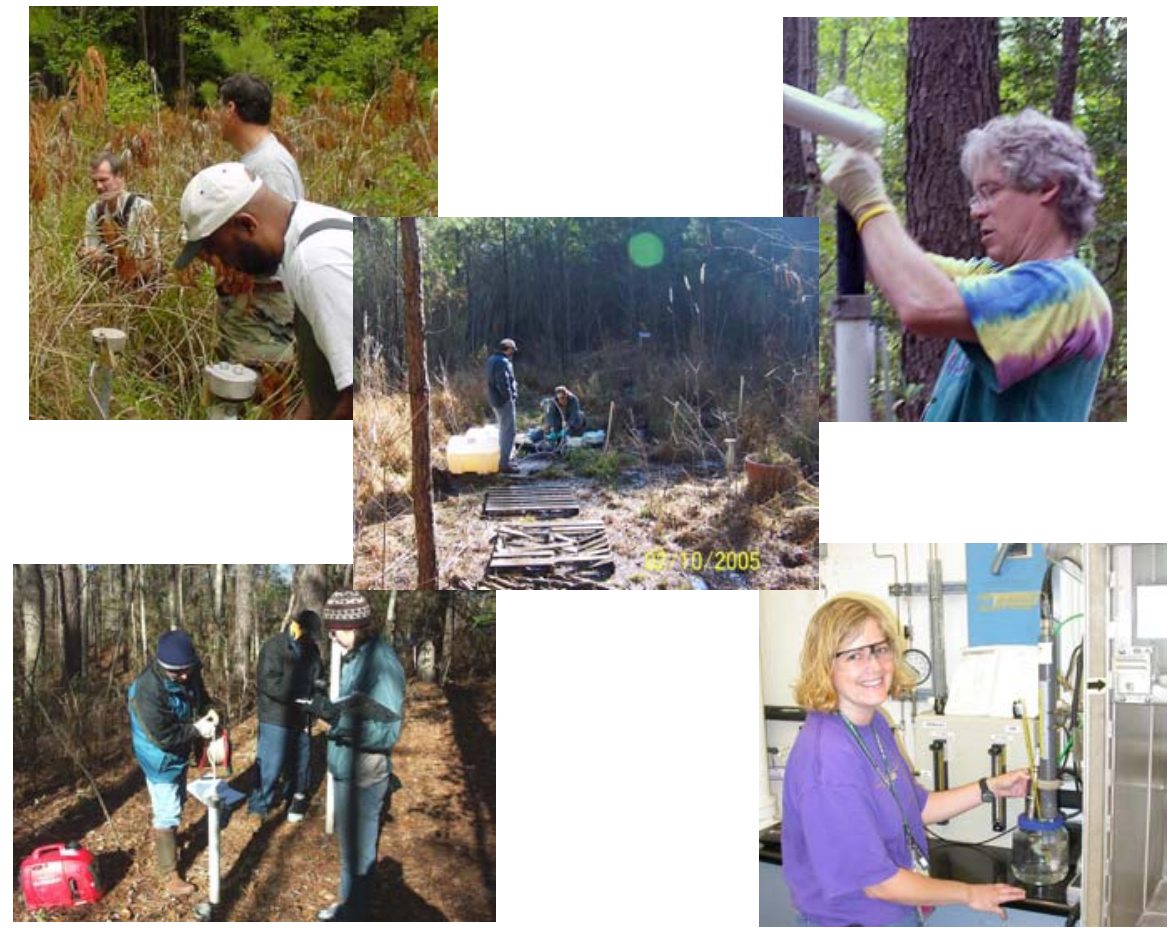

December 27, 2006

Washington Savannah River Company Savannah River Site Aiken, SC 29808

Prepared for the U.S. Department of Energy Under Contract Number DEAC09-96SR18500

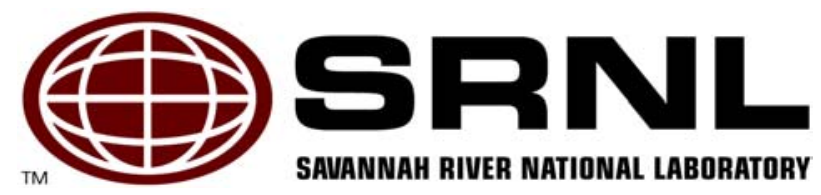




\title{
DISCLAIMER
}

Preparation of this report was coordinated by Washington Savannah River Company (WSRC) for the United States Department of Energy (DOE) under Contract No. DE-AC09-96SR18500. Extensive effort was made by the authors to assure the accuracy of the contents and interpretation. However, neither the DOE, nor WSRC, nor any of their employees makes any warranty, express or implied, or assumes any legal liability or responsibility for the accuracy, completeness, or usefulness of any information, apparatus, or product, or process disclosed herein, or represents that its use will not infringe privately owned rights. Reference herein to any specific commercial product, process, or service by trademark, name, manufacturer, or otherwise does not necessarily constitute or imply endorsement, recommendation, or favoring of same by the United States Government or any agency; thereof. The views and opinions of the authors expressed herein do not necessarily state or reflect those of the United States Government or any agency thereof.

\section{ACKNOWLEDGEMENTS}

We would like to acknowledge those who played a key role in the development of this work. The United States Department of Energy (US DOE) Office of Engineering and Technology sponsored this effort. We appreciate the guidance and support of Dinesh Gupta and Claire Sink of US DOE Headquarters and Karen Adams of US DOE Savannah River. We acknowledge the participation and collaboration of other federal agencies, notably, the U.S. Geological Survey (USGS) and the U.S. Environmental Protection Agency (US EPA), as well as state agencies such as the SC Department of Health and Environmental Control, the FL Department of Environmental Protection, and the multistate Interstate Regulatory and Technology Council. We are grateful to the independent peer review panel for their careful reviews and helpful input.

\section{Printed in the United States of America}

\author{
Prepared For \\ U.S. Department of Energy
}

Cover Photos: Center - Jack Istok, Oregon State University conducting Push-Pull tests to evaluate sustainability of MNA at SRS testbed with Glenn White of Haley Aldrich (visiting interested party) looking on. Upper Left - Paul Bradley and Frank Chapelle, USGS, and Johnny Simmons, SRNL, collecting sediment samples at SRS testbed for aerobic processes research study. Upper Right - Kirk Hatfield, University of Florida, retrieving a passive flux meter from the SRS testbed. Lower Right-Maggie Millings, SRNL, preparing laboratory testing apparatus in support of oxygen sensor study. Lower Left-Laura Jennings, Cornell University graduate student, and Bill Jones and Johnny Simmons, SRNL, collecting samples from SRS testbed for co-metabolism studies supporting developing of a molecular-based probe for microorganisms JS666. 
Key Words: remediation

environment

Retention:

Permanent

\section{Advancing the Science of Natural and Enhanced Attenuation for Chlorinated Solvents}

Final Technical Document for the Monitored Natural Attenuation and Enhanced Attenuation for Chlorinated Solvents Project

December 27, 2006

Brian B Looney, SRNL

Thomas O. Early, GeoConsultants, Inc.

Tyler Gilmore, PNNL

Francis H. Chapelle, USGS

Norman H. Cutshall

Jeffrey Ross, BSRI

Mark Ankeny, INL

Michael Heitkamp, SRNL

David Major, GeoSyntec

Charles J. Newell, Groundwater Services, Inc.

W. Jody Waugh, S.M. Stoller

Gary Wein, SREL

Karen M. Vangelas, SRNL

Karen M. Adams, DOE SR

Claire H. Sink, DOE HQ

Washington Savannah River Company

Savannah River Site

Aiken, SC 29808

Prepared for the U.S. Department of Energy

Under Contract Number DEAC09-96-

SR18500

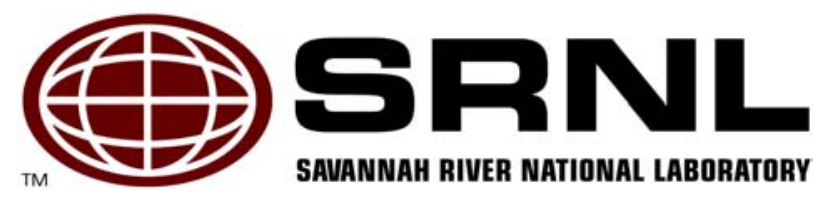




\section{Preface}

The U.S. Department of Energy funded Monitored Natural Attenuation and Enhanced Attenuation for Chlorinated Solvents Project began in early 2004. This report is a culmination of the three-year effort by the project team (the Technical Working Group and the 14 research teams). The objective of this document is to provide a summary of the major contributions of this project to the advance of natural attenuation based remedies for chlorinated solvents. The intended audience for this summary document includes state and federal regulators, stakeholders, and environmental managers, as well as environmental technology professionals. This document introduces the concepts of mass balance, sustainability, and enhanced attenuation and identifies technical contributions to support their use in natural attenuation remedies. We have attempted to provide references to both project documents and pertinent publications in the open literature for those readers who would like more technical details. 


\section{Table of Contents}

Executive Summary .............................................................................................................................vviii

Chapter 1.0 Introduction......................................................................................................................1 1

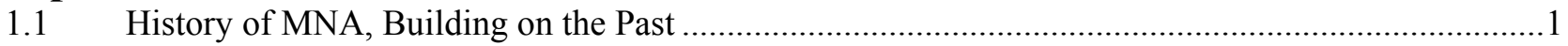

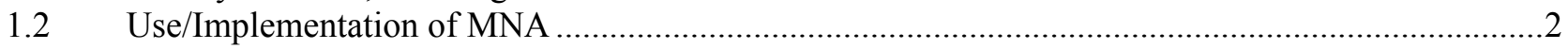

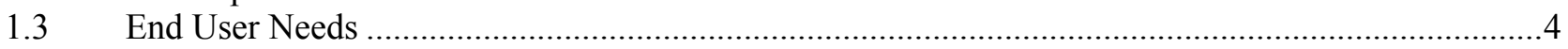

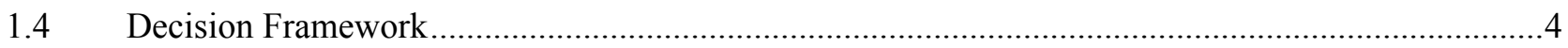

1.5 Importance of Plume Stability and Sustainability to Attenuation-Based Remediation ......................4

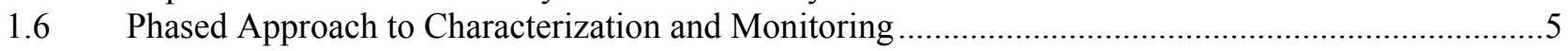

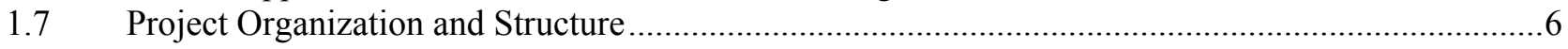

Chapter 2.0 Evaluating Plume Stability and Estimating Sustainability .................. 7

$2.1 \quad$ The Sustainability of Natural and Enhanced Attenuation.......................................................... 12

2.2 Field Tools to Measure Mass Balance and Support Attenuation................................................ 12

2.3 Mathematical Tools to Calculate Mass Balance and Support Natural and Enhanced Attenuation ...13

2.4 Summary of Mass Balance and Sustainability Concepts............................................................17

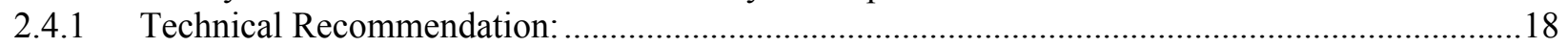

Chapter 3.0 Advances in Understanding Attenuation Processes/Tools .................. 19

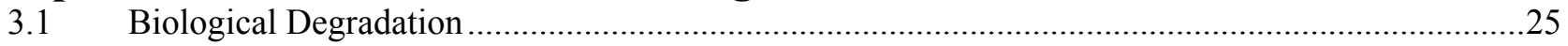

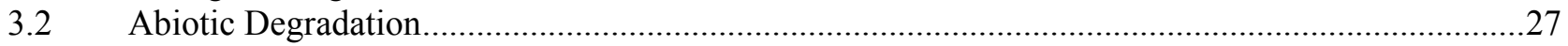

3.3 Nondestructive Physical, Chemical and Hydrogeological Attenuation Processes ..........................27

3.4 Boundary Condition Effects on Attenuation...........................................................................28

3.5 Supporting Chemical and Physical Characterization and Monitoring Tools...................................28

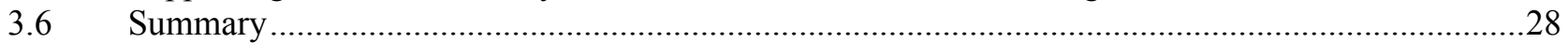

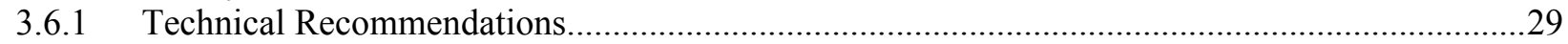

\section{Chapter 4.0 Enhanced Attenuation: A Bridge between Source Treatment and}

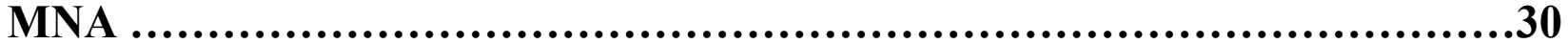

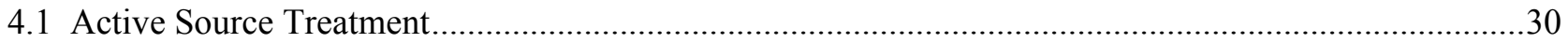

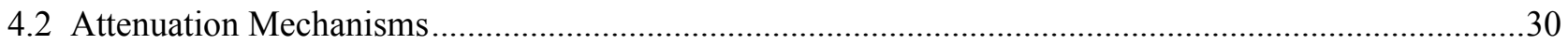

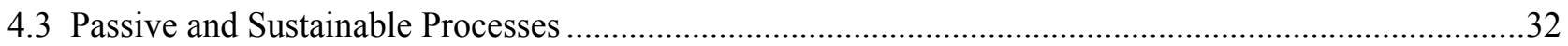

4.4 Linkage of EA to Mass Balance, Characterization and Monitoring ….................................................33

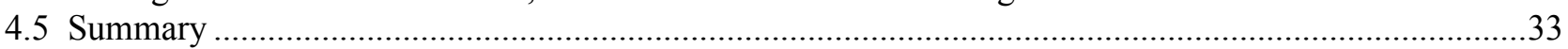

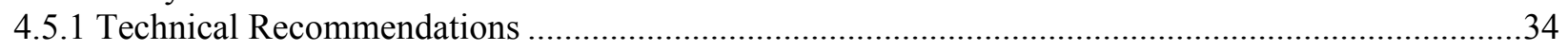

Chapter 5.0 Implementing the Science - Decision Making for Remedial Actions .35

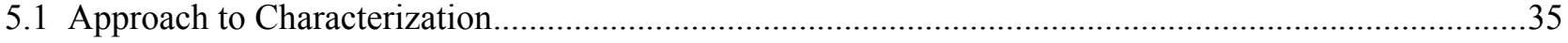

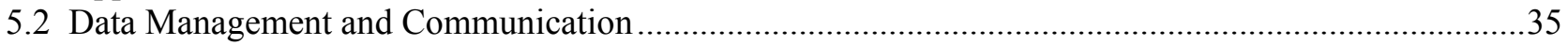

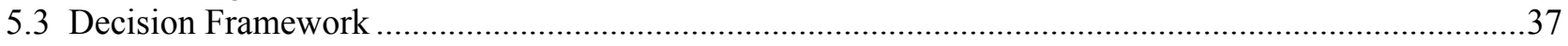

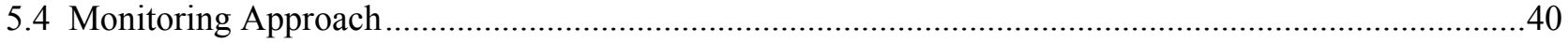

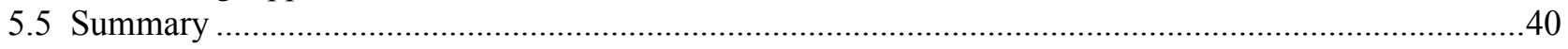

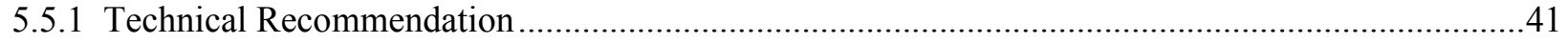

Chapter 6.0 Future Needs and Path Forward .................................................... 42

6.1 Interstate Technology and Regulatory Council (ITRC) ................................................................42

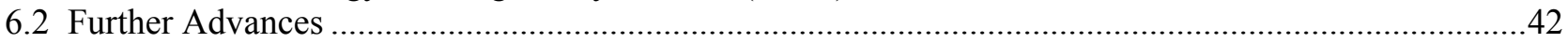

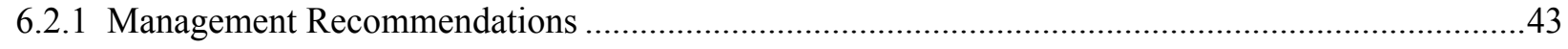

REFERENCES:...................................................................................................... 44

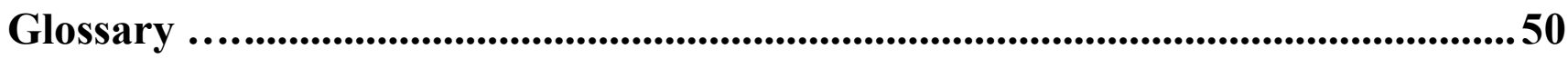




\section{Appendices}

Appendix A: Table of Research Projects (grouped by topic with title of project, PI, affiliation, title of research report (including document number), and major contribution to MNA/EA Project)

Appendix B: Project Bibliography (2004-2006)

Appendix C: Monitored Natural Attenuation/Enhanced Attenuation for Chlorinated Solvents Project Team

\section{List of Tables}

Table 1. Representative Chlorinated Solvent Tools and Models

Table 2. Key Mass Balance Related Questions Addressed by Representative Chlorinated Solvent Tools

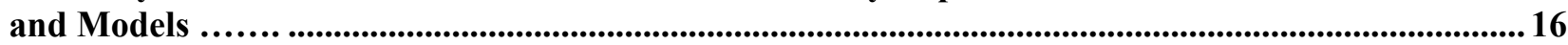

Table 3. Considerations for Selecting Modeling Approach based on Site Properties................................... 17

Table 4. Processes, Issues and Opportunities (ref Looney et al. 2006b) ........................................................ 20

Table 5. Attenuation Mechanisms and Processes and their Relative Effectiveness for Different Example

Contaminants (ref Looney et al. 2006b).

\section{List of Figures}

Figure 1. A range of technologies is required to meet plume remediation needs. 3

Figure 2. The unique project structure engaged participants from the technical community, end users and regulators.

Figure 3. The mass balance between contaminant loading and attenuation capacity defines the efficiency and viability of natural and enhanced attenuation.

Figure 4. Dynamic development of a contaminant plume and the relationship to mass balance and response actions.

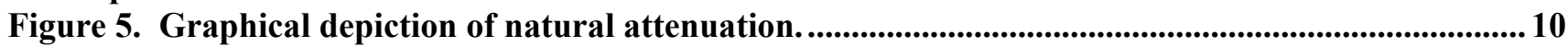

Figure 6. Graphical depiction of enhanced attenuation. .....................................................................10

Figure 7. Schematic showing examples of different types of enhancements and the zones where they

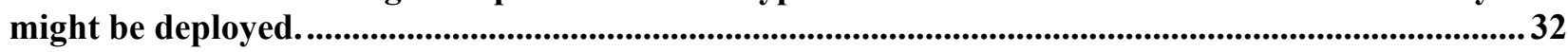

Figure 8. A Four-Phased Approach to Characterization and Monitoring to Support MNA and EA...... 36

Figure 9. General structure of the Decision Framework ........................................... 38

Figure 10. Flowchart to guide decision-making on remedial options for chlorinated solvent contaminated sites 


\section{Recommendations}

\section{Technical Recommendations}

T1. Incorporate additional attenuation mechanisms as they are identified in the literature into deterministic mass balance models

T2. Develop mass-balance tools for optimizing the efficiency and sustainability of enhanced attenuation

T3. Develop better tools to determine key parameters needed to implement a mass balance for diverse contaminated sites.

T4. Develop a better understanding of attenuation mechanisms

T5. Evaluate past datasets to assess effectiveness and sustainability of attenuation remedies under varying conditions..

T6. Perform focused field studies of enhancements with detailed monitoring and a sufficient period of record to document sustainability.

T7. Develop Strategies and Technologies for performance verification and long-term monitoring........ 41

\section{Management Recommendations}

M1 Review effectiveness and sustainability of MNA/EA designs and monitoring plans prior to closure

M2 Support and implement a project to meet needs for process and system performance monitoring and reduce long-term costs and risks.

M3 Develop a crosscutting initiative that includes the Department of Energy's Offices of Environmental Management, Legacy Management and Office of Science to coordinate and leverage planned remediation and research activities. 


\section{Acronym List}

CERCLA Comprehensive Environmental Response, Compensation, and Liability Act

cVOC chlorinated volatile organic contaminant

DNA deoxyribonucleic acid

DNAPL Dense Non-Aqueous Phase Liquid

DoD Department of Defense

DOE Department of Energy

EA Enhanced Attenuation

EACO Enhanced Attenuation Chlorinated Organics

EISB Enhanced in situ Bioremediation

EPA Environmental Protection Agency

ITRC Interstate Technology and Regulatory Council

MBT Molecular Biological Tools

MNA Monitored Natural Attenuation

NAPL Non-Aqueous Phase Liquid

NRC National Research Council

OSWER Office of Solid Waste and Emergency Response

RCRA Resource Conservation and Recovery Act

RNA ribonucleic acid

TWG Technical Working Group

SERDP Strategic Environmental Research and Development Program

SRNL Savannah River National Laboratory

\section{Chemicals}

$\begin{array}{ll}\text { CA } & \text { Chloroethane } \\ \text { CF } & \text { Chloroform } \\ \text { CM } & \text { Chloromethane } \\ \text { CT } & \text { Carbon tetrachloride } \\ \text { DCA } & \text { Dichloroethane } \\ \text { DCE } & \text { Dichloroethene } \\ \text { DCM } & \text { Dichloromethane } \\ \text { PCE } & \text { Tetrachloroethene } \\ \text { TCA } & \text { Trichloroethane } \\ \text { TCE } & \text { Trichloroethene } \\ \text { VC } & \text { Vinyl Chloride }\end{array}$




\section{Executive Summary}

This report summarizes the results of a three-year program that addressed key scientific and technical aspects related to natural and enhanced attenuation of chlorinated organics. The results from this coordinated threeyear program support a variety of technical and regulatory advancements. Scientists, regulators, engineers, end-users and stakeholders participated in the program, which was supported by the U.S. Department of Energy (DOE) and the Interstate Technology and Regulatory Council (ITRC). The overarching objective of the effort was to examine environmental remedies that are based on natural processes - remedies such as Monitored Natural Attenuation (MNA) or Enhanced Attenuation (EA). A key result of the recent effort was the general affirmation of the approaches and guidance in the original U.S. Environmental Protection Agency (EPA) chlorinated solvent MNA protocols and directives from 1998 and 1999, respectively. The research program did identify several specific opportunities for advances based on: 1) mass balance as the central framework for attenuation based remedies, 2) scientific advancements and achievements during the past ten years, 3) regulatory and policy development and real-world experience using MNA, and 4) exploration of various ideas for integrating attenuation remedies into a systematic set of "combined remedies" for contaminated sites. These opportunities are summarized herein and are addressed in more detail in referenced project documents and journal articles, as well as in the technical and regulatory documents being developed within the ITRC.

Natural attenuation processes occur in all soil and groundwater systems and act, to varying degrees, on all contaminants. Thus, a decision to rely on natural attenuation processes as part of a site-remediation strategy does not depend on the occurrence of natural attenuation, but on its effectiveness in meeting site-specific remediation goals. Meeting these goals typically requires low risk, plume stability, and documentation of accepted and sustainable attenuation processes. Plume stability and sustainability depend on the balance between contaminant loading into the plume and contaminant attenuation within the plume. This "mass balance" is a simple and powerful idea that developed into the central framework for all aspects of the DOE MNA/EA program. The centrality of mass balance has been advocated by Chapelle and others (e.g., 1995) for several years, and the concepts proved to be critical to conceptualizing natural attenuation remedies, designing enhancements, developing characterization and monitoring strategies, and developing regulatory decision frameworks that encourage broader use of MNA/EA with clarified technical responsibility.

Defining the potential role of emerging bioassessment tools - such as deoxyribonucleic acid (DNA), ribonucleic acid (RNA) and target protein analysis - in characterizing and monitoring attenuation mechanisms and rates led many of the notable achievements that built on recent scientific advancements. Researchers determined that these tools provide key information about the microbial ecology and the presence or absence of important organisms in the microbial community. Their results help define both the potential benefits and limitations of such methods. For example, researchers found that a widely used DNA-based tool (based on a particular kind of ribosomal RNA, known as 16S rRNA, to identify the types and strains of microorganisms in a sample) did not necessarily provide enough information to determine the specific attenuation capabilities of some of the important organisms - the researchers identified some relatively simple additional tests that target the enzymes for the functionally desired characteristics. The project fostered collaboration among the microbial ecology laboratories in the United States and Canada and facilitated some early standardization of sampling, sample handling, preservation and storage techniques for DNA and RNA analyses. The biological research examined traditional metabolic pathways such as reductive dechlorination, as well as other emerging attenuation pathways such as cometabolism, and anaerobic oxidation/mineralization. The research portfolio also addressed abiotic degradation resulting from interaction of contaminants and mineral phases and nondestructive chemical and physical attenuation mechanisms such as sorption. 
Notable achievements related to regulatory and policy developments and real-world experiences were primarily related to developing and evaluating concepts for enhancement of natural attenuation processes and for the monitoring of MNA and EA. Since the publication of the EPA protocol and directive, innovators from industry, academia and federal agencies have developed a wide array of environmental remediation technologies. These include "aggressive" source removal or destruction technologies, but also include techniques such as bioremediation and permeable reactive barriers. Further, within these broad classes, many options have been developed that allow a range of deployment opportunities - in several cases, these deployment options include long-lived performance that facilitates and accelerates the site transition to a stable natural attenuation state. Around the country, state and federal regulators have explored the best ways to combine technologies into systems that provide environmental protection while minimizing the unnecessary use of resources or causing adverse collateral damage. The efforts of the scientists and regulators developing EA concepts documented significant promise for many technologies to contribute to EA. The promising concepts included the technologies one would expect, such as various configurations of bioremediation with long-lived electron donor. Importantly, based on the mass balance idea, several unexpected ideas also appeared promising, such as hydrologic modification, constructed wetlands, and many others. Innovative characterization and monitoring was determined to be a key to the viability of all potential MNA and EA concepts. Once again, mass balance provides the framework for optimization and for setting the performance goals, and for selecting and identifying tools and techniques. Three notable characterization and monitoring findings were: 1) more direct measures of processes are important to decision characterization and may be useful throughout both short- and long-term monitoring, 2) innovative uses of push-pull tests and similar field tests have the potential to provide more realistic measures of controlling process rates, and 3) alternative integrating measures such as flux and water balance may provide substantial opportunities for optimizing longterm monitoring.

There were numerous notable achievements related to integrating attenuation remedies into systematic site remediation. These ranged from a practical taxonomic screening system to support site-specific planning, to simple mass balance based modeling tools such as BIOBALANCE, to modules for sophisticated numerical biogeochemical models such as RT3D or SEAM3D, to decision support tools. The simple philosophy of the effort was that tools of varying sophistication are needed to advance the scientific implementation of MNA and EA, and that insertion of tools at all of these levels is the best way to contribute to the advancement. The mass balance concept proved useful in developing consistent and logical modeling tools across investigators and institutions. Supplementing these tools was research and case-study implementation of a decision support system and the related development of a regulatory flowchart by the ITRC Enhanced Attenuation Chlorinated Organics (EACO) team. The various tools that have been developed can be used by the ITRC as they develop training classes and technical and regulatory guidance. The many practical support and implementation advancements over the past several years, combined with the progress on the various specific targeted scientific, technical and policy topics will support future transition of chlorinated solvent sites to MNA.

As a snapshot, the DOE MNA/EA program supported the following activities and products:

- Development of technical targets by recognized experts in natural attenuation and related disciplines;

- 14 major research projects and three working groups to address these targets in an organized and comprehensive manner (see Appendix A);

- Field research at DOE sites to support appropriate use of natural and enhanced attenuation remedies under a variety of conditions;

- Open publication of the research results and a process to integrate the results to address the original objectives;

- Regular information exchange with regulatory agencies, DOE site advisory boards and operators, environmental public interest groups, scientific peers, and others;

- Practical tools for evaluating and implementing MNA/EA including a screening tool, computer based mass balance models, a decision support tool, a regulatory decision flowchart, etc.; 
WSRC-STI-2007-00377, Final

December 27, 2006

Page $x$ of $x i$

○ A popular newsletter, “The Natural Attenuation Monitor," and publicly available journal articles, and reports (see Appendix B); and

- Collaboration with the ITRC EACO team as they develop technical and regulatory guidance, outreach and training.

Substantive progress was made within this program - progress that will directly support proper use of MNA and EA to achieve remediation goals. The effort also identified several areas where continued rapid scientific advancement is being made, as well as areas where future advancement is needed. These, in turn, are the basis of seven technical and three management recommendations for the future. A short listing of these

recommendations is provided below. Each individual recommendation along with a more detailed supporting narrative is provided in the appropriate section of the report.

Technical Recommendations:

T1. Incorporate additional attenuation mechanisms as they are identified in the literature into deterministic mass balance models

T2. Develop mass-balance tools for optimizing the efficiency and sustainability of enhanced attenuation

T3. Develop better tools to determine key parameters needed to implement a mass balance for diverse contaminated sites

T4. Develop a better understanding of attenuation mechanisms

T5. Evaluate past datasets to assess effectiveness and sustainability of attenuation remedies under varying conditions

T6. Perform focused field studies of enhancements with detailed monitoring and a sufficient period of record to document sustainability

T7. Develop strategies and technologies for performance verification and long-term monitoring

Management Recommendations:

M1. Review effectiveness and sustainability of MNA/EA designs and monitoring plans prior to closure

M2. Support and implement a project to meet needs for process and system performance monitoring and reduce long-term costs and risks

M3. Develop a crosscutting initiative that includes the Department of Energy's Offices of Environmental Management, Legacy Management and Science to coordinate and leverage planned remediation and research activities. 


\section{Chapter 1.0 Introduction}

Advances in understanding attenuation mechanisms have been made and improved tools have been identified that enable greater reliance on Monitored Natural Attenuation (MNA) for cleaning up chlorinated-solventcontaminated groundwater. A successful and highly productive 3-year project, based at Savannah River National Laboratory (SRNL), was designed with a national scope that is relevant to both public and privatesector sites. End-users and regulators joined development scientists and engineers from Department of Energy (DOE) laboratories, other federal agencies, several private companies and several research universities to address the most important concerns about dependence on MNA. Although it was focused on chlorinated solvents (tetrachloroethene (PCE) and trichloroethene (TCE)), many of the project advances are expected to also support remediation of metal- and radionuclide-contaminated plumes. A major contribution of this project is the development of "Enhanced Attenuation" approaches, which build on established natural attenuation practices, but target cases where natural attenuation alone is not sufficient.

\subsection{History of MNA, Building on the Past}

Natural attenuation occurs at all sites and has been either explicitly or implicitly a fundamental component of virtually every modern waste management strategy. Beginning in the early 1990s, natural attenuation for biodegradation of petroleum hydrocarbon sites, primarily encouraged by the Department of Defense (DoD) and the National Research Council (NRC, 1993), gained acceptance and has since increased to widespread application. More recently, explicit dependence on natural attenuation for remediation of contaminated groundwater is growing. The U.S. Environmental Protection Agency (EPA) formally recognized regulation of the use of natural attenuation for chlorinated solvents and the use of the term "Monitored Natural Attenuation" with issuance of two documents, the protocol (EPA, 1998) and directive (EPA, 1999). Organizations such as the NRC (2001) and state regulatory agencies (e.g., MPCA, 2006, WI-DNR, 2003) evaluated and extended the ideas. These documents encouraged the use of MNA in combination with other actions, as needed, to achieve remediation goals.

Natural attenuation has several advantages. By definition, it must be sustainable and operate without intervention during the course of remediation. It is generally more environmentally friendly than aggressive measures, which are sometimes highly disruptive. It does not require expensive systems, other than for monitoring. However, there are also disadvantages. Natural attenuation may be slow compared to more aggressive actions. Regulators and skeptical stakeholders may view it as equivalent to no action and, therefore, an evasion of responsibility. Nonetheless, the final stages of remediation and attenuation at the fringe of contaminant plumes all must eventually depend on natural processes to contain or destroy the last traces of contamination.

Selection of MNA alone or following active remediation for sites contaminated with chlorinated solvents increased in the late 1990s and continued beyond 2000. The greatest numbers of applications were for relatively small sites (McGuire, et al, 2003) although it was also generally recognized that very large contaminated areas, such as existed at DOE sites, would eventually depend on MNA. DOE therefore initiated an Alternative Project in 2003 (referred to hereafter as the "MNA/EA") designed to advance the use of MNA for chlorinated solvent cleanup. This project was intended to build on the progress that had been achieved by EPA and DoD programs. The project was initially designed to meet three goals:

Advance fundamental understanding - Identifying and better quantifying the natural processes contributing to attenuation-based remedies are critical elements for relying on MNA at real-world sites. This goal was pursued by examining and supporting research on mechanisms and rates of processes that occur using MNA alone or with enhancement, including: biological destruction (anaerobic and aerobic mechanisms), abiotic destruction, physical processes (retardation, dispersion and volatilization), and other concepts (e.g., modifying boundary conditions and hydrology). This work also focused on 
scenarios, uncertainties, and the active processes occurring at major system interfaces such as the groundwater-surface water interface.

Improve monitoring approaches and techniques-Decisions on when to rely on MNA are dominated by considerations of the potential costs of elaborate monitoring for years or perhaps decades. In some cases it may therefore seem that aggressive actions that can be completed in a relatively short time are preferable. To support decision-making on the need for aggressive measures, more direct and less expensive monitoring strategies and systems were sought as a part of the MNA/EA Project.

Facilitate end-user and regulator participation-No remediation approach can or will be selected without acceptance by end users and approval by the regulatory authorities who are responsible for oversight. It is necessary that their questions and concerns be recognized and addressed by any proposed improvements in practice. Therefore, end user representatives were consulted throughout the project and a partnership with the Interstate Technology Regulatory Council (ITRC) was formed at the outset.

It was recognized that situations would arise where natural attenuation alone would not be sufficient for remediation because of risk/exposure to receptors, plume growth, or long timeframes to achieve remediation goals. In such cases alternative approaches would be needed to prepare sites for attenuation-based remedies specifically, targeted approaches would be necessary to overcome the reason(s) that MNA alone is not adequate. Developing innovative strategies to couple novel remediation techniques with natural attenuation was also identified as an original aim for the project because of risk/exposure to receptors, plume growth, or long time frames to achieve remediation goals. These strategies that promote coupling technologies are consistent with the "treatment train" approach widely discussed in the 1990s. The term "Enhanced Attenuation" (EA) was adopted to represent sustainable actions that fill the gap between active cleanup and MNA (Figure 1).

Whereas the conventional philosophy of remediation usually proceeds from active measures to passive MNA, this project followed a passive-to-active approach that would add actions only as deemed necessary based on observations. A comprehensive review of EA methods was a significant portion of the project (Early, et al. 2006).

\section{$1.2 \quad$ Use/Implementation of MNA}

According to EPA statistics (EPA, 2004a) Records of Decision that selected MNA alone increased from 6\% in 1996 to $32 \%$ in 1998 but declined to $4 \%$ in 2002. The decrease was attributed to EPA's issuance of the directive for use of MNA in 1999 with a more restrictive definition of MNA. In addition, it may be that 'easy' sites were selected first and their numbers were depleted. A steady increase in selection of in situ treatment technologies occurred over the same time frame.

In 2005, the ITRC conducted a survey of member states to evaluate factors in acceptance and permitting of MNA (Kean, et al. 2006). They found that most states use EPA protocols directly or with adaptations in assessing applications for MNA. Rejection of MNA proposals was most frequently attributed to impact on a receptor or because a plume was expanding. They reported that most state regulators support MNA for chlorinated solvent sites depending on site-specific information but concluded that the success of MNA was undecided since most sites had not yet attained their remediation goals.

The MNA/EA Project described by this report began with a review of prior use of MNA for chlorinated solvents (McGuire, et al. 2003). Case studies were compiled for 20 sites and a survey with 34 respondents provided general information on 190 sites as well as site-specific data on the implementation of MNA to treat 

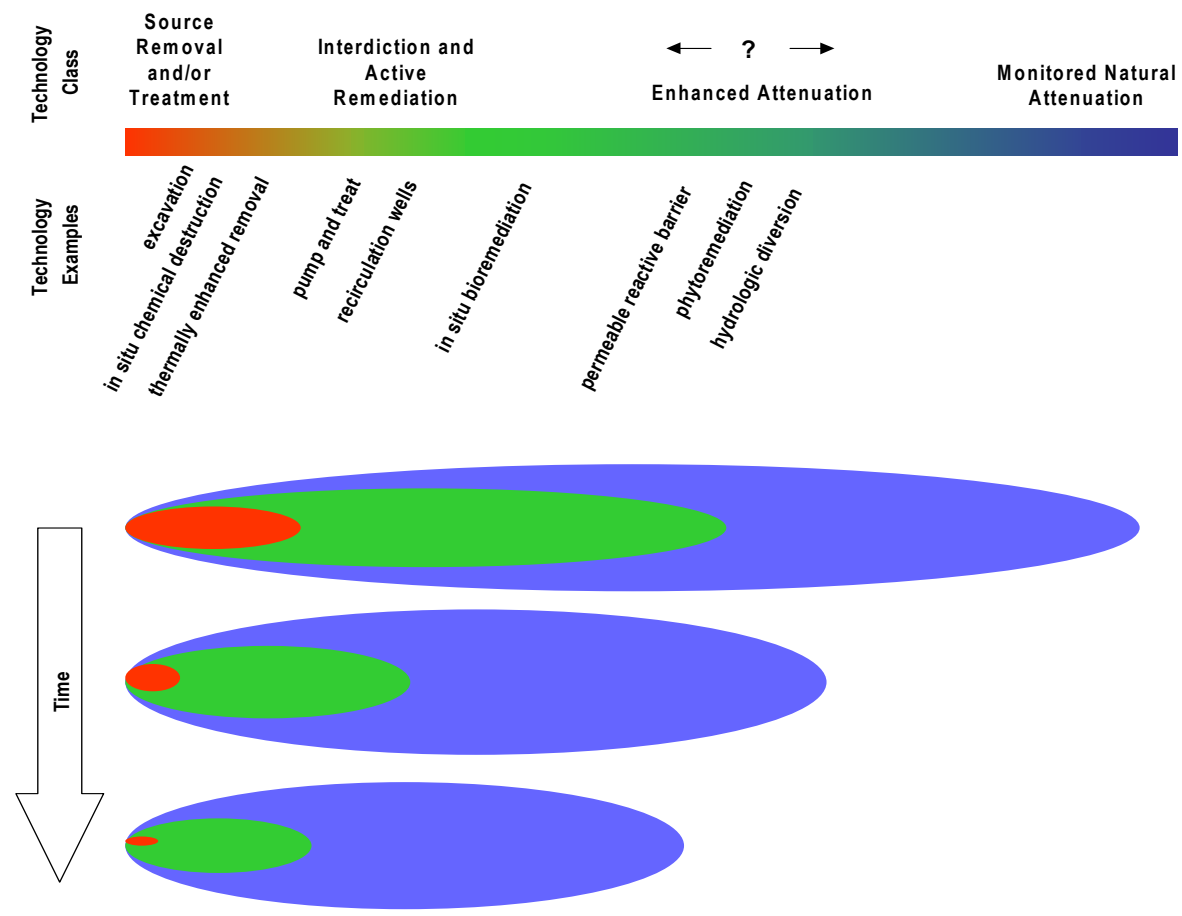

Figure 1. A range of technologies is required to meet plume remediation needs.

45 plumes. Primary findings from the review are quoted in the inset below.

Survey Conclusions (McGuire, et al. 2003, p 60)

Several trends related to application of MNA at chlorinated solvent sites emerged from the study including:

- The 1998 US EPA protocol was most often referenced as the guideline for MNA implementation (36\%). Notably, about $27 \%$ used a site-specific protocol.

- Over $70 \%$ of respondents stated that anaerobic biodegradation is the primary natural attenuation process occurring in the plume.

- A variety of geochemical indicators are reportedly used to assess MNA, but over $90 \%$ rely on the presence of biodegradation daughter products to demonstrate MNA occurrence.

- Computer models of various types were used to evaluate MNA at $43 \%$ of the sites. The most commonly used model was BIOCHLOR. 


\subsection{End User Needs}

Page 4 of 68

The regulated community has often historically struggled to gain the acceptance of the regulators or stakeholders when proposing a MNA remedy. Unlike more traditional groundwater alternatives for chlorinated solvents, where treatment processes with "known" or presumed rates of contaminant destruction could be used to estimate the contaminant mass removed or the time to reach regulatory standards, much greater uncertainty exists in understanding what natural processes act to degrade these contaminants and the rates at which these processes occur.

This report provides guidance across a wide cross-section of topics that support the evaluation of MNA and EA as alternatives to operationally intensive remedies that often do not provide significant added benefit in terms of risk reduction or resource restoration. This includes guides to initial characterization for evaluation of processes likely to contribute to natural attenuation; references to various groundwater models designed to aid in understanding the effects of attenuation on the contaminant mass, flux, and concentration over time; a decision framework and tools that may help in determining the appropriate remedy or when a transition to enhanced or natural attenuation is appropriate; and references to case studies (Early et al., 2006b, Looney et al., 2006a) where these concepts have been applied.

\subsection{Decision Framework}

Advancements in understanding attenuation processes (natural or enhanced) help to reduce the uncertainties in predicting whether these processes are sustainable and thus can be relied upon as a long-term solution for groundwater contamination. In order to reach a decision implementing either enhanced or natural attenuation, consensus must be reached between the stakeholders on the preferred remedy. A decision framework has been developed to facilitate this process and is presented in Chapter 5. This framework has been worked on in conjunction with the ITRC Enhanced Attenuation of Chlorinated Organics (EACO) team (see http://www.itrcweb.org/homepage.asp), which is a state-led coalition working to gain regulatory acceptance of environmental technologies.

Decision Making
It is noteworthy that decision-
making does not need to address
whether or not to use natural
attenuation. Natural attenuation will
happen. Decision-making must only
address whether supplemental
measures are needed to meet
remediation goals or if natural
attenuation alone is sufficient.

It is noteworthy that decisionmaking does not need to address whether or not to use natural attenuation. Natural attenuation will happen. Decision-making must only address whether supplemental measures are needed to meet attenuation alone is sufficient.

\subsection{Importance of Plume Stability and Sustainability to Attenuation-Based Remediation}

\begin{tabular}{l}
\hline Plume stability and \\
sustainability are \\
critical factors in \\
assessing the \\
effectiveness of \\
MNA. \\
\hline
\end{tabular}

Natural attenuation processes occur in all hydrologic systems and act, to some degree, on all anthropogenic contaminants. The decision to rely on natural attenuation processes as part of a site-remediation strategy, therefore, depends less on the occurrence of natural attenuation than on its ability to meet site-specific remediation goals. One basic site-remediation goal, which is widely accepted by the regulatory community, is that plumes emanating from contaminant source areas (1) not be presently expanding, and (2) will not expand in the future. The first requirement is generally referred to as "plume stability"; the second is referred to as "sustainability".

Plume stability depends on the balance between contaminant loading and contaminant attenuation - the mass balance. Depending on the hydrologic characteristics of a site, plume stability can be reached in timeframes ranging from years to decades. However, given a properly constructed well network for site characterization, the stability of a plume can be assessed by site monitoring over time periods of 1-3 years. A key element of this monitoring is the measurement of the amount of contaminant moving through different parts of the system 
- the mass flux - to assess the mass balance under field conditions. Thus, assessing plume stability is a basic component of site characterization and monitoring.

Sustainability of natural attenuation processes is more complex, and depends on the conditions for degradation being maintained until remediation goals are achieved. Using reductive dechlorination as an example, both a sufficient supply of electron donor and an energy supply to drive ongoing contaminant degradation are needed. For chlorinated solvents, organic carbon is the most common source of energy for driving the degradation. Thus, if the amount of organic carbon present in a system is sufficient to support degradation for the life cycle of the remediation system, natural attenuation is inherently sustainable. Conversely, if the amount of organic carbon is insufficient to drive contaminant degradation over the remediation life cycle, natural attenuation is inherently unsustainable. In the latter case, EA through carbon-addition may be used to ensure the sustainability of natural attenuation for the required timeframes.

\subsection{Phased Approach to Characterization and Monitoring}

Managers of successful monitoring programs emphasize that a monitoring plan is essential and that the plan should guide long-term performance. The plan must specify what is to be sampled and measured and why, as well as how the resulting data will be used and managed. It should be flexible so that it can be adapted to new information or purposes. It should identify 'off-ramps' for reducing the frequency of sampling or the number of analyses where appropriate. The aims of characterization and monitoring change throughout the lifetime of a remediation project and the plan should recognize those changes. To aid in the development of robust monitoring plans a "Four-Phased Approach" is recommended (Figure 8 in Chapter 5).

Phase 1-Screening Characterization involves the development of a site conceptual model and identification of important attenuation mechanisms. Data needed to support preliminary decisions on possible remediation alternatives should be identified. This phase may involve exploration of multiple environmental scenarios and may involve both empirical (data-based) and deterministic (theoretical or model-based) methods.

Phase 2-Decision Characterization fully informs the selection of preferred remediation methods from available alternatives and it identifies the expected performance envelope for the preferred method. It enables estimation of a remediation timetable and includes contingency planning for actions in response to unforeseen results.

Phase 3-Process Monitoring is designed to confirm or refute the effectiveness of the chosen remedy. It demonstrates any need to implement contingency actions and formulates a baseline that sets the stage for long-term monitoring. Process monitoring may continue for as much as five years but, ideally, is completed in a shorter period.

Phase 4-System Performance Monitoring is typically the longest phase and extends until attainment of remediation objectives is demonstrated. It adapts to changing environmental conditions and adapts to departures from baseline conditions.

The four-phased approach is consistent with the schedules and logic sequences specified in regulations under the Comprehensive Environmental Response, Compensation, and Liability Act (CERCLA) or the Resource Conservation and Recovery Act (RCRA).

As characterization and monitoring progress, there is a tendency to adapt existing facilities to the new application. Thus, extensive well networks installed for characterization become part of the monitoring phases potentially increasing the scope of monitoring and unnecessarily adding to cost. Adherence to the purposes of each monitoring phase can help avoid such mistakes. 


\subsection{Project Organization and Structure}

Page 6 of 68

Diverse goals required a unique management structure for a research and development project (Sink, et al., 2004). Technical and operational leaders at SRNL were supported by a Technical Working Group (TWG) comprised of participants from other DOE laboratories and the technical community (Appendix C).

Additionally, the TWG included representatives of end users and a working alliance was formed with local regulators and with the ITRC. TWG members selected both the research topics and projects for support. TWG members also prepared several topical reports and journal articles (Appendix B). Presentations were made for national technical meetings and for end users and regulators at the major DOE sites. University, industry and government laboratory investigators conducted fourteen cutting-edge research projects on a wide array of topics related to MNA (Appendix A). The TWG met twice each year and conducted weekly conference calls throughout the project. All written products were externally peer-reviewed and action plans were prepared in response to reviewer comments. This structure enabled the project to rapidly progress with continuous internal and external communication (Figure 2).

\section{Common Goal for All Participants}

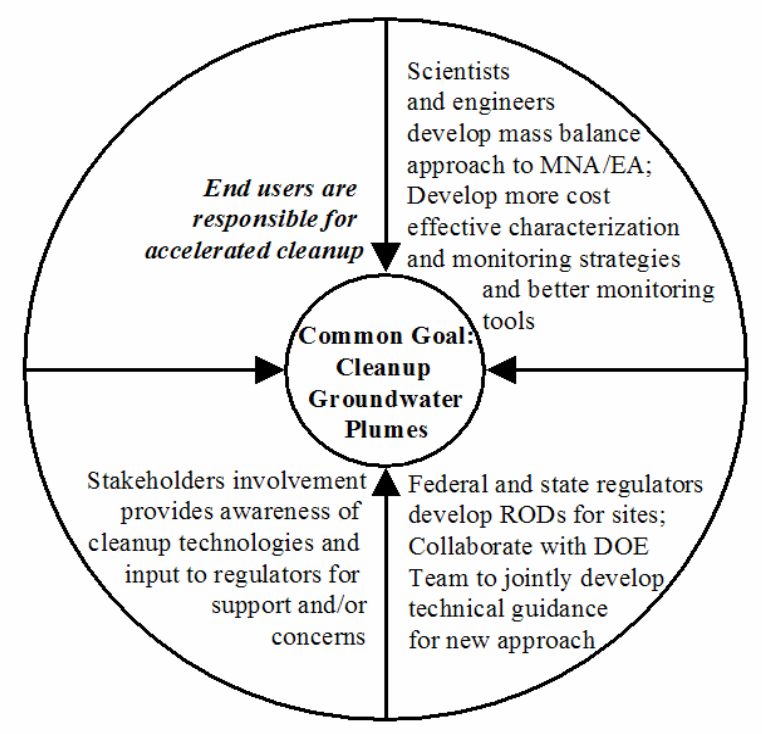

Figure 2. The unique project structure engaged participants from the technical community, end users and regulators.

"We like three things about this project. First we think the organization is a model for other research efforts. Second, we are pleased that the results can be used here at the Site and third, this type of project fits well with our new EM role to work with and support the entire DOE complex."

Paul Deason, Ph.D., Deputy Director Savannah River National Laboratory 


\section{Chapter 2.0 Evaluating Plume Stability and Estimating Sustainability}

Natural and enhanced attenuation can be understood by considering the balance between contaminant loading and contaminant attenuation in ground-water systems (Chapelle et al., 2004). When contaminant loading is small relative to the attenuation capacity (Figure 3), attenuation is relatively efficient and contaminant plumes tend to be small. Conversely, when contaminant loading is large relative to attenuation capacity, attenuation is less efficient and larger contaminant plumes can develop. In either case, the efficiency of natural and enhanced attenuation can be quantified by evaluating the mass balance between contaminant loading and contaminant attenuation (Figure 3).

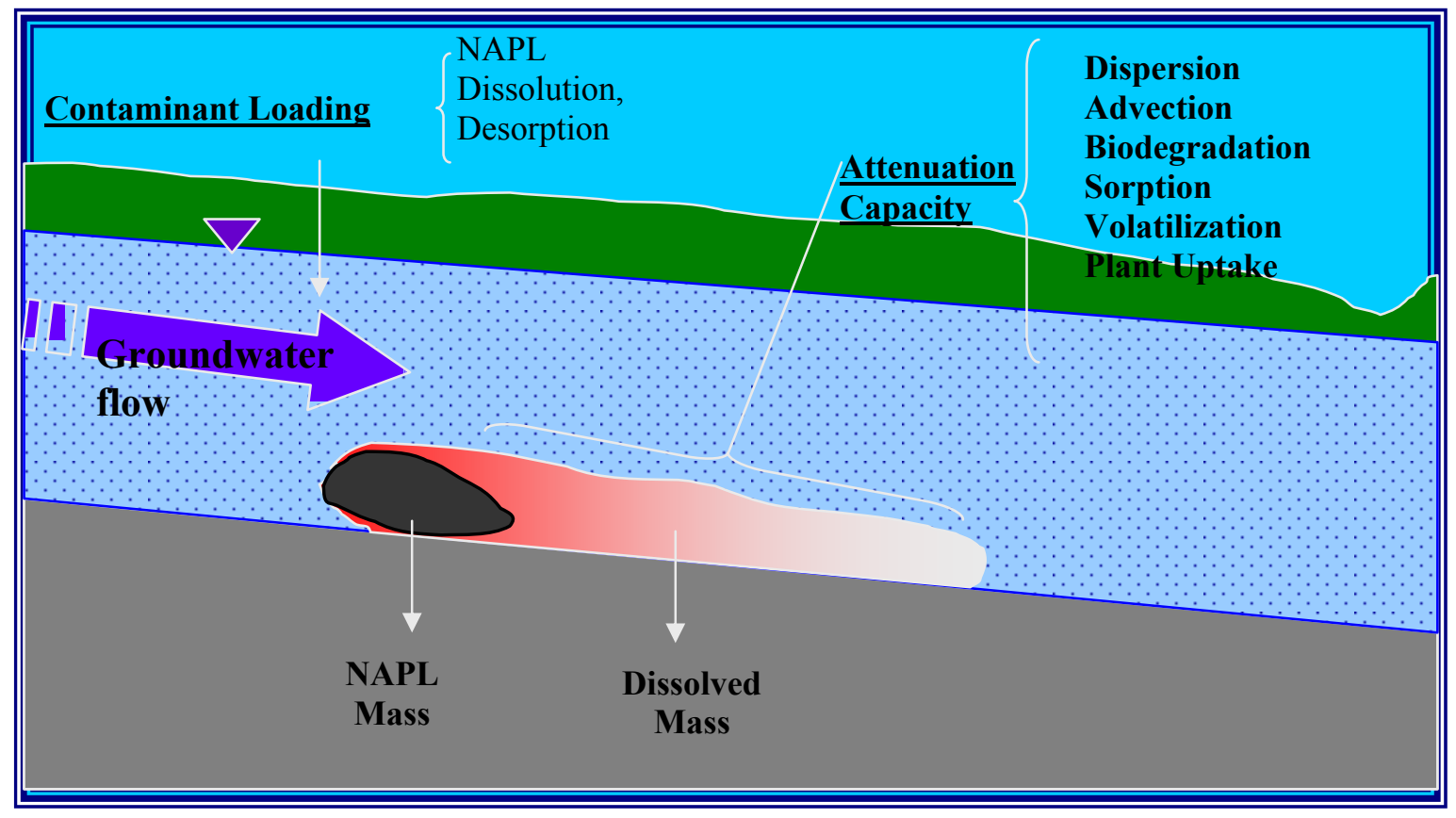

Figure 3. The mass balance between contaminant loading and attenuation capacity defines the efficiency and viability of natural and enhanced attenuation.

The concept of mass balance between source loading and attenuation capacity is implicit in the EPA directive on MNA, but is not addressed directly. However, attenuation mechanisms are identified, as is the need to focus site characterization on obtaining

... a quantitative understanding of source mass; groundwater flow (including preferential pathways; contaminant phase distribution and partitioning between soil, groundwater, and soil gas; rates of biological and non-biological transformation; and an understanding of how all of these factors are likely to vary with time. (EPA, 1999; pg. 13)

For the example of biodegradation, the directive states:

...characterization also should include evaluation of the nutrients and electron donors and acceptors present in the groundwater, the concentrations of co-metabolites and metabolic by-products, and perhaps specific analyses to identify the microbial populations present. (EPA, 1999; pg. 15) 
WSRC-STI-2006-00377, Final

December 27, 2006

Page 8 of 68

These types of characterization data need to be

...sufficient to estimate with an acceptable level of confidence both the rate of attenuation processes and the anticipated time required to achieve remediation objectives. (EPA, 1999; pg. 15)

The directive goes on to identify a three-tiered approach to the evaluation that incorporates historical data defining decreasing trends in contaminant mass and/or concentrations over time, indirect measures of the types of natural attenuation processes (and their rates) active at a site, and direct measures to obtain such information.

Elsewhere in the directive additional references are made to the concept of mass balance:

Therefore, sites where the contaminant plumes are no longer increasing in extent, or are shrinking, would be the most appropriate candidates for MNA remedies. (EPA, 1999; pg. 18)

Within the context of performance monitoring and evaluation the directive states that it is necessary to

Verify that the plume(s) is not expanding (either downgradient, laterally or vertically). (EPA, 1999; pg. 22)

Although the directive clearly is embracing the concept of a quantitative understanding of mass balance, no formal guidance is provided as to how this might be accomplished.

This concept of mass balance can be used to explain the observed behavior of contaminant plumes over time (Figure 4). Immediately following a contaminant release, contaminant loading far outweighs attenuation and the plume expands rapidly. Over time, due to forming a "bigger reactor" and lower concentrations, attenuation capacity comes into balance with contaminant loading and the plume stabilizes. As the contaminant source is depleted, contaminant loading decreases relative to attenuation capacity, and the plume begins to shrink. Finally, contaminant loading ceases altogether and the plume becomes exhausted. Thus, while the processes balancing contaminant loading and attenuation capacity may be complex (Figure 3), the concept of mass balance simplifies understanding natural and enhanced attenuation. In the simplest sense, such a mass balance integrates all of the controlling boundary conditions and processes and determines the dynamics of plume growth, stabilization and shrinkage over time (Figure 4).

The concept of mass balance is most useful when applied to the flux of contaminants. This is illustrated graphically in Figure 5 in which the width of each arrow represents the flux of contaminants. At the source, the flux (arrow width) is the greatest. As the contaminant migrates, the various attenuation mechanisms reduce the central plume flux in proportion to the efficiency of each attenuation mechanism. The width of the attenuation arrows is subtracted from the width of the plume migration arrow, impacting the amount of plume discharge and the overall growth and stabilization of the plume. The difference in the size of the arrows is a measure of the "attenuation capacity" within the plume volume. In some cases, the attenuation is sufficient to reach remediation goals without further human intervention. In other cases, natural attenuation mechanisms are insufficient to reach remedial goals and additional actions are needed. The additional actions can include source removal/destruction and active remediation. In addition, enhancements to the natural attenuation system may be a viable option. EA uses technology to alter the mass balance (i.e., reduce loading or increase attenuation rates) to achieve remedial goals. This is depicted by increasing the size of the attenuation arrows, concordantly decreasing the plume flux and growth (Figure 6). 
time evolution of a plume if it undergoes attenuation

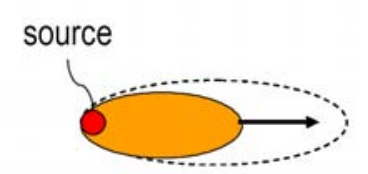

EXPANDING

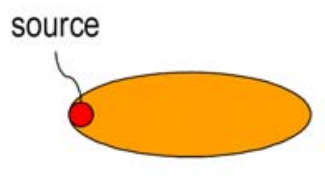

STABLE

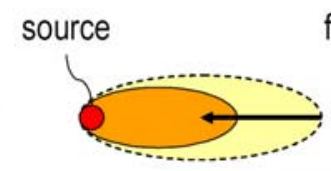

SHRINKING

former source

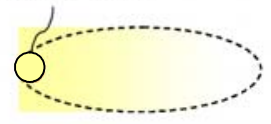

EXHAUSTED

Mass Balance Condition:

loading from source

below level of concern

Mass Balance Condition:

loading from source $\leq$

attenuation capacity in plume

large source, high strength

source, and/or slow

attenuation

\section{Response:}

Source removal, active interdiction ( e.g., pump and treat or permeable reactive barrier), active remediation (e.g., bioremediation), or EA.

\section{Factors:}

small source, low strength source, and/or rapid attenuation, and/or long timeframe

Response:

MNA if risk and time frame acceptable and sustainable; otherwise, EA or active interdiction/remediation
Factors:

remediation goals achieved

\section{Response:} confirm / no further action.

Figure 4. Dynamic development of a contaminant plume and the relationship to mass balance and response actions. 
WSRC-STI-2006-00377, Final December 27, 2006

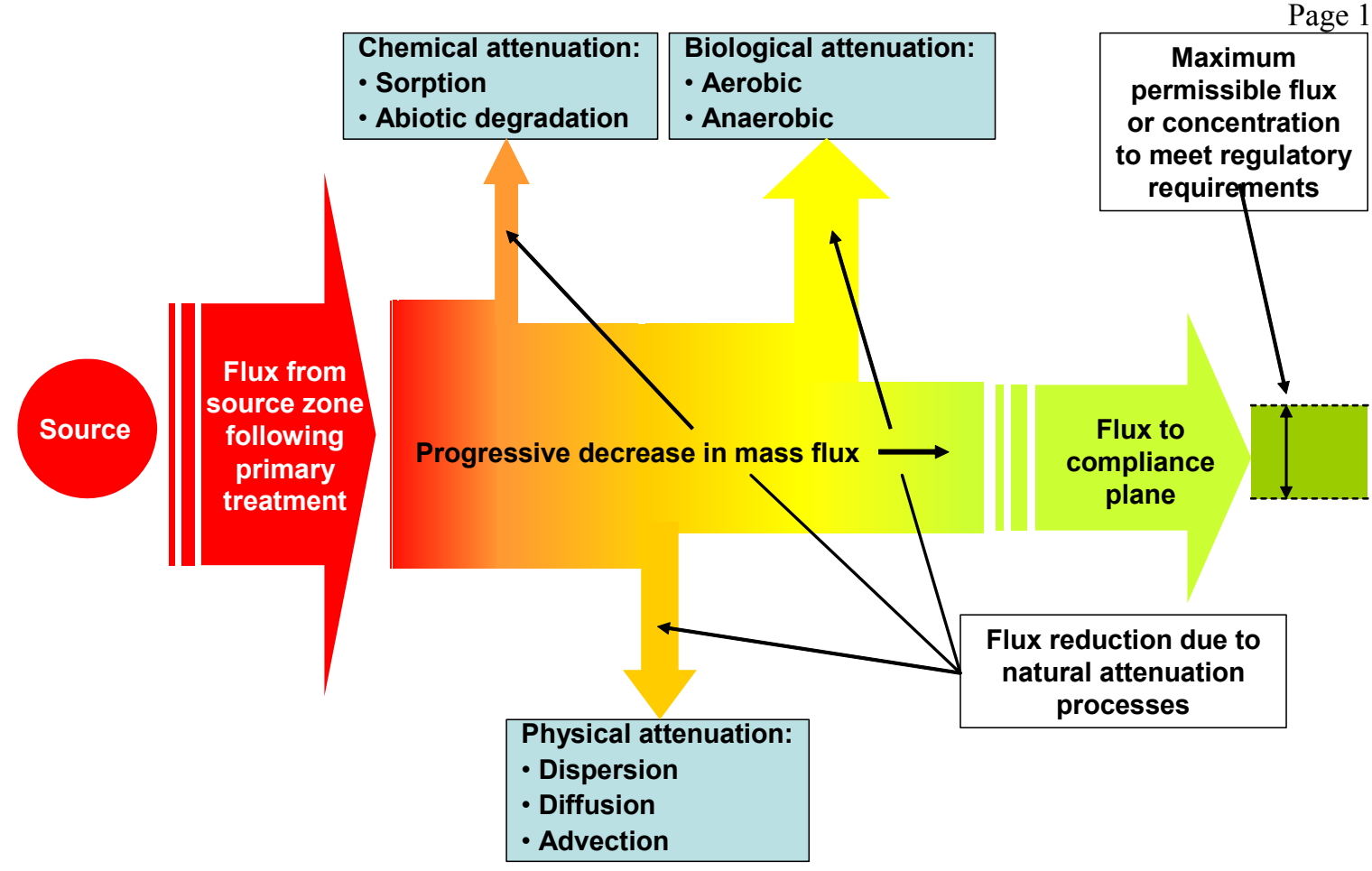

Figure 5. Graphical depiction of natural attenuation.

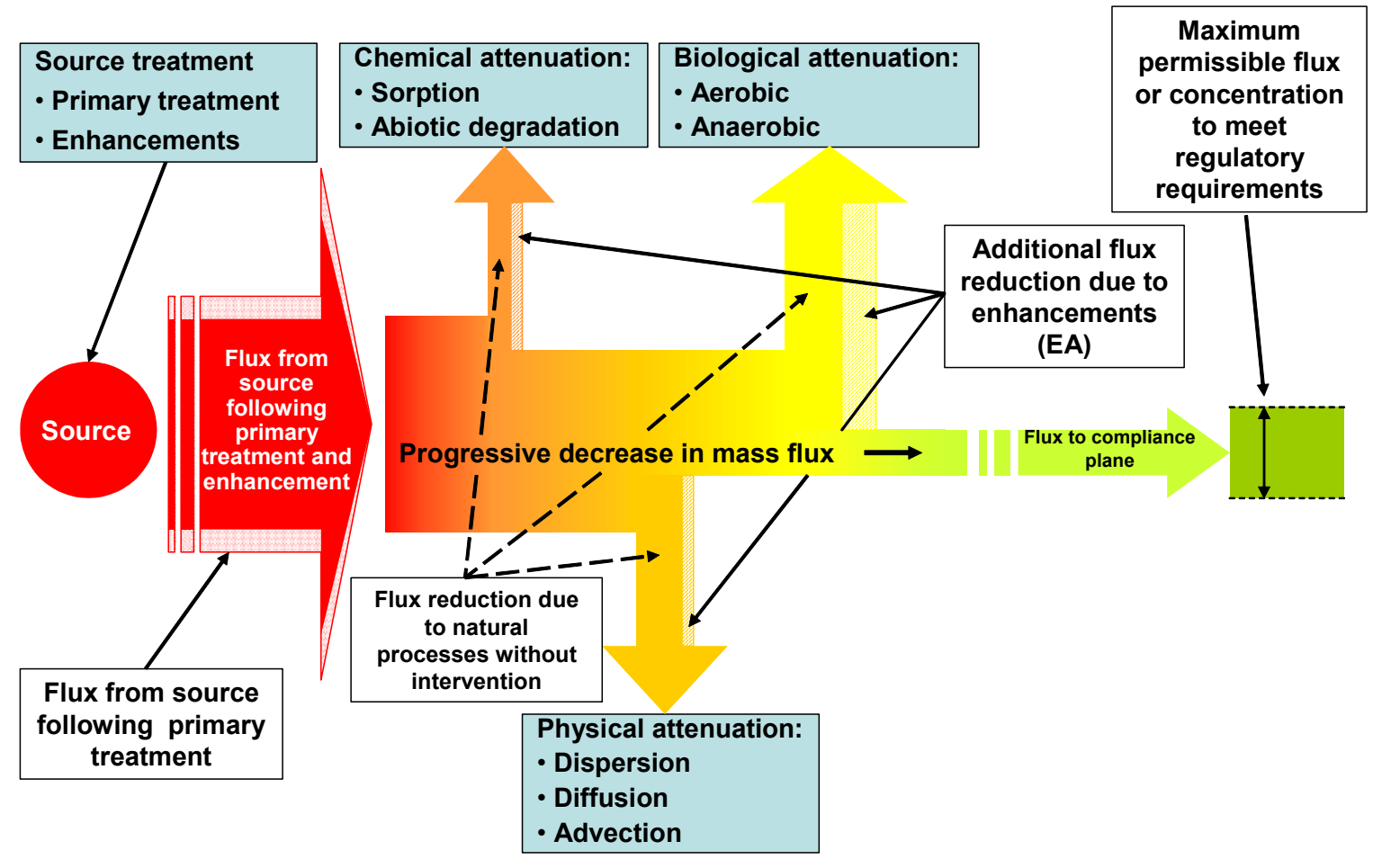

Figure 6. Graphical depiction of enhanced attenuation. 
Attenuation processes can be observed and quantified by measuring or calculating the change in total flux at different locations within a developing/stabilizing/shrinking plume. The total flux, or integrated mass flux, is the total quantity of a migrating substance that moves through a transect across the plume. If the transect is at the entry point to the system, the integrated mass flux is the loading. If the transect is at the exit point from the system, the integrated mass flux is the discharge. Note that these terms have units of mass per time (e.g., $\mathrm{Kg} / \mathrm{yr}, \mathrm{g} /$ day or the like) and they represent an extension of the traditional engineering definition of flux (e.g., $\mathrm{Kg} / \mathrm{yr} / \mathrm{m}^{2}$ ) in which the values are normalized to a unit area.

\section{Part of the power of the integrated mass flux concept is that the discharge from the source represents the loading to the plume - this is a critical link that unifies decision- making and modeling at contaminated sites and that helps address difficult questions related to the value of source treatment and the amount of source treatment that is needed.}

Traditionally, natural attenuation protocols have addressed plume stability and mass balance empirically, using historical monitoring data from well networks to document plume behavior (concentration and mass flux) in time and space, and that biogeochemical conditions are favorable for attenuation processes. This field-based approach, when feasible, provides useful documentation of plume behavior and mass balance (Chapelle et al., 2005a, Looney et al., 2006b). It integrates the operative attenuation processes measured by observing their actual impact on the plume.

The empirical approach is not always appropriate for addressing specific remediation questions. It treats the plume

as a "black box", and it requires a relatively long period of undisturbed historical data. Thus, the empirical approach cannot be effectively applied to sites where active remediation was initiated quickly and is currently operating. Furthermore, it cannot be used to determine how much source removal is needed or when to turn off active remediation and transition to MNA. Finally, it cannot be used to efficiently evaluate potential enhancement options.

In those cases where the empirical approach is not sufficient, mass balance can also be approached deterministically, where models of the physical, chemical, and biological attenuation processes are used to assess contaminant loading and attenuation (Looney et al., 2006b, Chapelle et al., 2006a). The deterministic approach has the advantage that, when sufficient hydrologic, geochemical, and microbiologic data are available, it is possible to project how a system will respond to contaminant removal actions or enhancements of natural attenuation processes. The disadvantage of the deterministic approach is that it is often difficult to measure or estimate real-world hydrologic, geochemical, and biological parameters. Looney et al. (2006b) advocate combining these two approaches based on the individual challenges presented by a given site. The value of combining the approaches was also demonstrated by a series of case studies that evaluated plumes at Kings Bay Naval Station, Paducah Gaseous Diffusion Plant, Hill Air Force Base, and others (Looney et al., 2006a). In a particularly compelling case study, researchers demonstrated the importance of understanding the mass balance between naturally occurring organic matter (electron donors) and contaminant (electron acceptors) in limiting the growth of a plume (Chapelle et al., 2006b).

A purely empirical assessment may not always be an effective way to assess plume stability because of perturbations or system changes over time. The real-world empirical data, however, form the basis of all decisions and underpin both empirical and deterministic assessment processes. For example, regulators are typically required by state or federal statute to decide on the legal status of groundwater contamination on the basis of empirical data -- concentrations of contaminants are either above or below a target value that is agreed to be protective. A purely mass balance approach for evaluating natural attenuation remedies on the basis of a mass flux poses an inherent contradiction of various state laws concerning groundwater contamination. In Minnesota, for example, the "non-degradation" component of groundwater law that is embodied in Rule 7060 does not allow for the spreading of a plume beyond its current configuration for any reason. To decide, on the basis of an evaluation of mass balance, that the groundwater plume will stabilize after spreading another 
quarter mile is problematic. Emerging technical and regulatory guidance from the ITRC attempts to resolve these important and complex issues by proposing a blended decision framework. One goal of such a framework is to recognize that the decision process is not absolute and to lay out a disciplined process to help guide the balance between empirical and deterministic approaches.

\subsection{The Sustainability of Natural and Enhanced Attenuation}

The sustainability of ongoing attenuation processes is a basic requirement for using natural or enhanced attenuation as part of a remedial strategy (Aziz et al., 2000). In this context, the concept of a mass balance can be applied to compounds that drive, enhance, or compete with a degradation process over time. Biological reductive dechlorination, for example, requires a source of organic carbon to drive degradation. Dissolved oxygen, on the other hand, competes with chlorinated ethenes for available organic carbon and decreases the effectiveness of biodegradation. In these cases, a time-dependent mass balance that includes sources of organic carbon and competing electron acceptors can be used to assess the sustainability of attenuation (Chapelle et al., 2003a and 2006a). Importantly, when attenuation is enhanced by the addition of organic carbon, this approach can be used to determine the quantities of additive needed to consume competing electron acceptors such as oxygen, and to drive reductive dechlorination to completion.

\subsection{Field Tools to Measure Mass Balance and Support Attenuation}

Traditional evaluations of natural attenuation in the field are typically based on networks of monitoring wells. Contaminant concentration trends are evaluated over time at particular wells and over space along the flow path. To assure that attenuation could achieve remedial objectives, EPA (1999) required additional lines of evidence such as documenting individual attenuation processes and showing that appropriate biogeochemical conditions are in place. These traditional approaches will remain central to attenuation-based remedies in the future. Note that the quality and reliability of any monitoring system depends on having a sufficient number of wells and appropriate spatial coverage. General guidance on these issues has been well documented (e.g., EPA 2004b).

Recent technical developments may supplement this baseline approach. In addition, through optimization of well networks and inclusion of alternative monitoring strategies, improved decision-support at reduced overall costs are feasible. The mass balance approach allows inexpensively monitored parameters such as hydrologic boundary conditions to be considered. There are opportunities for cost effective monitoring of water entry and exit zones, water migration pathways, and the overall quantity of water moving through the system. These, and similar, nontraditional monitoring parameters control the driving force for contaminant movement through the subsurface including the loading to the plume from the source, delivery of competing electron acceptors, residence time for attenuation processes to act on the contaminant, dilution, etc. This coupled conceptual model opens up an array of technology ideas ranging from simple stream gauging and meteorology stations, to more complex technology solutions such as remote sensing of evapotranspiration.

Some potentially useful technologies are those that support direct measurement or improved estimates of integrated mass flux. Traditionally, flux is estimated using a transect of monitoring wells or sampling points (Wiedemier et al., 1999, Chapelle et al., 2004). In many cases, this traditional approach is both cost effective and provides the needed information (e.g., Looney et al., 2006b). Recently tested alternatives include passive flux meters, various pump tests, and push-pull tests. All of these methods appear promising and may provide opportunities for improving the quality of mass flux estimates and reducing costs depending on site-specific conditions.

○ The passive flux meter uses a sorbent medium in a bag inserted into a well through which groundwater flows. Presorbed tracers, such as bromide and alcohols, leach from the sorbent at a rate proportional to cumulative groundwater flow. At the same time, contaminant in that groundwater is sorbed -- the cumulative contaminant sorbed is proportional to mass flux in the vicinity of the well. 
- Pump tests can be used to determine integrated mass flux. Bockelmann, et al. (2001) extract water from a set of wells to temporarily capture the plume mass flux. While the interpretation can be confounded by heterogeneity or by proximity to complex sources, properly designed pump tests are powerful and effective tools.

- Push-pull tests are a particularly promising approach to determine water and mass flux and to determine aquifer properties and degradation rates under natural and amended conditions. Push-pull tests inject or "push" test solution into an aquifer followed by the extraction or "pull" of the injected test solution/groundwater mixture from a given well interval. The test solution consists of water with tracers and solutes. Tracers can be reactive and/or conservative and are selected to investigate specific aquifer properties or degradation mechanisms/rates.

- Expanded biogeochemical measurements that provide estimates of rates and fluxes more directly than the current standard analytes. Some of the most promising of these methods include: enzyme probes and nucleic acid assays to evaluate degradation processes and potential rates, and stable carbon isotope methods to assess contaminant transformation mechanisms and rates that result from isotopic shifts during the reaction pathway.

All field methods, including these approaches to measure flux and rates, have strengths and weaknesses and uncertainty associated with the result. Often site-specific factors, such as the contaminant source architecture and the type of hydrogeologic heterogeneity will determine the optimal method to use and help design the study to minimize uncertainty. To supplement the field characterization and monitoring techniques described above, a variety of data interpretation aids have been developed. Such aids range from statistical tools that perform a Mann-Kendall test on monitoring well time trends (e.g., WI-DNR, 2003), tools that calculate exponential decay constants from concentration-distance or concentration-time data (Newell et al., 2002), and more sophisticated tools such as SEQUENCE that provide insight into the "footprints" of various degradation mechanisms throughout a plume using visualizations (Carey et al., 1996; NRC, 2001).

\subsection{Mathematical Tools to Calculate Mass Balance and Support Natural and Enhanced Attenuation}

Various tools and computer models have been developed, or are in development, to assess mass balance at chlorinated solvent sites. The conceptual basis is the same: a certain mass of contaminant (such as TCE) is "released" to groundwater and a series of mathematical relationships are applied that show what happens to this contaminant mass. Some of the tools are relatively simple, with easy-to-visualize equations entered into the cells of a computer spreadsheet. Other models are more sophisticated numerical approaches that employ a wide variety of simulation processes, and intricate graphical displays of modeling results. Although they differ in complexity, both ends of this modeling spectrum are based on the fundamental concept of mass balance.

These tools/models described above can be divided into the following categories:

- Flux Calculation Tools. Some software has been developed to allow the user to convert flow data and monitoring well transect data to a mass flux estimate. Mass flux is an integrated metric of plume strength, and a key part of the mass balance approach. This type of software helps users determine the rate that contaminant mass is leaving a source zone or the mass flow rate at some point in the plume.

- Box Model of Source. These simple models assume the source is a simple box model, and make a priori assumptions about how the mass flux curve will diminish over time (such as an exponentially decaying source). These models are not dependent on simulating actual processes that occur in the source zone over time, but use a simple mathematical function(s) to describe how a source will decay over time. This method accounts for processes such as pool dissolution, ganglia dissolution, matrix diffusion, linear desorption, and dual-equilibrium desorption over the life of the source, but in an indirect, very simplified fashion. 
- Deterministic Source Models. More sophisticated source models have been developed to simulate the behavior of one or more phases in the life cycle of the source. Several of these models focus on nonaqueous phase liquid (NAPL) dissolution kinetics and transport over time. Key factors that go into these models include considering NAPL composition and employing Raoult's Law to assess dissolution kinetics, and considering source architecture (the way that NAPL is distributed in the source zone, such as the relative fraction of NAPL in pools vs. ganglia), to assess NAPL dissolution.

- Plume models. These "traditional" groundwater models simulate the fate and transport of dissolved contaminants once the contaminants have left the source zone. Typically these plume models include processes such as advection, dispersion, linear sorption and desorption, biodegradation, and sometimes more complex processes (such as nonlinear sorption and preferential flow). The resulting mass balance equations can be solved either analytically (exact mathematical solutions subject to simplifying assumptions) or numerically (where the model domain is divided into grids or elements and solved by stepping through time - this type of model also involves simplifying assumptions but can often be applied to more complicated problems or time varying boundary conditions).

Examples of each type of tool/model are presented in Table 1. Note this table only shows representative tools and models, and many other examples of tools and models are available in the scientific literature. The ability of these tools to help the user address several key questions regarding plume stability and sustainability is summarized in Table 2.

Recent progress has improved the tools/models in each category. Several researchers have focused on developing better ways to measure mass flux, including new sampling tools and new software tools (such as the Mass Flux Toolkit (Farhat et al., 2006)). Box model approaches have been used in groundwater models since 1996, but have recently been applied in new ways in recent software tools (such as BIOBALANCE). The BIOBALANCE software (Kamath et al., 2006) also includes: new algorithms for performing a mass balance on electron acceptors/electron donors and for evaluating the effects of competing electron acceptors (such as naturally-occurring dissolved oxygen or sulfate), new tools to calculate maximum plume size and timing of plume stabilization, and other features. Plume models have also become much more powerful over the past several years, both for analytical models (such as BIOCHLOR) and numerical models (RT3D). Finally, some research teams have worked on integrating source models more directly with plume models as a single software platform, allowing for a mass balance on the entire system (for example, BIOBALANCE and NAS).

Site specific conditions and the specific local scenario determine which modeling tools are the most appropriate and useful. Table 3 summarizes some of the key issues associated with matching a mass balance modeling and evaluation approach with a site. Note that the costs for modeling vary widely and are dependent on modeling objectives, site size and complexity, available data, and other factors that are specific to the target facility. Small, non-complex sites that have sufficient data and geochemical conditions suited to natural attenuation can often be addressed using simple conceptual models or calculations (circa \$10,000) while largecomplex sites might require significant investment in deterministic models (circa $\$ 100,000$ or more). The key to effective and efficient use of models is properly matching the model to the site. 
Table 1. Representative Chlorinated Solvent Tools and Models

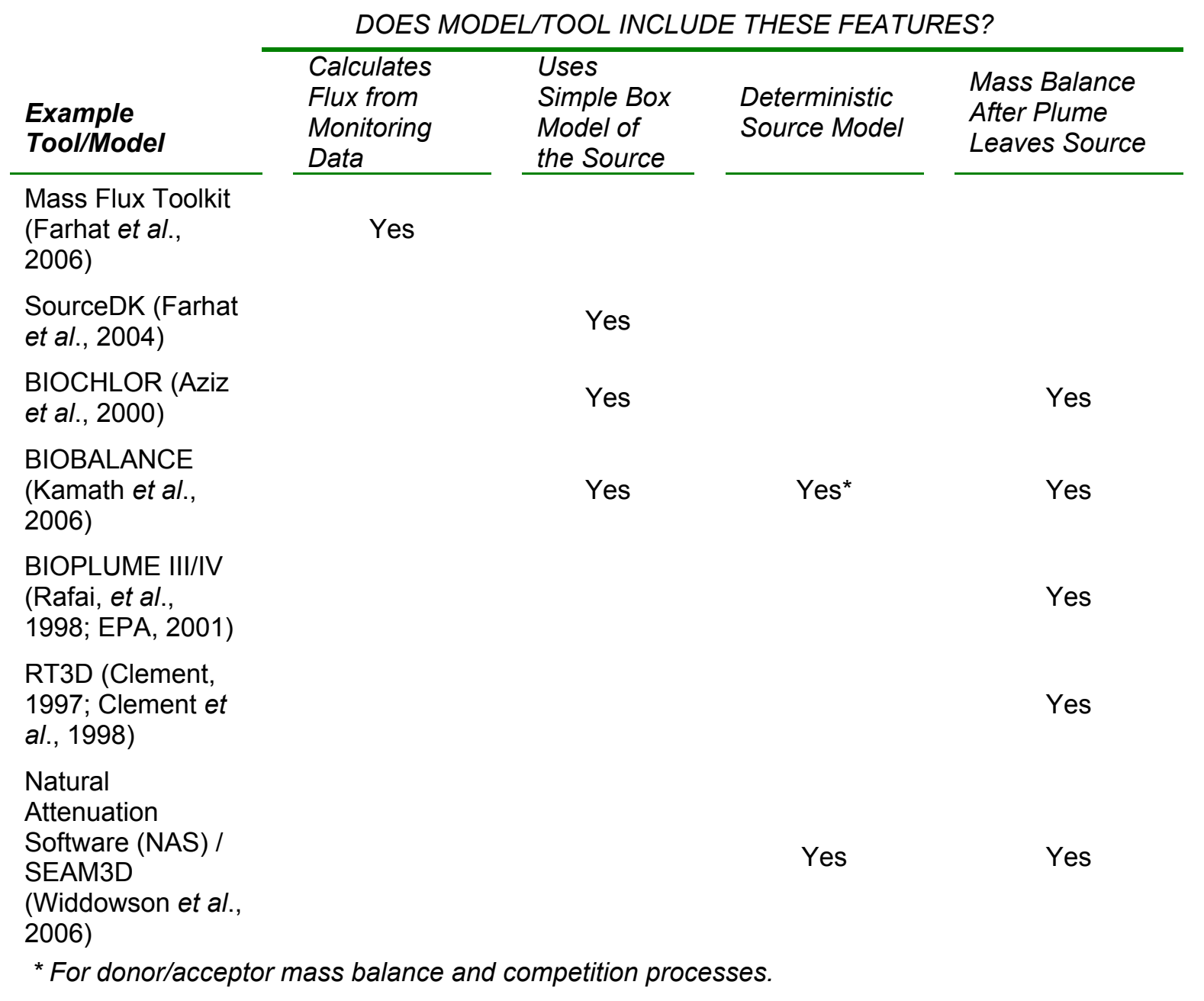


WSRC-STI-2006-00377, Final

December 27, 2006

Page 16 of 68

Table 2. Key Mass Balance Related Questions Addressed by Representative Chlorinated Solvent Tools and Models

\begin{tabular}{|c|c|c|c|c|c|}
\hline \multirow[b]{2}{*}{$\begin{array}{l}\text { Example } \\
\text { Tool/Model }\end{array}$} & \multicolumn{5}{|c|}{ CAN TOOL/MODEL HELP USER ADDRESS THESE QUESTIONS? } \\
\hline & $\begin{array}{l}\text { How Far Will } \\
\text { Plume Go } \\
\text { Before it } \\
\text { Stabilizes?* }\end{array}$ & $\begin{array}{l}\text { How Long } \\
\text { Will It Take } \\
\text { Plume To } \\
\text { Stabilize?* }\end{array}$ & $\begin{array}{l}\text { How Long } \\
\text { Will This } \\
\text { Plume } \\
\text { Persist?* }^{*}\end{array}$ & $\begin{array}{l}\text { What is } \\
\text { Balance of } \\
\text { Donors and } \\
\text { Acceptors? }\end{array}$ & $\begin{array}{c}\text { Are } \\
\text { Attenuation } \\
\text { Processes } \\
\text { Sustainable? }\end{array}$ \\
\hline Mass Flux Toolkit & No & No & $\begin{array}{l}\text { Not directly. } \\
\text { Can be used } \\
\text { to compare } \\
\text { mass flux } \\
\text { against } \\
\text { source mass } \\
\text { estimate }\end{array}$ & $\begin{array}{l}\text { Helpful to } \\
\text { analyze } \\
\text { relative } \\
\text { mass flux of } \\
\text { donors / } \\
\text { acceptors } \\
\text { leaving } \\
\text { source }\end{array}$ & $\begin{array}{l}\text { Can provide } \\
\text { supporting } \\
\text { information }\end{array}$ \\
\hline SourceDK & No & No & $\begin{array}{l}\text { Yes, with } \\
\text { box model }\end{array}$ & No & No \\
\hline BIOCHLOR & $\begin{array}{l}\text { Yes, with } \\
\text { simple } \\
\text { analytical } \\
\text { model }\end{array}$ & $\begin{array}{l}\text { Yes, with } \\
\text { simple } \\
\text { analytical } \\
\text { model }\end{array}$ & $\begin{array}{l}\text { Yes, with } \\
\text { box model }\end{array}$ & No & No \\
\hline BIOBALANCE & $\begin{array}{l}\text { Yes, with } \\
\text { simple } \\
\text { analytical } \\
\text { model }\end{array}$ & $\begin{array}{l}\text { Yes, with } \\
\text { simple } \\
\text { analytical } \\
\text { model }\end{array}$ & $\begin{array}{l}\text { Yes, with } \\
\text { box model }\end{array}$ & Yes & Yes \\
\hline BIOPLUME III/IV & $\begin{array}{l}\text { Yes, with } \\
\text { numerical } \\
\text { model }\end{array}$ & $\begin{array}{l}\text { Yes, with } \\
\text { numerical } \\
\text { model }\end{array}$ & No & No & No \\
\hline RT3D & $\begin{array}{l}\text { Yes, with } \\
\text { sophisticated } \\
\text { numerical } \\
\text { model }\end{array}$ & $\begin{array}{l}\text { Yes, with } \\
\text { sophisticated } \\
\text { numerical } \\
\text { model }\end{array}$ & No & No & No \\
\hline $\begin{array}{l}\text { Natural Attenuation } \\
\text { Software (NAS) / } \\
\text { SEAM3D }\end{array}$ & $\begin{array}{l}\text { Yes, with } \\
\text { simple } \\
\text { analytical } \\
\text { model }\end{array}$ & $\begin{array}{l}\text { Yes, with } \\
\text { simple } \\
\text { analytical } \\
\text { model }\end{array}$ & $\begin{array}{l}\text { Yes, with } \\
\text { numerical } \\
\text { model }\end{array}$ & Not directly & Not directly \\
\hline
\end{tabular}

* Also referred to as Distance of Stabilization (DOS), Time of Stabilization (TOS), Time of NAPL Dissolution (TNAD) by Chapelle etal., 2003a. 
Table 3. Considerations for Selecting Modeling Approach Based on Site Properties

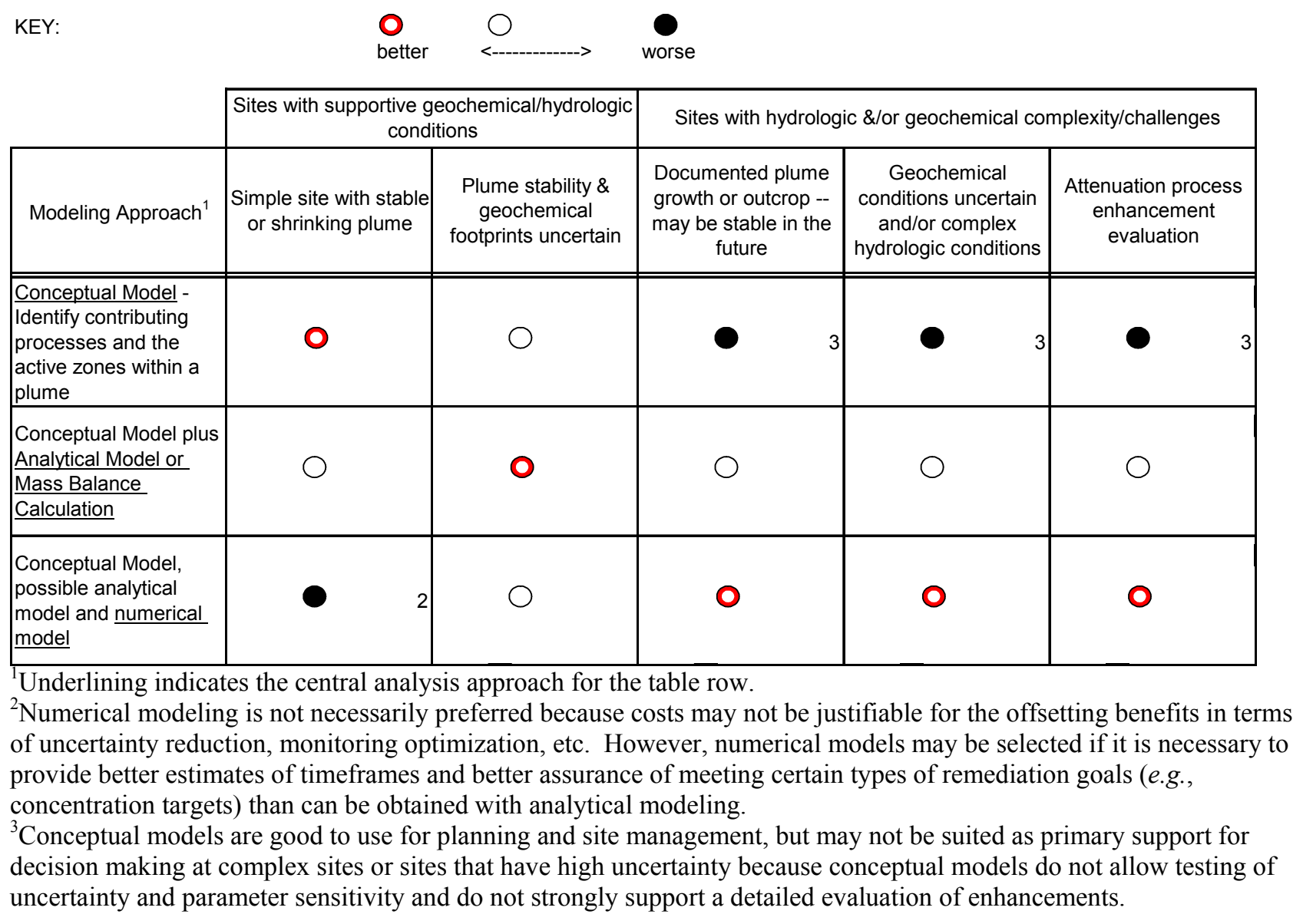

\subsection{Summary of Mass Balance and Sustainability Concepts}

The concept of mass balance is something that all people, including scientists, engineers, regulators, policymakers, and members of the public, inherently understand. As such it brings clarity to issues of natural and enhanced attenuation that otherwise may not be attained. More importantly, from an engineering point of view mass balance can be used to quantify the efficiency of natural and enhanced attenuation using both empirical and deterministic methods. This allows engineers to:

- Estimate if natural attenuation is capable of reaching remedial goals without applying other technologies.

- Estimate the amount of contaminant mass removal in the source-area needed to reach remedial goals if natural attenuation proves insufficient. This assessment must account for expected rebound following source removal.

- Estimate the level of enhanced attenuation downgradient of the source zone that is needed to reach remedial goals. If the attenuation rates can not be sufficiently and sustainably enhanced, then active treatment and/or interdiction will be needed.

In each case, applying the mass balance approach can improve the reliability of remedial actions that include natural or enhanced attenuation. 


\subsubsection{Technical Recommendations:}

\section{T1. Incorporate additional attenuation mechanisms as they are identified in the literature into deterministic mass balance models.}

A number of attenuation pathways - such as aerobic cometabolism or anaerobic mineralization and abiotic reductive dechlorination via reactive ferrous iron compounds such as iron(II) sulfide or magnetite - are just now starting to be recognized as potentially relevant processes. Additional mechanisms for contaminant attenuation are likely to be identified as long-term monitoring of sites continues. Incorporating the potential contribution of any new mechanisms into existing deterministic models, such as BIOBALANCE, or newly developed models should be a priority. The BIOPLUME 4 model is a good example in which abiotic degradation pathways have been recently added. Models that employ a straightforward mass balance approach should be developed in such a way that they are easily adaptable to include additional attenuation process as they are identified.

\section{T2. Develop mass-balance tools for optimizing the efficiency and sustainability of enhanced attenuation.}

The MNA/EA Project affirmed the centrality of mass balance as the framework for successful natural attenuation remedies. Mass balance is critical in conceptualizing natural attenuation remedies, designing enhancements, developing characterization and monitoring strategies, and developing regulatory decision frameworks that encourage broader use of MNA/EA with clarified technical responsibility. Tools of varying sophistication are needed to advance the scientific implementation of MNA and EA, and insertion of tools at all levels in the planning and implementation process is the best way to implement such advancement. As many of the chlorinated volatile organic contaminant (cVOC) groundwater plumes within the DOE complex are located in predominantly aerobic groundwater, mechanisms other than biological reductive dechlorination will play a contributing, if not dominant role, in attenuation based remedies. In order to support mass balance determinations, additional research to understand abiotic processes and subsequently tools must be developed to measure the rates of those processes so they can be incorporated into mass balance calculations. In order to document the stabilization and shrinkage of plumes and the sustainability of that stabilization/shrinkage, models must be able to simulate various attenuation mechanisms, be they biological, abiotic or physical, and processes that control boundary conditions and electron balances. At the sophisticated end of the spectrum, complex numerical models are available that can effectively simulate existing conditions and estimate future conditions. In order to support MNA/EA determinations, modules will need to be developed for those models that will represent the attenuation mechanisms and processes that may occur. Continued development is needed to support a balanced policy of environmental protection while minimizing resource use and collateral damages. To address implementation, guideline development is necessary to identify situations where a mass balance or mass flux approach is not warranted on a cost and need basis and when such an approach will be beneficial based on cost and need. 


\section{Chapter 3.0 Advances in Understanding Attenuation Processes/Tools}

As an initial step toward examining and including other processes in a mass balance for contaminants, the TWG developed a set of tables that examined a broad range of attenuation mechanisms and processes. The attenuation mechanisms and processes are broadly classified as: biological destruction, abiotic destruction, nondestructive physical and chemical processes, and boundary condition impacts. Table 4 identifies, describes and evaluates a broad range of attenuation mechanisms and processes - the final column provides a summary assessment of applicability and significance for each process. Table 5 is a matrix that describes the potential applicability of these processes to a variety of common chlorinated solvent contaminants (and daughter products). The table suggests that there are significant opportunities to improve the technical basis and robustness of MNA/EA remedies. One example is to consider coupling central reductive zones to surrounding or downgradient aerobic zones for a sequential process where the strengths of the various destruction processes are roughly matched to the target contaminants. Existence of sequential processes has been demonstrated in the field (e.g., Johnson et al., 2003; Clement et al., 2000). The EPA protocol (EPA, 1998) also discusses this type of coupling of processes. A second example, for some landfill settings it might be appropriate to consider co-disposed toluene as an aerobic co-metabolite (if oxygen is present) rather than as an electron donor for reductive processes. The success of these co-metabolic processes will be dependent on the relative concentrations and fluxes of toluene and oxygen (McCarty et al., 1998, Hopkins et al., 1993).

These and several other examples are tabulated where processes are opportunistically coupled. Some processes, such as longitudinal dispersion, are included but noted as relatively weak attenuation mechanisms. Finally, some of the mechanisms, such as phytoextraction or volatilization, can substantively contribute to attenuation but may not be dominant or sufficient when considered alone at typical sites. These alternative and substantive mechanisms may be appropriate candidates for adding to screening models for MNA/EA to improve the overall mass balance projections.

The dominant attenuation mechanism for chlorinated solvents at those sites with chemically reducing geochemical conditions is reductive biodegradation. However, other significant attenuation mechanisms include abiotic degradation, volatilization, chemical transformation, plant uptake, sorption, dispersion, advection and non-reductive microbiological processes. For example, sites with high oxygen and nitrate levels in the groundwater will not support reductive biodegradation as the dominant attenuation mechanism. In these cases, hydrolysis rates of the chlorinated solvents, although slow, are likely to be a primary determinant in the potential for the application of MNA. A MNA/EA Project document (Truex et al., 2006) provides more detailed information about which degradation reactions are important for each chlorinated compound, as well as additional technical references. Stable isotopes, (e.g. labeled carbon or chlorine atoms) have been used to determine degradation rates and pathways of chlorinated solvents. While isotopes have been used mostly in laboratory experiments they have more recently been tried under field conditions to determine degradation rates and pathways, whether there are biotic or abiotic mechanisms.

Since microbial degradation is generally recognized as a dominant attenuation mechanism at most sites, current practices of evaluating MNA for chlorinated solvents are focused primarily on the evaluation of in situ microbial processes. Recent advances in understanding microbial processes and the development of techniques and tools to rapidly and specifically evaluate microbial activity have significantly increased the scientific basis for deployment of MNA. 
Table 4. Processes, Issues and Opportunities (ref Looney et al. 2006b)

\begin{tabular}{|c|c|c|c|c|c|c|c|}
\hline 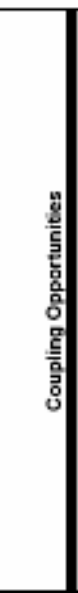 & 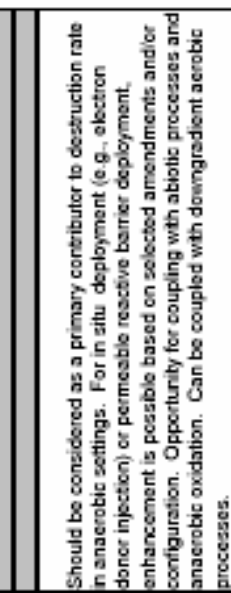 & 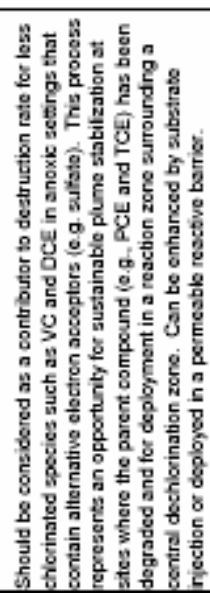 & 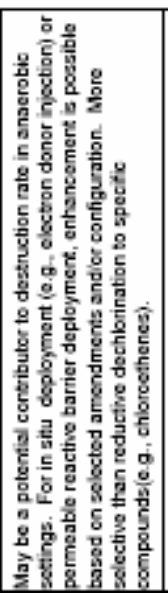 & 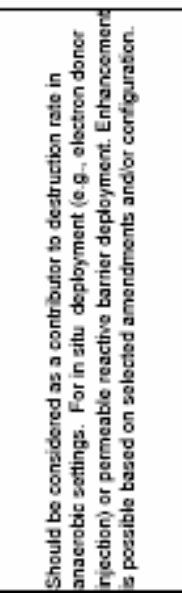 & 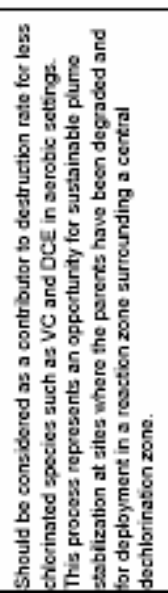 & 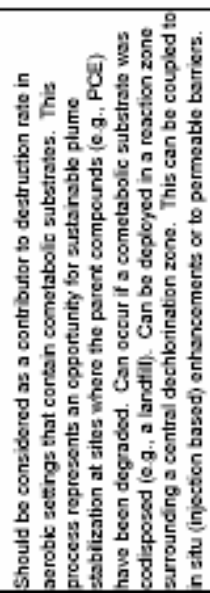 & 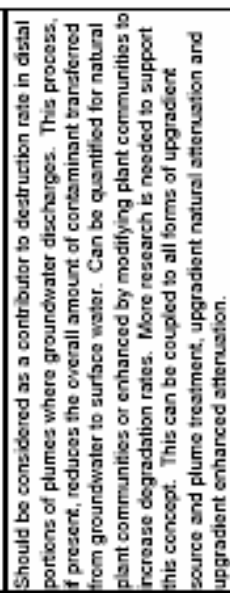 \\
\hline 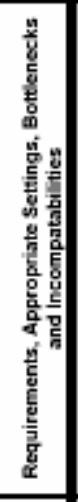 & 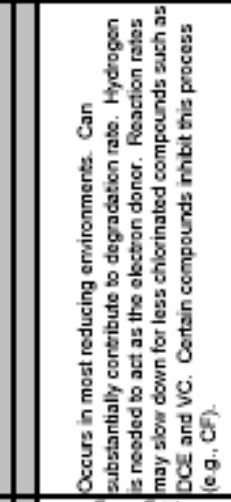 & 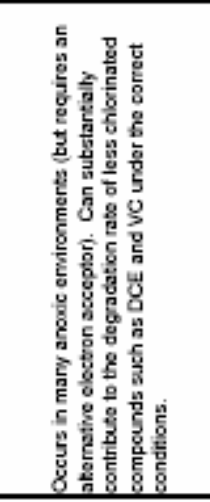 & 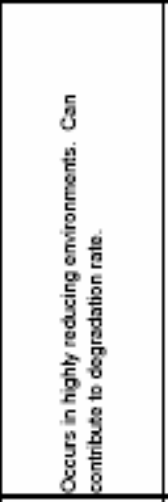 & 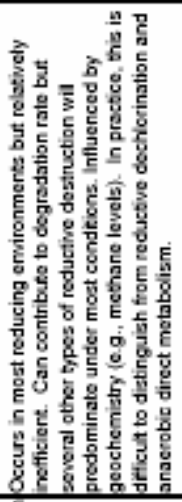 & 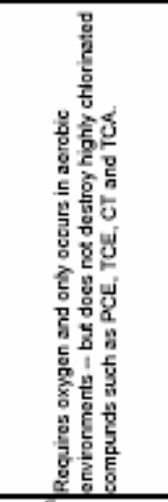 & 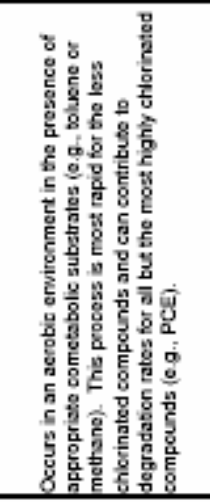 & 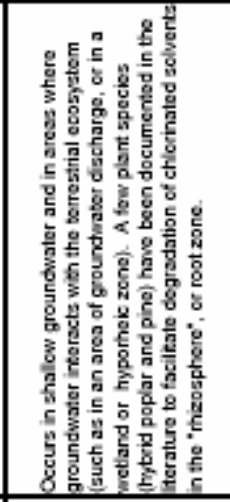 \\
\hline & 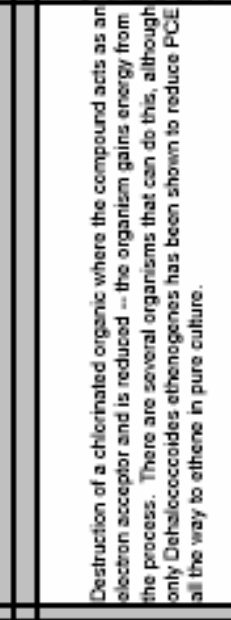 & 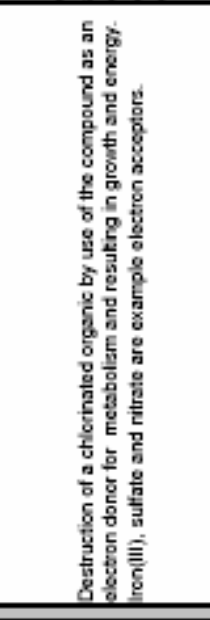 & 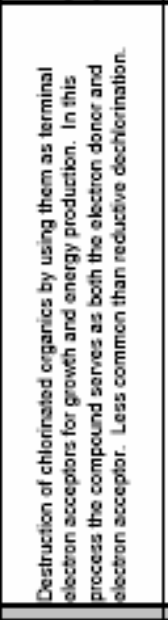 & 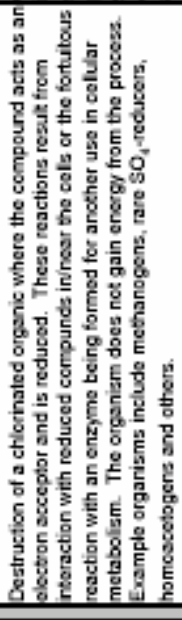 & 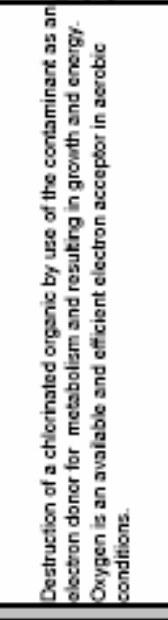 & 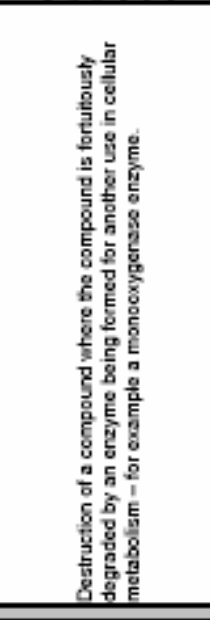 & 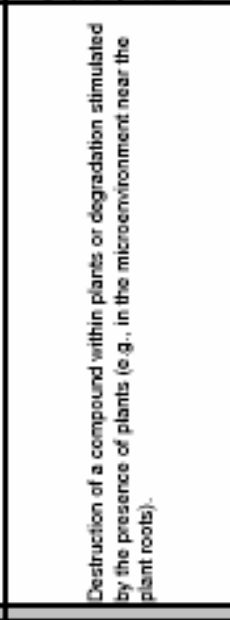 \\
\hline & 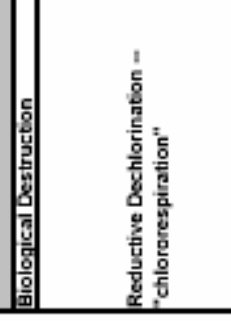 & 亮 & 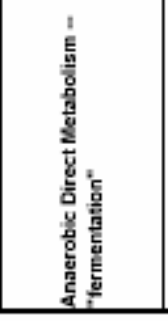 & 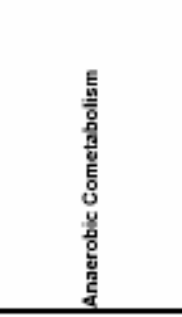 & 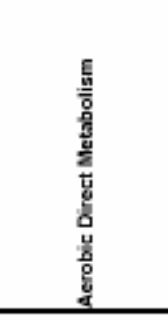 & 选 & $\frac{\bar{t}}{a}$ \\
\hline
\end{tabular}


Table 4. Processes, Issues and Opportunities (continued)

\begin{tabular}{|c|c|c|}
\hline 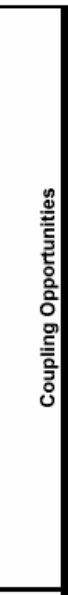 & 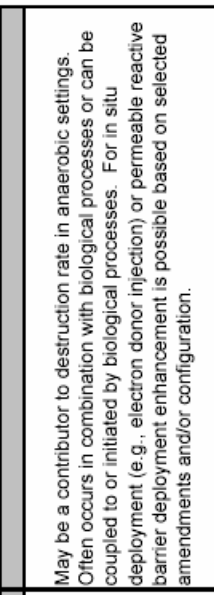 & 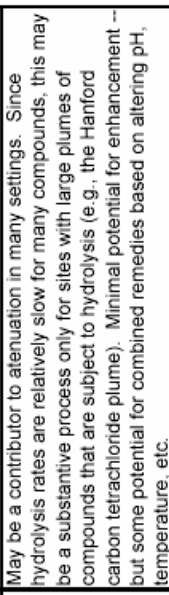 \\
\hline 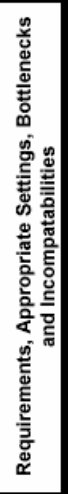 & 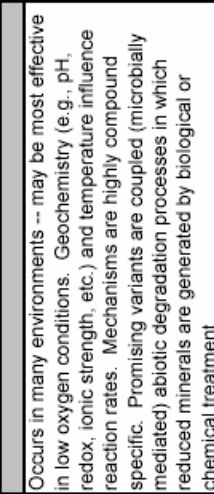 & 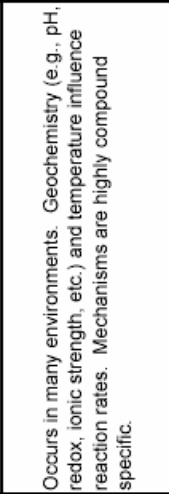 \\
\hline & 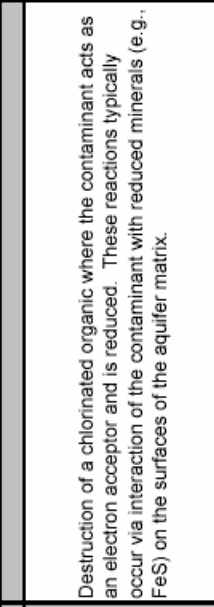 & 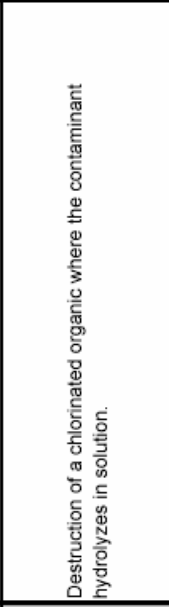 \\
\hline 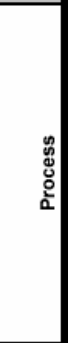 & 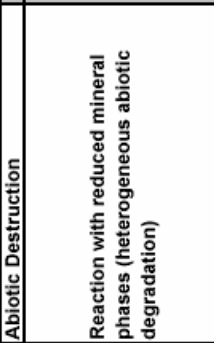 & 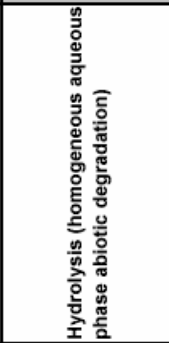 \\
\hline
\end{tabular}


Table 4. Processes, Issues and Opportunities (continued)

\begin{tabular}{|c|c|c|c|c|c|}
\hline 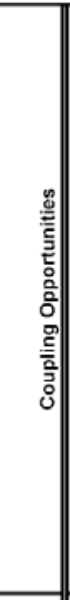 & 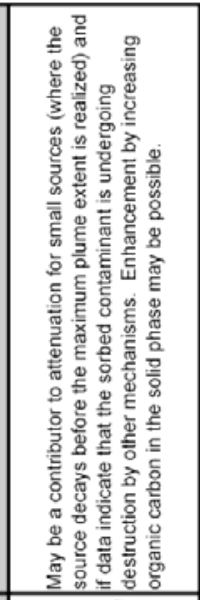 & 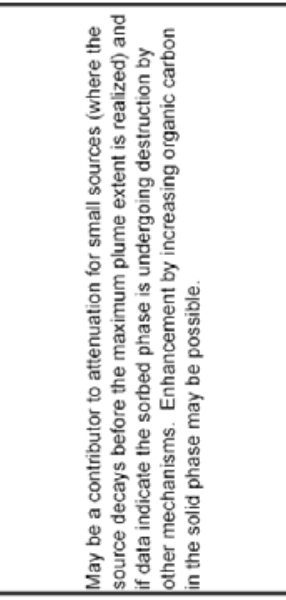 & 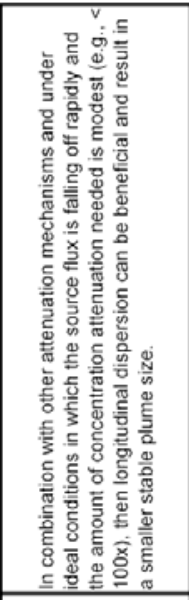 & 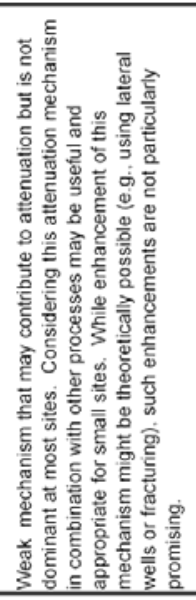 & 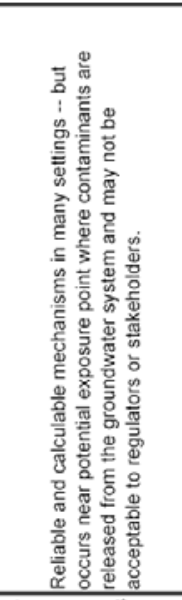 \\
\hline 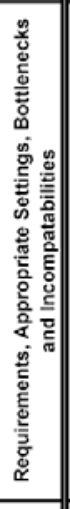 & 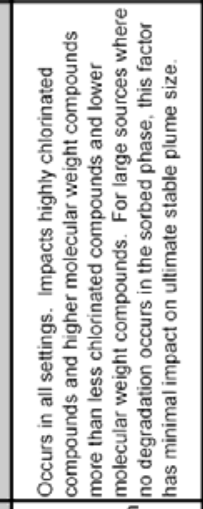 & 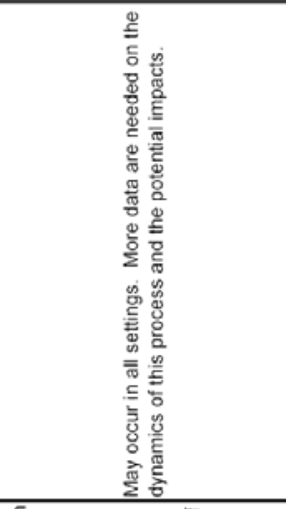 & 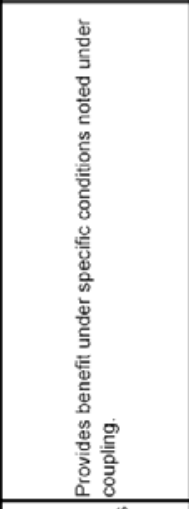 & 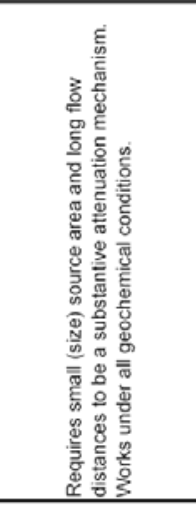 & 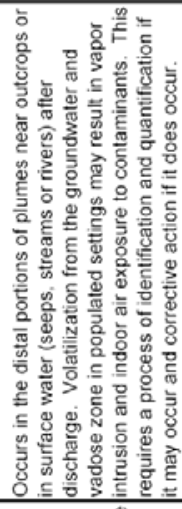 \\
\hline 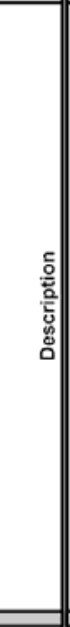 & 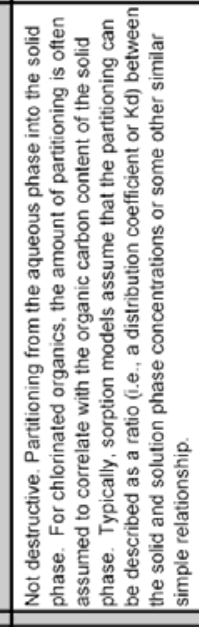 & 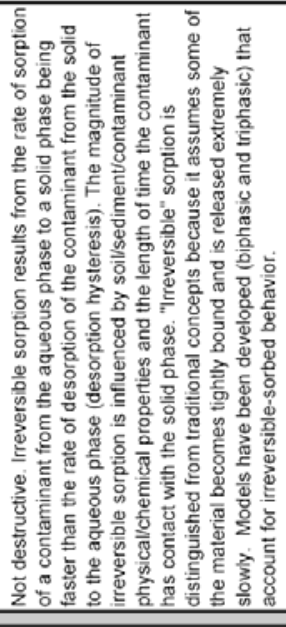 & 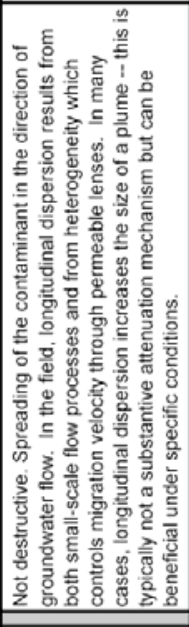 & 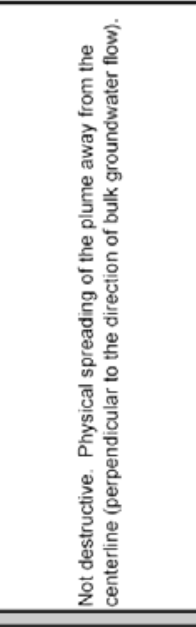 & 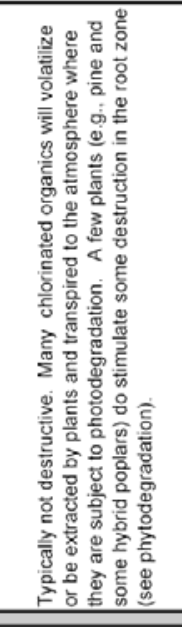 \\
\hline 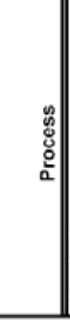 & 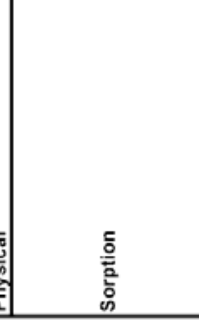 & 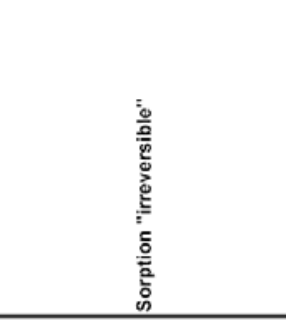 & 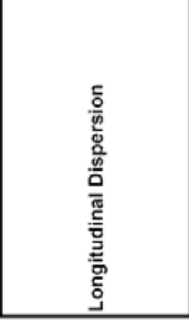 & 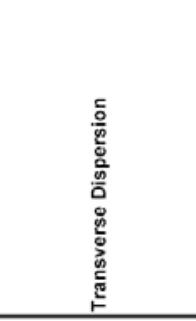 & 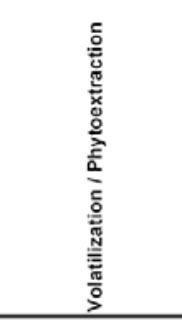 \\
\hline
\end{tabular}


Table 4. Processes, Issues and Opportunities (continued)

\begin{tabular}{|c|c|c|c|}
\hline 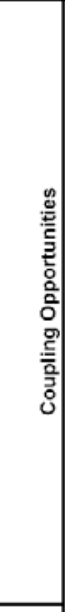 & & 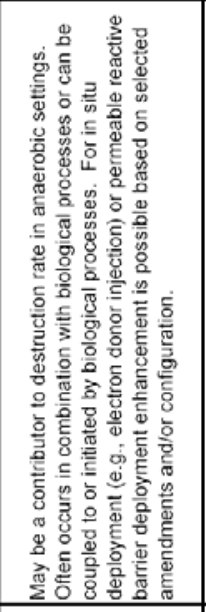 & 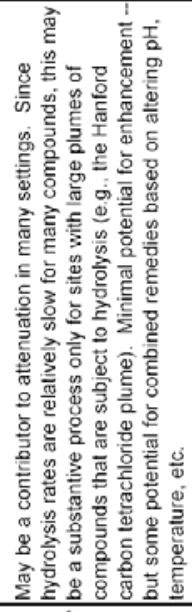 \\
\hline 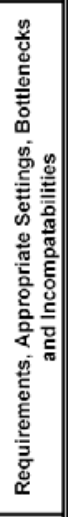 & & 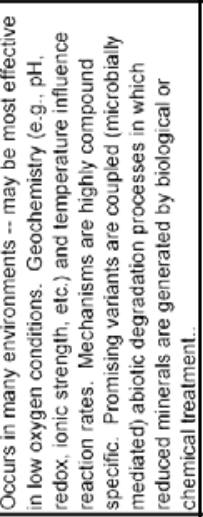 & 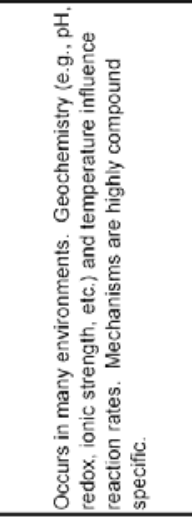 \\
\hline & & 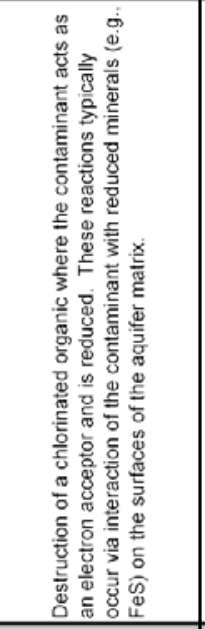 & 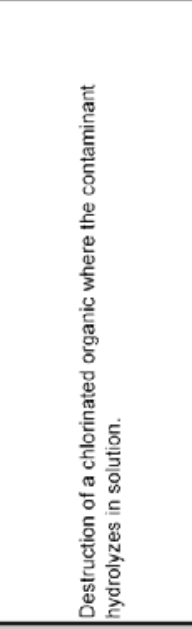 \\
\hline $\begin{array}{l}0 \\
0 \\
: \\
\vdots \\
\vdots \\
\end{array}$ & \begin{tabular}{||c|c} 
\\
0 \\
0
\end{tabular} & 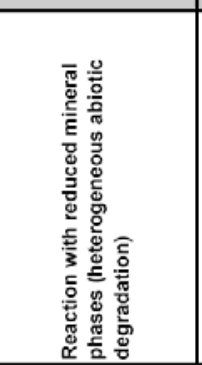 & 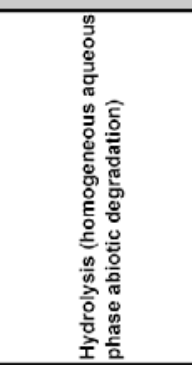 \\
\hline
\end{tabular}


WSRC-STI-2006-00377, Final

December 27, 2006

Page 24 of 68

Table 5. Attenuation Mechanisms and Processes and their Relative Effectiveness for Different Example Contaminants (ref Looney et al. 2006b)

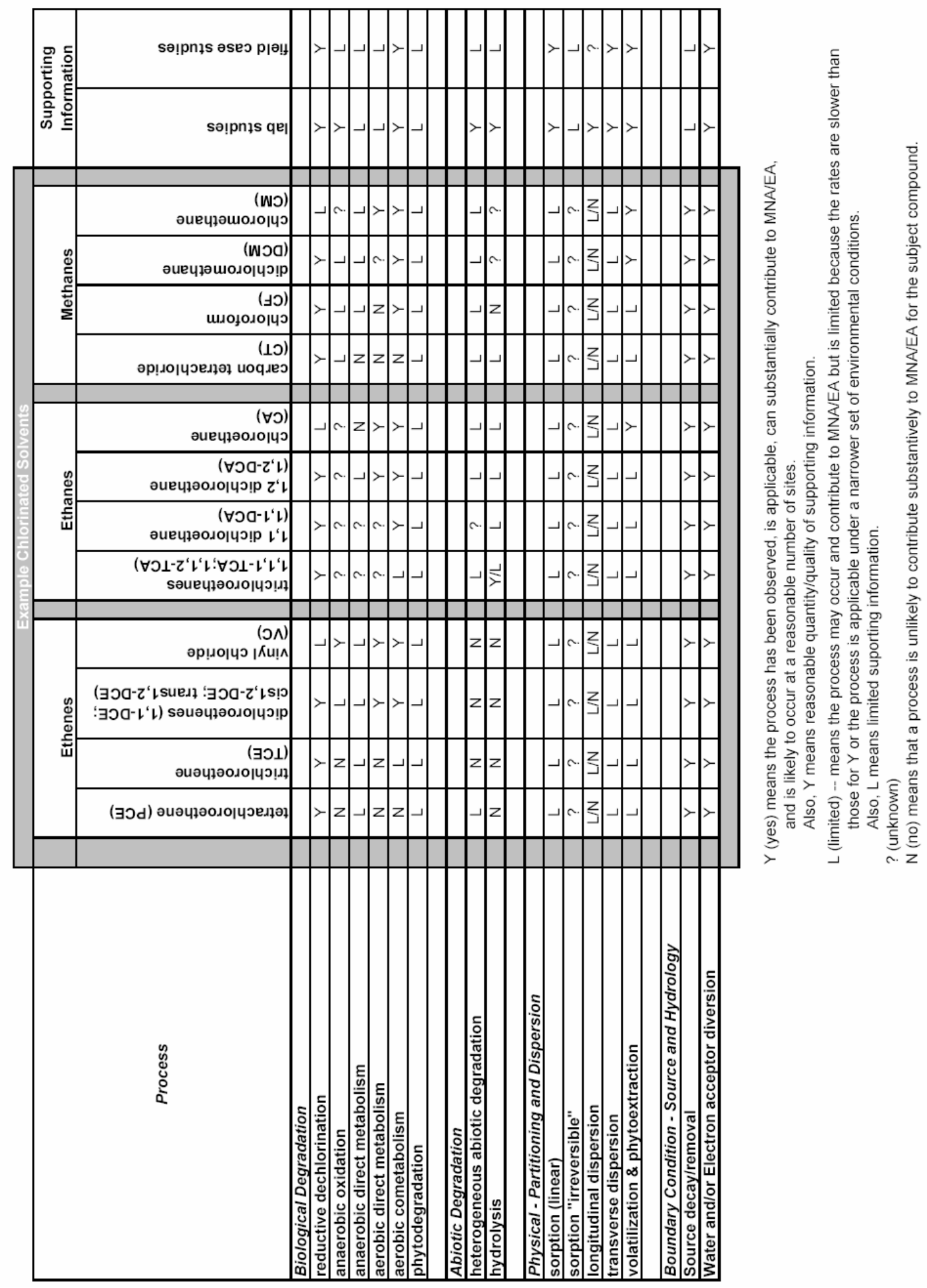




\subsection{Biological Degradation}

Table 4 identifies a wide range of biological degradation processes that may contribute to attenuation of chlorinated organic plumes. Most of the biological degradation processes are microbiological. These occur under a wide range of biogeochemical conditions with a wide range of rates and efficiencies. For highly chlorinated solvents such as PCE, reductive processes tend to be the most rapid and effective biological mechanisms, while for compounds with few chlorine atoms in the molecule such as chloroethene, oxidative processes tend to be the most rapid and effective. The challenges in assessing microbiological attenuation rates and microbial degradation impacts on the contaminant mass balance and plume dynamics include: determination of the relevant processes, identification of degradation byproducts and their fates, and characterizing and monitoring the attenuation in a cost effective fashion. Importantly, while much attention has been focused on anaerobic mechanisms in the literature and in protocol development for chlorinated solvent MNA, aerobic processes such as cometabolism have been shown to support natural attenuation, even for relatively highly chlorinated compounds such as TCE, at real-world sites including the Idaho National Laboratory Test Area North site (Wymore et al., 2005). As noted above, most of the biological destruction processes are microbially mediated. The potential role of macrobiology in contaminant destruction is recognized by the inclusion of a row in Table 4 for phytodegradation. Phytodegradation is the destruction of contaminants facilitated or mediated by plants, or resulting from the active microenvironment created by plants in their rhizospere, or root zone (Early et al., 2006a; Chapelle et al., 2003b).

Protocols and current practices used to evaluate MNA of PCE and TCE, have relegated traditional microbiological approaches (e.g. classical direct detection of specific microorganisms, characterization of microbial communities, and processes or rates via microcosm studies) to the "third line of evidence", a supporting role used only if absolutely required to confirm processes hypothesized from historical trends and geochemical footprints. Furthermore, the application of enhanced in situ bioremediation (EISB) has generally assumed that under the right environmental conditions chlorinated solvents will biodegrade. Due to this assumption, microbial identification and quantification have been considered to be expensive, time-consuming and not necessary. However, recent improved understanding of the role of key microbial species in the degradation of chlorinated solvents and the lack of their ubiquity has dispelled this assumption and increased recognition of the importance of directly detecting specific microorganisms and/or their functions both temporally and spatially within a potential MNA site.

Recent advances in molecular biology are now affording us an opportunity to open up the "black box" of microbial ecology to allow us to better predict, design, and monitor MNA and EISB remedies. Specifically, technology is rapidly advancing in this area and these new tools and capabilities now allow examination of the whole microbial genome, proteomic expression in natural systems, and support what has been termed a "systems biology approach". These rapid advances in system biology techniques/technologies are enabling the:

- "Finger-printing" to evaluate spatial and temporal changes in the composition, interactions, and metabolic responses of and within entire microbial communities in response to changes in their habitat;

- Discovery of new metabolic pathways and microorganisms that degrade chemicals;

- Understanding how these pathways and microorganisms are regulated;

- Development of monitoring tools to test for the presence, distribution, and activity (latent or expressed); and

- Predicting the sustainability and degradation capacity of natural systems.

Recognizing the potential benefit of systems biology in advancing MNA/EISB practices, the research supported by this and other DOE projects has led to further development of molecular biological tools (MBT) within the following areas:

- Advancement of nucleic acid based tools for monitoring in situ reductive dechlorination; 
- Quantitative relationships between specific Dehalococcoides sp. mRNAs and dehalogenation rates and system capacities;

- Characterization and performance assessment of aerobic cis-dichloroethene (cDCE)-degrading bacteria cultures;

- Identifying and characterizing microorganisms involved in integrated anaerobic-oxidative biodegradation of chlorinated solvents;

- Improving procedures for sample collection, handling and storage to optimize the quantity, quality and preservation of target nucleic acids.

- Use of enzyme probes to assess the existence and rate of aerobic cometabolism by a variety of organisms (e.g., methane degraders, toluene degraders, etc.).

The combined results of DOE sponsored studies have:

1) Identified limitations of $16 \mathrm{~S}$ rRNA gene-based approach (cannot sufficiently distinguish between strains with different metabolic capabilities) (Edwards and Löffler, 2006);

2) Identified key genes involved in "housekeeping activity" vs. those involved in reductive dechlorination (Edwards and Löffler, 2006);

3) Developed libraries of gene fragments for use in microarrays that will allow testing of entire dechlorinating genomes to determine how reductive dechlorination is regulated (Edwards and Löffler, 2006);

4) Started to develop the relationship between various classes of genes and their transcriptional regulation/expression versus correlations with halorespiration (Richardson, 2006);

5) Improved our understanding of the relationship between genes, gene translation/transcription and specific peptides associated with halorespiration (Richardson, 2006);

6) Characterized good and poor performing cultures of aerobic cDCE-degrading microbial cultures (Jennings et al., 2006);

7) Provided an initial comparison of currently available commercial products and methods for filtration, extraction, purification and storage of nucleic acids from environmental samples (Yeager, 2006); and

8) Documented the viability of enzyme probes as a primary basis for documenting and quantifying aerobic cometabolic attenuation, selecting MNA as a plume remedy, and monitoring the system (Lee et al., 2005, Clingenpeel et al., 2005).

The ultimate goal of this research is to develop tests, improved methods, deployment strategies and guidance for interpretation of test results from field sites where MNA is being considered. It is noteworthy that the potential value of these MBTs and the research and development needs for their successful environmental application as identified in the MNA/EA Project are consistent with the research needs identified in a recent Strategic Environmental Research and Development Program (SERDP) sponsored workshop that focused on MBTs (SERDP, 2005)

The research highlights several intriguing uses of MBTs to support the implementation of MNA/EA, such as:

- Mass Balance: MBTs can be used to identify key degradation processes and identify microbial processes for those chlorinated solvents and attenuation processes that do not leave easily measured daughter products and other types of "smoking gun" chemical evidence. Furthermore, reductive dechlorination processes may not account for all mass loss observed at a particular site and MBTs that show the presence and activity of other processes would provide powerful evidence that MNA was occurring by other mechanisms.

- Capacity/Sustainability: Estimation of a degradation rate from the "total" expressed dehalogenases (or other degradative enzymes or proteins) provides a means to determine whether the biological degradation is in balance with the mass flux of cVOCs into the system. Similarly, sustainability of systems could be assessed based on expressed genes/proteins and could be correlated to required degradation rates to maintain steady-state plumes. For example, changes in the amount of expressed genes/proteins could be 
correlated to increasing or decreasing cVOC mass flux and rates. Furthermore, detection of key genes downgradient of the source/plume could be used to indicate future capacity.

Although MBTs are powerful for research purposes, particularly to more quickly discover new metabolic pathways, their regulation, and the specific microorganisms associated with these metabolic processes, there are several remaining issues related to their practical application which must be addressed. Some of these issues include:

- When to use: Are they used routinely or only in special situations (e.g., when mass loss or sustainability are not understood or predictable)?;

- Heterogeneity: Is there an integrated or scalable expression that can be used to relate microbial data and heterogeneity to real-world performance?;

- Practicality: How will these tools be deployed? Will the analysis always be done in a fixed lab or are mobile devices possible?;

- Reliability: How accurate and precise are the measurements versus in situ activities? How will false positives and negatives be detected and corrected? Will the analysis induce non-induced genes?;

- Cost: Much of the current cost is the labor to extract the markers from the sample. Will technical advances or broadscale acceptance (increased volume) bring down costs?; and

- Cost Benefit: How will understanding the microbiology avoid costly design errors or assist in developing cost-effective designs?

\subsection{Abiotic Degradation}

An emerging body of literature has identified and quantified the role of abiotic degradation in attenuation of chlorinated solvents (Ferrey et al., 2004, Lee and Batchelor, 2002a, 2002b, Reinhard et al., 1990, Vogel and McCarty, 1987). The most common abiotic reactions affecting these compounds include reduction reactions (including hydrogenolysis and reductive elimination) and hydrolysis. Abiotic reduction reactions require an electron donor. While this donor can occur in the aqueous phase, the sites where abiotic degradation is observed to occur at significant rates typically have reduced solid phase minerals (e.g., minerals containing reduced iron and manganese). In some cases, these minerals are naturally present in a formation, while in other cases, the minerals are formed by addition of a reducing agent or by coupling a biological reduction process with formation of the desired mineral phases to leave a residual abiotic degradation capacity. These options and coupling opportunities are described in more detail in Tables 4 and 5. Hydrolysis (and similar processes) occurs in the aqueous phase and reaction rates typically vary significantly as a function of the specific contaminant, temperature, $\mathrm{pH}$, ionic strength, etc. While these reactions often occur slowly, they can become importantdominant attenuation mechanisms for contaminants such as carbon tetrachloride if the plume is large and the transport times are long.

\subsection{Nondestructive Physical, Chemical and Hydrogeological Attenuation Processes}

A variety of nondestructive physical, chemical, and hydrological attenuation mechanisms contribute to the stabilization and shrinkage of contaminant plumes and to reduction in concentrations. These include dispersion, and sorption (reversible and "irreversible"), and the coupled interactions of the water/electron donor inputs and outputs. All of the nondestructive attenuation mechanisms are relatively weak compared to the destructive mechanisms. Thus, the nondestructive mechanisms are typically coupled with destructive processes to achieve remedial objectives. Recent research studies suggest that the attenuation due to sorption will vary from site to site and that the assumption of reversible (linear) sorption may be valid at some sites (Riley et al., 2006), while resistance to desorption (so called irreversible or nonlinear) may be manifested for some contaminants at some sites (Chen et al., 2000, Riley et al., 2005). Table 4 describes the various nondestructive processes and their potential role(s) in attenuating contaminant plumes as well as how these processes can be coupled into a more comprehensive MNA/EA conceptual framework. 


\subsection{Boundary Condition Effects on Attenuation}

Though not an attenuation mechanism in the traditional sense, boundary condition impacts influence mass balance. Boundary conditions, in terms of both water and contaminant, can directly and indirectly impact attenuation mechanisms. For example water flux entering the system from up-gradient in some situations will result in dilution and conversely if water flux is reduced near a source zone the contaminant flux could be reduced. Another example is to divert water containing competing electron acceptors and thereby increase contaminant attenuation capacity within the system. In terms of the contaminant mass balance, source removal and/or source decay directly influence the loading of the contaminant and the overall viability of MNA and EA.

\subsection{Supporting Chemical and Physical Characterization and Monitoring Tools}

As discussed above, many of the attenuation mechanisms rely on a conducive geochemical or hydrogeologic environment. Monitoring for change in the overall health of the environment may be a powerful method to document that MNA/EA remedies are working as planned. In this case, the geochemical or hydrogeologic measurements are surrogates for a more expensive paradigm of frequent concentration measurement from large numbers of wells. Example data types that are often under-utilized include meteorology data, evapotranspiration and other ecological data, stream gauging and other hydrologic data, geophysical survey data, and flux data (from trenches, horizontal wells or other integrating sampling methods). Also, sensors and improved sampling techniques for contaminants will aid in the implementation and monitoring of MNA/EA. The MNA/EA Project supported several studies to explore the potential for improved monitoring tools (such as an improved oxygen sensor (Millings et al., 2006) and chlorinated organic sampler (Cantrell et al., 2006)), techniques (including pushpull tests (Istok et al., 2006) and fluxmeters (Hatfield et al., 2006)), and interpretation methods (including neural networks (Conrads et al., 2006), a scenario based planning tool (Truex et al., 2006), a decision analysis tool (Geomatrix, 2006), and various modeling tools (Kamath et al., 2006, Johnson et al., 2006)). These studies (Appendix A) were informative and they documented that improved characterization and monitoring is a substantive topic that requires continued development to support MNA and EA remedies.

\subsection{Summary}

Every natural system has a capacity to attenuate environmental contaminants through a variety of physical, chemical, and biological processes and the final stages of remediation must rely on this capacity. It is therefore important to understand and measure the natural processes that will achieve final remediation of contaminated sites. Characterization is needed to identify and estimate the contribution of the attenuating mechanisms and enable comparison of contaminants loading to attenuation. Further, the various attenuation rates vary over both space and time within a contaminant plume. Monitoring is needed to assure that the desired contaminant control (attenuation) is in place and sustainable. Cost effective sampling strategies and disciplined-reliable methods to generalize attenuation rates to the overall plume are needed to support technically based attenuation remedy decisions and to monitor the attenuation performance through time.

A major difficulty in measuring natural attenuation lies in its complexity and in the fact that most of the dominant and critical attenuation mechanisms are inferred from indirect evidence rather than measured directly. Typically, indicators that measure conditions suitable for biodegradation and breakdown products are collected to provide evidence biodegradation is occurring. Therefore, multiple parameters are needed plus an understanding of their relationships to accurately assess MNA. Research into stable isotope ratios and microbial tools that are capable of more directly measuring degradation is ongoing and critical to the development of better tools to support implementation of a mass balance approach to MNA. While advances in developing tools that provide direct measures of degradation processes and rates are being made by the research community, future advances are still needed to result in widespread use within the environmental community. 


\subsubsection{Technical Recommendations}

\section{T3. Develop better tools to determine key parameters needed to implement a mass balance for diverse contaminated sites.}

Natural and enhanced attenuation rely on the balance of contaminant loading to a plume and attenuation capacity within that plume. The overall process is observable as a change in the integrated mass flux from place to place resulting from the various degradation, retardation and dispersion mechanisms. The estimated lifetime of the plume is related to the estimate of the original source mass, a parameter that is often difficult to accurately determine. Thus, more direct and integrated measures of critical mass balance parameters are needed, including: initial source mass, integrated mass flux, degradation and attenuation rates in heterogeneous-dynamic conditions, and field scale processes (e.g, matrix diffusion). The goal of this development should be to reduce uncertainty, reduce costs and improve natural and enhanced attenuation decisions.

\section{T4. Develop a better understanding of attenuation mechanisms.}

Reductive biodegradation is recognized as a principal attenuation mechanism for chlorinated solvents at many sites. However, other attenuation mechanisms including volatilization, oxidative biodegradation, chemical (abiotic) transformation, plant uptake, sorption, and dispersion may have a significant role at sites where reductive dechlorination is limited by geochemical conditions or microbial ecology. To aid in the further understanding of the relative contributions of all potential attenuation mechanisms, increasing focus should be given to these alternative processes, including the kinetic rates, degradation pathways, and sustainability in natural systems. 


\section{Chapter 4.0 Enhanced Attenuation: A Bridge between Source Treatment and MNA}

As noted in the Introduction, EA is a remediation strategy that involves intervention to augment the natural attenuation capacity of a contaminant source-plume system. By this approach, sites with limited attenuation capacity that are not suitable candidates for MNA may be amenable to effective plume management by EA. Nonetheless, MNA and EA share many common features. The objective of this chapter is to explore their similarities and differences. Although both MNA and EA have application to a broad spectrum of contaminants, the current focus of EA for the MNA/EA project is on chlorinated solvents.

The foundation of EA as a viable approach for plume management can be traced directly to the concept of MNA as defined in EPA's Office of Solid Waste and Emergency Response (OSWER) guidance (EPA, 1999). There are three key elements of convergence for these two approaches:

- Active source treatment associated with application of MNA or EA, if necessary;

- Reliance on a variety of sustainable attenuation mechanisms (potentially applied to sources and/or plumes) to create a stable or shrinking plume within a time-frame that is reasonable in comparison to other treatment alternatives; and

- Applying mass balance as a tool for assessing both MNA and EA.

\subsection{Active Source Treatment}

Both MNA and EA recognize the importance for active source treatment of "principal threat" wastes whenever practicable as a precursor to or contemporaneous with plume management. Where treatment is not realistic, engineering controls for sustainable waste containment should be employed (e.g. engineered covers to reduce infiltration, french drains to intercept and divert groundwater). The objective of aggressive treatment of the source is mass reduction of contaminants that will translate to a decrease in plume loading and an overall reduction in the longevity of the source. In the case of a dense non-aqueous phase liquid (DNAPL) source, recent field investigations have documented the impact of partial source removal with an associated reduction in the resultant mass flux of dissolved cVOCs (Wood, 2003). Numerical modeling supports these observations, although there is considerable debate about the time-dependent, quantitative impact of active source treatment (Falta, 2003; Parker and Park, 2004).

\subsection{Attenuation Mechanisms}

Both EA and MNA depend on the action of passive sustainable, attenuation mechanisms to reduce the mass flux of contaminants. For example, MNA relies on a variety of naturally occurring physical (e.g. dispersion, diffusion), chemical (e.g. radioactive decay, sorption, abiotic reactions), and biological (e.g. reductive dechlorination reactions) attenuation mechanisms "...to reduce the mass, toxicity, mobility, volume, or concentration of contaminants in soil or groundwater" (EPA, 1999). The EPA guidance for MNA emphasizes mechanisms that destroy contaminants rather than to simply cause dilution or delay their migration.

The physical, chemical, and biological attenuation processes that are of fundamental importance to MNA also are central to the success of EA. However, there are several significant differences that serve to distinguish these two approaches. One major distinction is illustrated by the EPA OSWER guidance for MNA, which states the following:

While MNA is often dubbed "passive" remediation because natural attenuation processes occur without human intervention, its use at a site does not preclude the use of "active" remediation or the application of enhancers of biological activity (e.g. electron acceptors, nutrients, and electron donors). However, by 
definition, a remedy that includes the introduction of an enhancer of any type is no longer considered to be "natural" attenuation.(EPA, 1999; pg. 4)

It is noted that some Records of Decision (RODs) for some sites specifically incorporate active source treatment alternatives that are coupled with MNA and are part of the overall treatment strategy ${ }^{1}$.

In contrast to MNA, EA recognizes that application of enhancers to improve the effectiveness of natural attenuation mechanisms or to provide novel ways of containing and slowing the release of contaminants can be an effective plume management strategy. For example, nutrients can be added to enhance the growth of indigenous bacteria and facilitate degradation of cVOCs such as TCE (biostimulation), although breakdown beyond cis-1,2DCE might be limited. Alternatively, a new consortium of microbes capable of complete degradation of TCE can be introduced into the zone of contamination (bioaugmentation) ${ }^{2}$. These approaches may have potential for producing a sustainable change in the attenuation. Because human intervention is involved, according to the EPA guidance, such measures cannot be considered MNA.

A second element of distinction addresses the scope of the enhancements. Whereas MNA tends to focus on attenuation within the plume, the EA paradigm addresses the source and plume together as a system, with application of enhancements to both components of the system. Enhancements applied to the source zone are a means of reducing the source loading to the plume. Loading - transfer of contaminants from the source to the plume - is the product of concentration and flow. Therefore, source loading can be manipulated by reducing the flow of water into or through the contaminant source zone.

Many of these approaches rely on large-scale manipulations of the hydrology in the vicinity of the source, although passive source reduction methods are available. Large-scale manipulations of source-zone hydrology typically involve various engineering measures. Examples include interception and diversion of surface runoff and stormflow from up-slope areas, passive drains or siphoning wells that intercept groundwater upgradient from the source and redirect it downgradient, and reducing infiltration and percolation of precipitation through the source zone by enhancing soil water storage, plant growth, and evapotranspiration. Alternatively, source reduction technologies (e.g. passive soil vapor extraction for cVOCs) reduce source loading by limiting the availability of source mass for dissolution into groundwater.

Figure 7 illustrates examples of different kinds of enhancements that might find application in source-plume systems within the context of EA. Whereas the MNA guidance strongly favors attenuation mechanisms that result in contaminant degradation, those leading to dilution or retardation of contaminant migration are not excluded. Likewise, for EA, a broad spectrum of enhancement types is possible including contaminant destruction, containment, and dilution processes. A more detailed discussion of enhancements is provided in Early, et al. (2006a).

Although the MNA/EA Project has focused on enhanced attenuation of chlorinated solvents, the basic EA paradigm is applicable to any class of contaminants. However, the types of enhancements that might be considered for deployment at a site must be compatible with the contaminants. Some enhancements (e.g. hydraulic manipulation) are not contaminant specific whereas others (e.g. reductive dechlorination for cVOCs; precipitation for certain metals or radionuclides) must be tailored to specific properties of the target contaminants.

\footnotetext{
${ }^{1}$ Examples of RODs that involve the concept of coupling treatment of sources and plumes can be reviewed by accessing the EPA ROD System (http://www.epa.gov/Superfund/sites/rods/index.htm) and using "source treatment" and "monitored natural attenuation" as search criteria.

${ }^{2}$ There are many examples of successful experience with biostimulation; testing of bioaugmentation is more recent, but outcomes of field projects at Dover Air Force Base (AFB), Kelly AFB, and Cape Canaveral are very promising (Ellis, et al., 2000; Major, et al., 2002; Hood, et al., in review).
} 

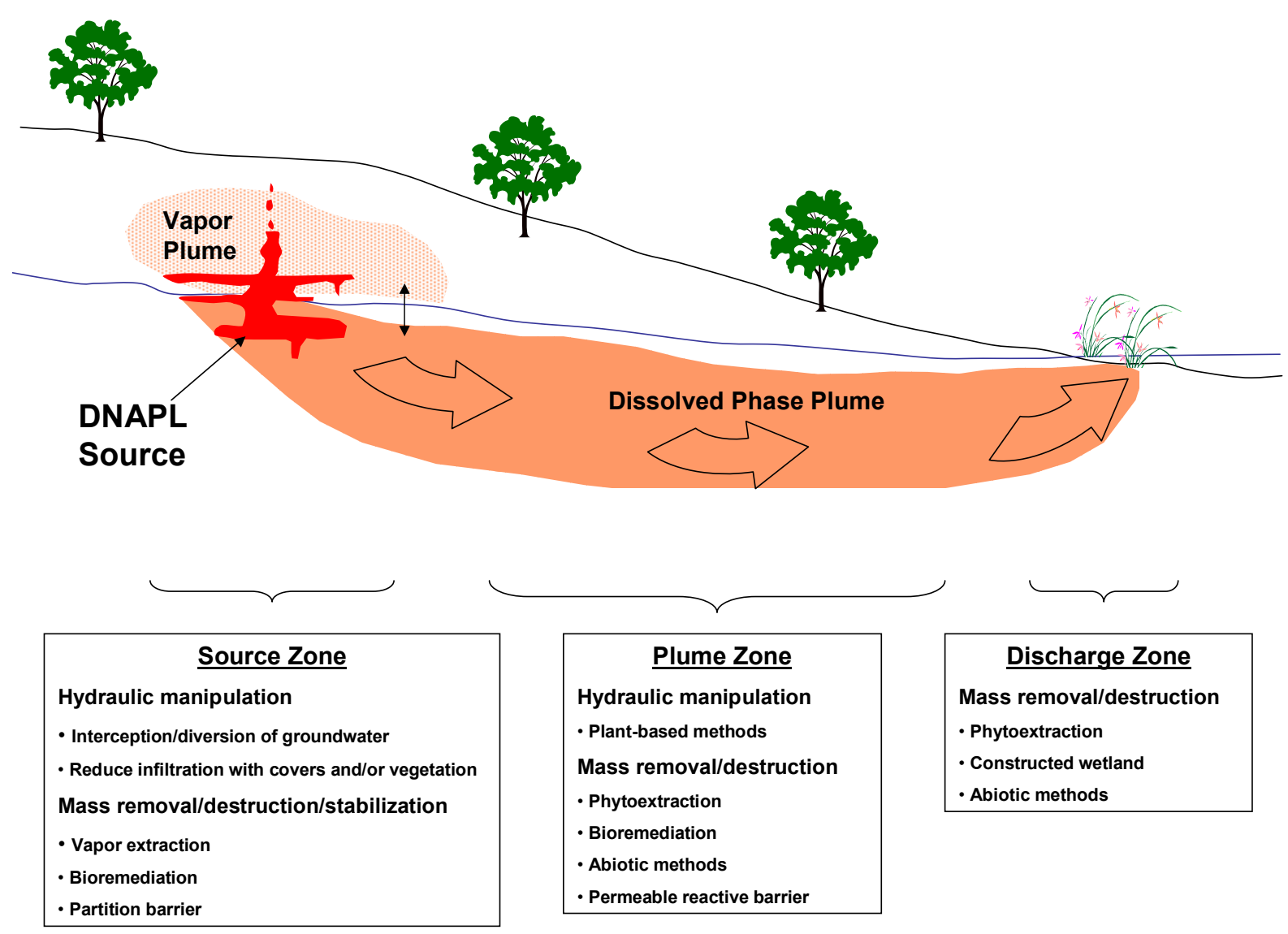

Figure 7. Schematic showing examples of different types of enhancements and the zones where they might be deployed.

\subsection{Passive and Sustainable Processes}

Within the context of MNA, natural attenuation processes are passive because they must operate "without human intervention" (EPA, 1999). In a similar manner, one goal of EA is to utilize enhancements that once implemented are passive (i.e. limited or no human intervention following deployment). Ideally, an enhancement will be deployed with a single phase of intervention sufficient to maintain its effectiveness without further intervention (i.e. the passive criterion). However, for some enhancements, infrequent, periodic intervention may be desirable. For example, if trees are planted to improve evapotranspiration in a source area, periodic (e.g., annual) fertilization of the trees might be desirable, especially if the trees are to be harvested every few years as a short rotation crop with commercial application as a biofuel feed stock.

The concept of sustainability is equally important to both MNA and EA, but there are subtle differences in the way the term is applied. For MNA, natural attenuation processes must be effective as long as necessary to maintain a stable or shrinking plume until such time that regulatory objectives are met and there is no further concern to human health and the environment. Barring significant environmental changes to the aquifer system it is expected that the natural attenuation processes will continue to be effective indefinitely.

It is understood that many or most enhancements will not necessarily maintain their effectiveness indefinitely, nor should they be expected to do so. For example, over time, if not designed to accommodate ecological succession and soil development processes, engineered covers gradually will deteriorate. Similarly, the reactivity and/or 
permeability of permeable reactive barriers will decrease, and nutrients added to stimulate microbial reactions (e.g. hydrogen release compound - $\mathrm{HRC}^{\circledR}$ - or emulsified oil substrate - EOS ${ }^{\circledR}$ ) eventually will be consumed or migrate out of the target treatment zone. Rather, enhancements only must operate as long as necessary to maintain a favorable balance between source loading and system attenuation capacity. As the source term progressively decreases due to gradual depletion, the necessity for an enhancement to operate at peak efficiency also declines, so that at some point in time (perhaps 10 or 20 years or more) the treatment or containment effectiveness of the enhancement is no longer required as a supplement to the natural attenuation capacity of the system. In this way EA can be viewed as a bridging technology to MNA.

\subsection{Linkage of EA to Mass Balance, Characterization and Monitoring}

One of the key contributions of the MNA/EA project has been development of a more explicit approach to mass balance. It offers a roadmap for expressing attenuation capacity for a variety of attenuation mechanisms into succinct mathematical expressions with a common set of units (Looney et al., 2006b). A second and equally important contribution of this project has been efforts to identify characterization and monitoring strategies and tools that can be utilized to measure directly input parameters to these expressions (e.g. rates of reactions, etc.) to achieve a quantitative measure of integrated system attenuation capacity (Gilmore et al., 2006). Coupling of the quantitative measures of source loading and natural attenuation capacity can provide defensible estimates of mass balance to support the selection of MNA or EA for a site.

Possibly the greatest challenge for EA is to obtain reliable estimates of the impact of enhancements on the mass balance of the system. This analysis must include an assessment of the initial effectiveness of the enhancement as well as the sustainability, or the rate at which this effectiveness deteriorates over time. Some types of enhancements that involve straightforward engineered approaches (e.g. french drains, slurry walls) should yield relatively predictable performance results because there is lengthy experience in their use. Other enhancements for which there are fewer, long-term, empirical data will have a greater level of uncertainty. One of the key conclusions in Gilmore et al. (2006) is the need to address these uncertainties in a cost-effective and creative fashion by developing monitoring strategies for EA that are matched to the specific mechanisms that are enhanced - to document that the enhancement is still active. For example, confidence in an enhancement might be best documented using a few simple parameters like bulk redox conditions, dissolved oxygen or water balance rather than on detailed measurement of contaminant concentrations in a large number of wells coupled with statistical analysis.

\subsection{Summary}

It should be apparent that MNA and EA involve several common threads that link them. Reliance on passive, sustainable, attenuation mechanisms to achieve an end-point for plume management acceptable to regulators is chief among these. The major point of departure between the two strategies is that MNA specifically prohibits the introduction of enhancements, whereas for EA, enhancements are a critical means of reducing the plume loading rate and/or increasing the attenuation capacity of the system beyond that provided by natural processes alone. This approach may permit sites that are not suitable candidates for MNA to be amenable to effective plume management by EA. Ideally, introduction of enhancements will lead to a stable or shrinking plume, a condition that can be maintained as the effectiveness of the enhancements gradually declines over time, but keep pace with reduction of source loading. When the impact of the enhancements has declined below some threshold value and the source term has diminished significantly, the goal is for the natural attenuation capacity of the system to be sufficient to sustain the stable or shrinking plume and meet all regulatory objectives for site closure. Consequently, EA can be viewed as a bridging technology that transitions to MNA. 


\subsubsection{Technical Recommendations}

One of the key questions related to incorporating EA into remediation design is for how long will the enhancement be sustainable. Though sustainability of an action will be site specific, it should be possible to develop design parameters for various EA technologies. To accomplish this it will be necessary to conduct field investigations associated with technologies that can be implemented under the EA concept. The following two recommendations provide for gathering this information and are relevant to the interests of the end users, regulators, stakeholder, and scientific community as discussed in Section 1.7, Figure 2.

\section{T5. Evaluate past datasets to assess effectiveness and sustainability of attenuation remedies under varying conditions.}

There are thousands of sites around the country where long-term groundwater monitoring programs have been in place for long time periods (e.g., up to 25 years at some sites). The data from these sites, collected at great effort and expense, have typically been used for a single purpose: to determine the location of a contaminant plume. However, the very nature of these data present a unique opportunity to study long-term natural attenuation processes and the sustainability of MNA/EA processes.

Focused data mining studies (also called historical or retrospective studies) can be designed with great care where these long-term monitoring datasets are compiled and analyzed together to develop information on trends, long-term changes over time, and sustainability. This approach can be performed at MNA sites, or at sites where enhanced attenuation projects were performed. Overall, these data mining projects are a very cheap and efficient way to generate large quantities of MNA/EA data because the data have already been paid for at a fraction of the original cost of acquiring the data.

\section{T6. Perform focused field studies of enhancements with detailed monitoring and a sufficient period of record to document sustainability.}

Many potential enhancements involve relatively new concepts with limited testing at field-scale and/or an inadequate period of monitoring to assess their long-term effectiveness and sustainability. In order to obtain sufficient information with which to predict the impact of enhancements on the attenuation capacity of a source-plume system with sufficient resolution over a sufficiently long period of time it is necessary to perform focused field studies These studies must include performance evaluation of enhancements under a range of site conditions using appropriate monitoring methods. 


\section{Chapter 5.0 Implementing the Science - Decision Making for Remedial Actions}

This chapter focuses on how the concepts, tools, and scientific advances in understanding attenuation processes are integrated into the regulatory process that often guides how data is collected to characterize a site, making a remedial decision, and monitoring and evaluating the success of the remedial alternative.

\subsection{Approach to Characterization}

Initial characterization of a contaminant plume often focuses on defining the problem rather than collecting data to determine the appropriate remedy. In order to help guide the characterization so that MNA or EA can be effectively evaluated against traditional active alternatives, data objectives must be established early in the process that will satisfy evaluation of these alternatives. A "Four-Phased Approach" is recommended that is summarized below in Figure 8. (Gilmore et al., 2005).

In the screening characterization phase, a preliminary understanding will be developed for extent and location of the primary source, the contaminant loading and the attenuating mechanisms. During this initial phase, it will be important to use the data to develop a site conceptual model taking into account both spatial and temporal variations. The goal of this phase is to determine whether MNA or EA are viable remedial options at the site. The decision characterization phase provides the information necessary to make a decision to either (1) select MNA as a remedy (2) consider EA or an active treatment in conjunction with MNA or (3) reject MNA and proceed toward use of a more active remediation technology. In this phase, a more detailed estimate of the system's mass balance is determined in terms of system capacity and contaminant loading. The attenuating mechanisms, their rates, and an estimate of sustainability are identified. Initial guidance for determining the types of biogeochemical data that should be collected to assess conditions was developed by EPA (EPA, 1998). A scenarios evaluation tool (Truex, et al., 2006) has been developed to help the practitioner focus characterization efforts, based on the identification of 13 different MNA scenarios to account for the wide spectrum of chlorinated solvent sites. The scenarios are based on the hydrogeologic and geochemical setting as primary factors, and consider source strength and type, location of receptors/travel time, and plume stability as modifying factors. Information related to the types of data, tools and models to be used to evaluate mass balance and sustainability are provided in Chapter 2.

\subsection{Data Management and Communication}

Evaluation of natural and enhanced attenuation as viable solutions for groundwater remediation requires interpretation of spatially distributed data typically collected over years. Management of this data in a readily retrievable format is important to allow for efficient interpretation and decision-making. Environmental database systems should be established that allow for ease of importation into models or into geographic information systems that can spatially display data that will aid both the scientist and manager in interpretation. Trend analysis of contaminant and geochemical data, and biological indicators is often key to establishing the long-term performance of sustainability of MNA. Flexibility in database design should be considered to capture nontraditional types of data, such as contaminant flux, biological indicators, and genomic information.

The importance of open communication with the stakeholders and regulators cannot be emphasized enough, as remedial decisions are rarely made unilaterally. Early and frequent communication is key to laying the groundwork for establishing an environment where all stakeholders can reach consensus on an appropriate final remedy. 


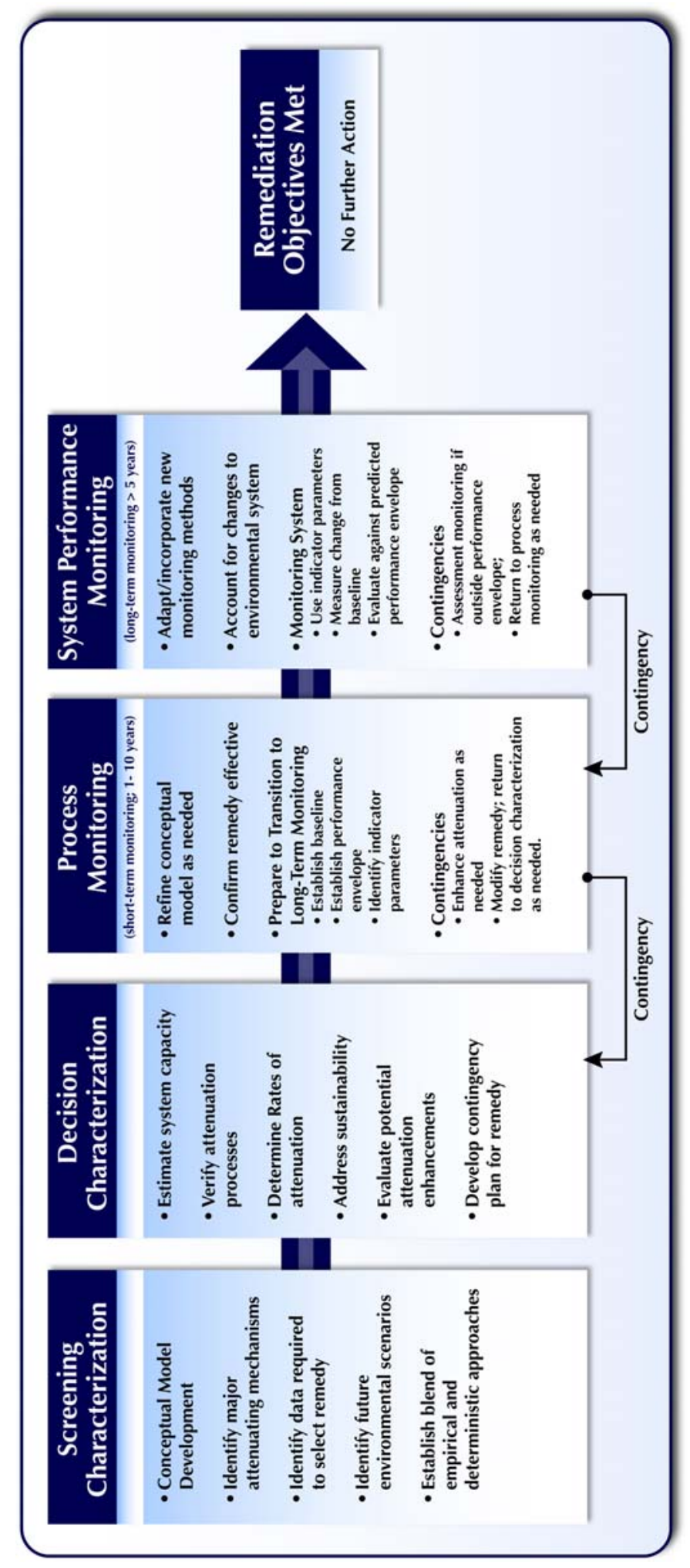

Figure 8. A four-phased approach to characterization and monitoring to support MNA and EA. (Gilmore et al., 2006) 
Open communication can start with the accessibility to data and reports by stakeholders. Automated data reporting using a web-based interface is one example. The potential uses of website application for monitoring and stewardship are: data processing and analyses, a simple interface for direct access to reports, and access to measured and calculated data. The system and data access is password controlled. Stakeholders having access to the data often helps to increase confidence in the data interpretation and remedy selection.

At many federal facilities, formalized processes have been developed to facilitate open communication. One example was the development of the core team scoping process at DOE-Savannah River Site. The goal is to build consensus within the Core Team (one designated decision-maker from the site owner and each regulatory agency). Scoping consists of communicating existing information throughout the project lifecycle to ensure the Core Team and the supporting project team shares a common understanding of site conditions and cleanup strategies. Throughout the scoping process, the teams employs the DOE Principles of Environmental Restoration (DOE, 1999) as a guide for establishing a more effective approach to remedial decision-making, summarized below.

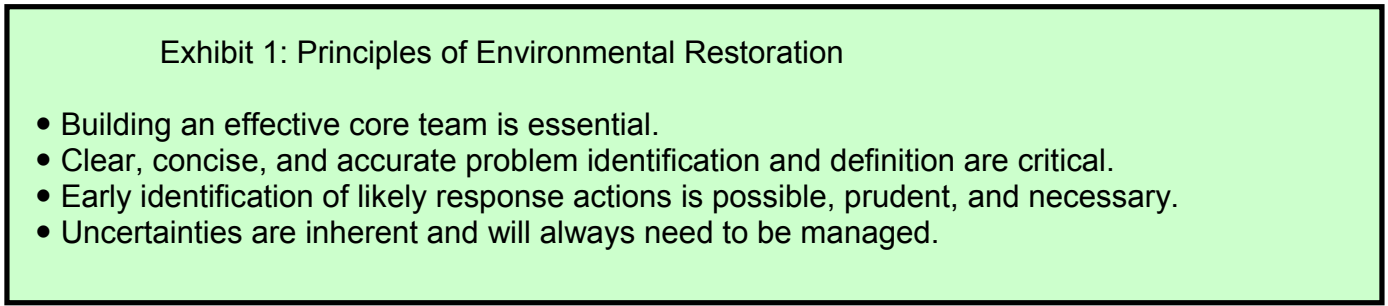

Multiple scoping meetings are typically held, each at a key decision point throughout the remedial process. These scoping meetings are typically facilitated by an objective third party. The intention of frequent scoping is to establish a paradigm of "communicate - agree - document" by which the formal cleanup documentation is a result of collaboration. The emphasis on each scoping meeting is a thorough presentation of the most current project information, a shared technical understanding of conditions and problems, and robust questioning of the technical information to ensure confident real-time decision making. The expected outcome of scoping is alignment of the core team and project team with respect to the following decisions:

- Identification of and scope of problem warranting action;

- Remedial action objectives;

- Response action(s); and

- Key uncertainties

Typically a range of likely response actions is identified. Although applicable to all potential remedial alternatives, identifying and managing the uncertainties is often an important part of reaching core team consensus on an MNA or EA remedial option.

\subsection{Decision Framework}

Two themes resonating in the technical community are the idea of equating plume stability with mass balance, and the idea of using sustainable enhancements as an alternative intervention and transitional remedy leading to MNA. While these ideas have received broad-general support, the challenge is in the details of real-world implementation. As a result, the ITRC has focused on turning the general scientific concepts into a more specific decision flowchart. The primary objectives of the flowchart are to identify the conceptual sequence needed to implement the evolved paradigm; show how mass balance and the option of enhancement fit into the current toolkit for reaching remedial objectives; encourage a decision process that is innovative and disciplined; encourage combining technologies; and provide a defensible mechanism for transitioning technologies as sites 
progress through the remedial process. The general structure of the flowchart (Figure 9) is familiar and consistent with existing guidance documents and protocols. A more detailed version is shown in Figure 10. As depicted, the process encourages implementation of MNA according to the existing protocols with additional emphasis on mass balance based assessment of plume stability and with additional documentation of sustainability. This latter requirement, applicable for example to sites that may have co-disposed hydrocarbons that serve as electron donors to facilitate attenuation, represents an additional level of documentation and rigor to supplement current protocols. Importantly, if a site is approaching MNA but does not meet the requirements of MNA (i.e., it does not pass through the gantlet of requirements on the left side of the figures), the flowchart provides an additional potential option of EA. In this case, the scientist/engineer determines if there is a sustainable action that will modify the risk, plume stability, remediation timeframe, etc. and allows for implementation of that action. This additional loop within the flowchart should encourage a smoother and more efficient and defensible transition to MNA from traditional source treatment (e.g., aggressive physical, thermal or chemical removal, or intensive treatments with chemical and/or microbial methods) and traditional plume treatment (e.g., pump-and-treat or active bioremediation). Note that the process is iterative. If enhancements are not viable, then traditional treatment continues. If enhancement is viable, then it is implemented and monitored to document that the desired change was achieved so that the site can transition into traditional MNA. In addition, because the flowchart is iterative, if a site is undergoing MNA and it is found to not be sustainable, one can enter the chart (Figure 10) in the "evaluate performance and implement contingencies, if needed" section of the flowchart which allows movement to the top of the chart due to lack of sustainability.

The selection of the preferred response action or the decision to transition from active to natural or enhanced attenuation typically requires an analysis of a short list of remedial alternatives that have been recommended by the project team and agreed to by the stakeholders. Consistent, logical, and defensible decisions about what remediation alternatives to implement at a site require that alternatives be evaluated against a clear and consistent set of fundamental objectives. Often objectives are defined or alternatives evaluated based on RCRA/CERCLA guidelines and the nine criteria based on EPA guidance (EPA, 1988) but those decision criteria are often qualitatively defined and evaluated, making them difficult to be used consistently. For a specific site or contamination problem, objectives are typically negotiated and often defined at a very detailed level, such as "reduce concentrations to $5 \mathrm{ppb}$ at the point of compliance." While both types of objectives can be useful, a decision tool was developed to identify a set of fundamental objectives that are broadly applicable for selecting approach(es) for managing and remediating chlorinated solvent plumes (Geomatrix, 2006). Those objectives should be at a high enough level that they can be applied at multiple sites, but detailed enough to allow for consistent and logical evaluation of alternatives.

The defined objectives for the MNA/EA decision tool, applicable to all chlorinated solvent sites, include:

- Minimize health and safety risks to the public and workers

- Minimize adverse environmental impacts

- Minimize costs

- Minimize time to closure

- Maximize regulatory responsiveness 


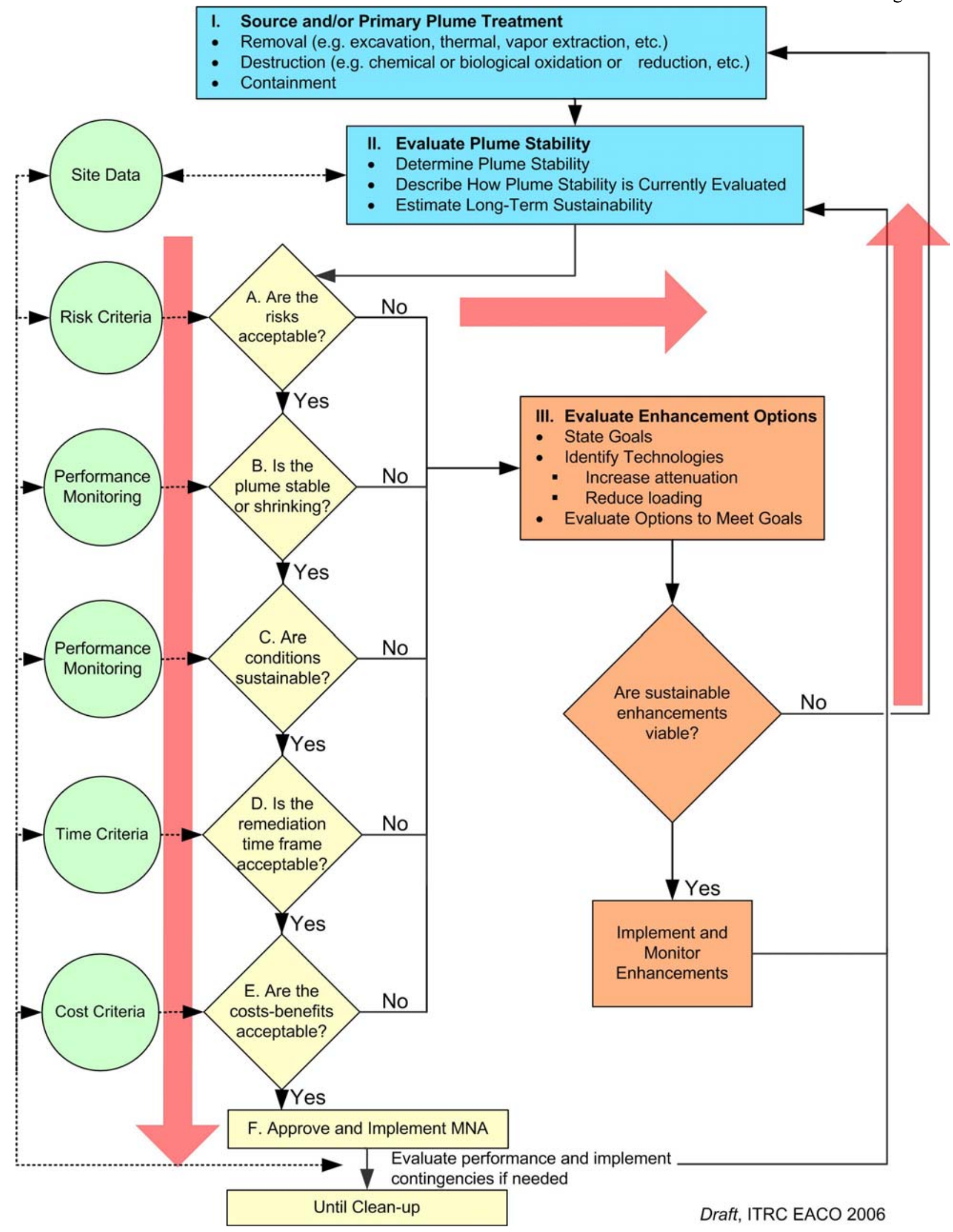

Figure 10. Flowchart to guide decision-making on remedial options for chlorinated solvent contaminated sites. 
The last objective, although more subjective in nature, was included to account for regulatory or stakeholder preference. For example, an alternative including an air stripper may be negatively perceived by the public/regulator. While applicable to all chlorinated solvent sites, decisions will be a balance of objectives, as there may be competing objectives.

\subsection{Monitoring Approach}

Emphasis during the monitoring phases is fundamentally different from the characterization phase, which was focused on collecting data over a short time period to support problem identification and remedy selection. Upon implementation of the remedy, monitoring is required to verify that the attenuation capacity is maintained over time and as conditions vary or remediation goals are met. There are two distinct phases of monitoring; process monitoring where the effectiveness of the remedy is verified and performance or long-term monitoring where the goal is to ensure the remedy is sustained until attainment of remediation objectives is demonstrated.

Verification of the remedy during the process monitoring phase will logically be a continuation of some of the characterization approaches. In particular, attenuation mechanisms and rates will continue to be measured. For EA, empirical data should be collected that can be used to verify the mechanism and predicted attenuation rates of the enhancement. Although many of the monitoring wells used during characterization may be used to conduct process monitoring, the monitoring system should be designed to provide data to verify enhancement performance.

Current approaches to long-term monitoring focus on gradually reducing the number of samples and sampling locations through optimization of well networks, data quality objective approaches, combining contiguous waste sites, and automated systems. For long-term monitoring, the EPA (1999) document establishes a review process used to adjust data collection over time in order to optimize or streamline data collection. Similarly, the State of Minnesota guidance document (MPCA, 2006) recommends that long-term monitoring strategies include a reduction in sampling frequency. Other recent work on long-term monitoring also focused on optimization techniques (Minsker 2003, Chan Hilton and Li 2005, and Herrera and Pinder 2005). While these optimization approaches are merited, given the long time periods some of these sites may be monitored, the resulting cost and lack of integrated data, monitoring networks based on wells may not be appropriate in the long run.

In developing new approaches, the objectives and desired attributes of a performance monitoring (long-term) system need to be identified and considered. The objectives according to the EPA guidance, Performance Monitoring of MNA Remedies for VOCs in Ground Water (EPA, 2004b), are that MNA monitoring be able to demonstrate that natural attenuation is occurring according to expectations (measuring within a predicted range) and verify attainment of remediation objectives. To cost-effectively reach these objectives, expanded use of the following approaches is recommended:

- Utilize indicator parameters that represent a set of properties (e.g., a geophysical measure such as resistivity)

- Utilize spatially integrated measures (e.g. flux)

- Utilize measures of ecological health

\subsection{Summary}

The key to long-term monitoring is to monitor for change that is outside the predicted range.

As natural attenuation processes and rates become better understood, regulatory acceptance of MNA as a significant component of groundwater remedies should increase. To facilitate this decision-making process, appropriate and focused data characterization should be conducted to identify the biogeochemical conditions, major attenuating mechanisms, rates, and sustainability. A decision framework developed by ITRC provides a 
major attenuating mechanisms, rates, and sustainability. A decision framework developed by ITRC provides a flowchart to guide the evaluation of the applicability of natural or enhanced attenuation, i.e., does it meet risk and time thresholds. Open communication between stakeholders is essential in the decision-making process. Initial remedy selection should include MNA, EA options and active treatment technologies so that an objective remedial alternative analysis can be conducted that will guide the stakeholders in their selection of an appropriate final remedy. Furthermore, given that active alternatives often do not meet predicted expectations, the transition to EA remedies or natural attenuation should be more common as a way to reduce operational costs while still meeting cleanup objectives. Process and system performance monitoring is required to confirm that the remedy is performing within the predicted range. Since attainment of remedial goals are likely to require long-term monitoring, the development and acceptance of cost-effective techniques that monitor the overall system rather than reliance on many individual point measurements will be critical.

\subsubsection{Technical Recommendation}

\section{T7. Develop strategies and technologies for performance verification and long-term monitoring.}

Monitoring, particularly long-term monitoring using traditional methods, is a primary cost of MNA. With many sites leaving contaminants in the ground to naturally attenuate it will become even more important to adapt methods that make monitoring as effective and efficient as possible. Long-term monitoring will be most effectively implemented in the context of the overall natural system approach that accounts for all the key interactions between the plume and the environment. The challenge is to identify the most reliable and cost-efficient tools, methods, and processes, focusing on those parameters that will verify that MNA processes are continuing within an acceptable range.

High-priority areas for research include developing monitoring strategies that go beyond optimizing detection-well networks. Long-term monitoring approaches should include combining new and developing technologies with comprehensive approaches in monitoring with increased focus on system-wide monitoring. These techniques can rely on natural properties or techniques that alter the natural properties to amplify the measurements. Measurement techniques can include remote sensing strategies for larger scale environmental effects, passive or accumulator sampling techniques on biological indicators in discharge zones (e.g. clams or periphyton as sentinel species for long-term monitoring), and geophysical methods that interrogate a subsurface area. For example, the electrical conductivity of the subsurface could be altered with the injection of a material such as graphite. In the presence of a chlorinated solvent, graphite will alter its electrical properties which in turn may be measurable with a resistivity survey. These types of measurements will promote alternate strategies to performance and long-term monitoring.

Other approaches that will promote the most cost effective characterization and monitoring include mathematical optimization techniques and systems, including use of artificial intelligence for decision support, and autonomous performance monitoring systems. These approaches can ease labor costs and improve confidence. It is important the research and development of these techniques begin early because their use may dictate the long-term planning for many waste sites. The purpose is to have techniques and approaches in place that will reduce costs while maintaining ability of managers and stakeholders for reliable decision-making. 


\section{Chapter 6.0 Future Needs and Path Forward}

The work of the MNA/EA Project has advanced a broad range of topics that support the evaluation and use of MNA and EA as alternatives for site cleanup. This includes the use of a mass balance approach to guide the evaluation, characterization and monitoring of MNA and EA; tools to evaluate the processes that contribute to natural attenuation; references to various groundwater models designed to aid in understanding the effects of attenuation on the contaminant flux, and concentration over time; a decision framework and tools that may help in determining the appropriate remedy or when a transition to enhanced or natural attenuation is appropriate; and references to case studies where these concepts have been applied.

The overarching objective of this work was to achieve regulatory acceptance of Monitored Natural Attenuation and Enhanced Attenuation as a plume management strategy. This objective will be accomplished by transferring these technical advances to regulators, technical environmental professionals, site managers, property owners, and interested members of the public for consideration and use. To promote these technical advances and develop advanced guidance for MNA, a partnership with the ITRC was formed.

\subsection{Interstate Technology and Regulatory Council (ITRC)}

The ITRC, established in 1995, is a state-led, national coalition of personnel from environmental regulatory agencies from 46 states and the District of Columbia, three federal agencies, tribes, and public and industry stakeholders. The organization strives to reduce barriers to, and speed the interstate deployment of, innovative environmental techniques.

Collaboration with the ITRC through their Enhanced Attenuation Chlorinated Organics (EACO) team has been an integral component of this project and supports one of our three initial goals to facilitate regulator participation leading to decreased barriers. The EACO team was instrumental in refining the initial concept of and in furthering the development of Enhanced Attenuation. The decision-framework, discussed in Chapter 5, developed in partnership by the DOE and EACO teams, will be more fully documented in a technical-regulatory document authored by the EACO team and published by the ITRC. It is anticipated that the document on Enhanced Attenuation will be written by the EACO team in 2007 and will contain the decision-framework, important background information, and references to state regulator survey results, case studies, and technical guides/articles on specific EA technologies.

Technical regulatory guidance documents are designed to aid regulators and others in developing a consistent approach to the technical evaluation, regulatory approval, and deployment of specific technologies and processes at individual sites. In addition to the document, training related to the material in the technical-regulatory guidance document will be made available to persons interested in the topic. Though, an exact date has not been set for this training, it is expected to be available in 2008, after the technical-regulatory guidance document has been published. Information on the training will be available at a future date on the ITRC website. In addition, ITRC document as described above will be available from the ITRC webpage. The website can be accessed at ITRC Home page (http://www.itrcweb.org/homepage.asp).

\subsection{Further Advances}

The MNA/EA Project sponsored research and reviewed new and developing approaches in support of using the mass balance approach with the measurement and modeling tools by which it will be evaluated to produce a reliable estimate of time-dependent performance, sustainability, and impact on meeting remediation goals at a site. (Gilmore et al., 2006, Looney et al., 2006b; Early et al., 2006a). New strategies and techniques were identified to make the application of MNA more efficient. Some approaches and tools hold great promise for 
further advances. Seven major technical recommendations for continued development were identified and are presented in the preceding chapters. These seven recommendations fall into three general areas;

- Develop a better understanding of the attenuation mechanisms including their rates and sustainability

- Monitoring tools to measure the system's mass balance for both short-term and long-term monitoring

- Estimating methods that translate performance of an enhancement into impact on system mass balance

In particular future development of monitoring tools, performance assessment methods and enhanced attenuation concepts should focus on real-world testing and the development of guidance on when to use various tools and determining when such tools are cost effective.

\subsubsection{Management Recommendations}

While addressing the technical barriers to implementation of MNA the TWG also identified a number of practical or management barriers to implementation. These include:

\section{M1 Review effectiveness and sustainability of MNA/EA designs and monitoring plans prior to closure.}

Efforts to design and deploy sustainable remedies now will reduce stewardship costs and risks to human health and the environment in the future. Such efforts will require cooperation between the DOE's Office of Environmental Management (EM) and Office of Legacy Management (LM) prior to EM's closure and transfer of the sites to LM for long-term surveillance and maintenance (LTS\&M). Cooperation should include: (1) evaluation of remedy designs from a long-term performance perspective prior to implementation, (2) design and installation of monitoring systems for both performance verification and long-term performance in concert with designing remedies, (3) evaluation of verification monitoring results prior to transfer of sites, and (4) preparation of long-term surveillance plans (LTSPs) prior to transfer of sites.

\section{M2 Support and implement a project to meet needs for process and system performance monitoring and reduce long-term costs and risks.}

A systematic program to identify and accelerate the development of technologies and systems to meet requirements for future process and system performance monitoring is a critical need for the DOE's EM and LM programs. This program should build on the concepts and technical recommendations developed within the MNA/EA Project and other DOE initiatives, as well as the recommendations made by other organizations and agencies such as the EPA and the Army Corps of Engineers. As with the MNA/EA efforts, key technical targets should be identified and then a broad suite of technologies and approaches selected and applied to meet those targets in a relatively comprehensive fashion. The central theme of the program should build on the ideas of mass balance (stability), sustainability, and achieving remedial goals using the least intensive methods possible. To address this, a variety of innovative approaches and techniques will be needed and will be organized into technical sectors: biomolecular tools, push-pull tests and other field deployment options, sensors, automated systems, and the like.

\section{M3 Develop a crosscutting initiative that includes the Department of Energy's Offices of Environmental Management, Legacy Management and Science to coordinate and leverage planned remediation and research activities.}

Identify and utilize field sites for simultaneous closure and research activities. Develop and document cooperative synergistic agreements across traditional institutional boundaries. Implement EA at a range of sites and invest in obtaining data for a sufficient period or time to reach objectives related to sustainability. 


\section{REFERENCES}

Page 44 of 68

Aziz, C.E., C.J. Newell, J.R. Gonzales, P.E. Haas, T.P. Clement, and Y. Sun, 2000. BIOCHLOR Natural Attenuation Decision Support System, User's Manual Version 1.0, U.S. EPA, Office of Research and Development, EPA/600/R-00/008, Washington D.C., January 2000. www.gsi-net.com

Bockelmann, A., T. Ptak, and G. Teutsch, 2001. "An Analytical Quantification of Mass Fluxes and Natural Attenuation Rate Constants at a Former Gasworks Site.” Journal of Contaminant Hydrology, 53(3-4):429-53.

Carey, G. R., M. G. Mateyk, G. T. Turchan, E. A. McBean, F. A. Rovers, and J. R. Murphy, 1996. Application of an innovative Visualization Method for Demonstrating Intrinsic Remediation at a Landfill Superfund Site. Proceedings of the API/NGWA Petroleum Hydrocarbons and Organic Chemicals in Groundwater Conference, Houston, Texas, November 1996

Chan Hilton AB and Y Li. 2005. Development of Ant Colony Optimization Algorithm for Groundwater Monitoring. GECCO ’05, June 25-29, 2005, Washington, DC.

Chapelle, F.H., 1995, Bioremediation: Nature's Way to a cleaner Environment: U.S. Geological Survey Fact Sheet FS-054-95, 2 p.

Chapelle, F.H., Widdowson, M.A., Brauner, J.S., Mendez, Eduardo III, and Casey, C.C., 2003a. Methodology for estimating times of remediation associated with monitored natural attenuation: U.S. Geological Survey WRIR03-4057, $51 \mathrm{p}$.

Chapelle, F., R. Brigmon, T. Early, K. Finneran, T. Gilmore, M. Heitkamp, C. Journey, B. Looney, D. Major, R. Riley, G. Wein, T. Wiedemeier, 2003b. Baseline Natural Attenuation Processes: Lines of Inquiry Supporting Monitored Natural Attenuation of Chlorinated Solvents. WSRC-TR-2003-00329. Westinghouse Savannah River Company, Aiken, SC.

Chapelle, F.H., B.B. Looney, and C.H. Sink, 2004. A mass balance approach to monitored natural attenuation, in A.R. Gavaskar and A.S.C. Chen (Eds) Proceedintgs of the Fourth International Conference on Remediation of Chlorinated and Recalcitrant Compound (Monterey, CA, May, 2004) paper 3E-06. Battelle Press, Columbus, $\mathrm{OH}$.

Chapelle, F.H., B.G. Campbell, B.B. Looney, T.H. Wiedemeier, and C.H. Sink, 2005a. Empirical and deterministic methods for assessing monitored natural attenuation, in B.C. alleman and M.E. Kelley, Proceedings of the Eighth International In Situ and On-Site Bioremediation Symposium (Baltimore, Maryland; June 6-9, 2005) paper G-17. Battelle Press, Columbus, OH.

Chapelle, F.H., B.G. Campbell, B.B. Looney, M.A. Widdowson, T.H. Wiedemeier, and C.H. Sink, 2006a. A deterministic approach for assessing monitored and enhanced natural attenuation, Proceedings of the Fifth International Conference on Remediation of Chlorinated and Recalcitrant Compounds (Monterey, CA, May 2226, 2006). Battelle Press, Columbus, OH.

Chapelle, F.H., B.G. Campbell, and M.A. Widdowson, 2006b, Assessing the long-term sustainability of monitored natural attenuation, Proceedings of the Fifth International Conference on Remediation of Chlorinated and Recalcitrant Compounds (Monterey, CA, May 22-26, 2006). Battelle Press, Columbus, $\mathrm{OH}$.

Chen, W., A.T. Kan and M. B. Thomson, 2000. Irreversible Sorption of Chlorinated Benzenes to Natural Sediments: Implications for Sediment Quality Criteria. Env. Sci. Tech., 34:385-392. 
Clement, T.P., 1997. RT3D - A Modular Computer Code for Simulating Reactive Multi-Species Transport in 3Dimensional Groundwater Aquifers, User's Manual Version 1.0 (PNNL-11720), May 1997. bioprocess.pnl.gov/rt3d.htm

Clement, T.P., Y. Sun., B.S. Hooker, and J.N. Petersen, 1998. Modeling Multi-species

Reactive Transport in Groundwater Aquifers, Groundwater Monitoring \& Remediation, 18(2):79-92.

Clement, T.P., C.D. Johnson, Y. Sun, G.M. Klecka, and C. Bartlett. 2000. "Natural Attenuation of Chlorinated Ethene Compounds: Model Development and Field-Scale Application at the Dover Site." J. Contaminant Hydrology, 42(2-4):113-140.

Clingenpeel, S.R., W.K. Keener, C.R. Keller, K. De Jesus, M.H. Howard, and M.E. Watwood, 2005. Activitydependent fluorescent labeling of bacterial cells expressing the TOL pathway. Journal of Bicrobiol. Meth., 60:4146.

Conrads, P.A., E.A. Roehls, R.C. Daamen, F.H. Chapelle, M.A. Lowery, and U.H. Mundry, Visualization and Time-Series Analysis of Groundwater Data for C-Area, Savannah River Site, South Carolina, 2006 (A Research Study of the Monitored Natural Attenuation/Enhanced Attenuation for Chlorinated Solvents Technology Alternative Project), WSRC-STI-2006-00335, In Review.

DOE, 1999. Environmental Response Design and Implementation Guidance. DOE/EH-413-9915. Washington DC. December 1999.

Early. T. O., B. Borden, M. Heitkamp, B. B. Looney, D. Major, W. J. Waugh, G. Wein, T. H. Wiedemeier, K. M. Vangelas, K. M Adams and C. H. Sink, 2006a. Enhanced Attenuation: A Reference Guide on Approaches to increase the Natural Attenuation Capacity of a System, WSRC-STI-2006-00083.

Early, T.O., W.H. Albright, E.S. Becvar, C.H. Benson, E. Hood, P.M. Jardine, M. Lorah, E. Majche, D. Major, W.J. Waugh, G. Wein, and O.R. West, 2006b. Enhancements to Natural Attenuation: Selected Case Studies. WSRC-STI-2006-00XXX. Washington Savannah River Company, Aiken, SC. U.S. Department of Energy Office of Scientific and Technical Information, In Review.

Edwards, E. and F. Löffler, 2006. Advancement of Nucleic Acid-Based Tools for Monitoring In Situ Reductive Dechlorination (A Research Study of the Monitored Natural Attenuation/Enhanced Attenuation for Chlorinated Solvents Technology Alternative Project), WSRC-STI-2006-00332. U.S. Department of Energy Office of Scientific and Technical Information, In Review.

Ellis, D. E., E.J. Lutz, J.M. Odom, R.J.J. Buchanan, C.L. Bartlett, M.D. Lee, M.R. Harkness, and K.A. Deweerd, 2000. "Bioaugmentation for accelerated in situ anaerobic bioremediation," Environmental Science \& Technology 34(11):2254-2260.

EPA, 1988. Guidance for Conducting Remedial Investigations and Feasibility Studies under CERCLA, Interim Final. EPA/540/G-89/004. OSWER Directive 9355.3-01. Washington DC. October 1988.

EPA, 1991. A Guide to Principal Threat and Low Level Threat Wastes. Office of Solid Waste and Emergency Response. Superfund Publication 9380.3-06FS. Washington DC. November 1991.

EPA, 1998. Technical Protocol for Evaluating Natural Attenuation of Chlorinated Solvents in Groundwater, EPA/600/R-98/128. Washington DC. September 1998. 
WSRC-STI-2006-00377, Final

December 27, 2006

Page 46 of 68

EPA, 1999. Use of Monitored Natural Attenuation at Superfund, RCRA Corrective Action and Underground Storage Tank Sites, OSWER Directive 9200.4-17P. Washington DC. April 21, 1999.

EPA, 2001. Evaluation of the Protocol for Natural Attenuation of Chlorinated Solvents: Case Study at the Twin Cities Army Ammunition Plant. EPA Office of Research and Development. EPA/600/R-01/025. March 2001.

EPA, 2004a. Treatment Technologies for Site Cleanup: Annual Status Report (Eleventh Edition),

EPA-542-R-03-009. Washington DC. February 2004.

EPA, 2004b. Performance Monitoring of MNA Remedies for VOCs in Ground Water. EPA/600/R-04/027. Office of Research and Development, Cincinnati, OH. April 2004.

Falta, R.W., 2003. Modeling sub-grid-block-scale dense nonaqueous phase liquid (DNAPL) pool dissolution using a dual-domain approach. Water Resources Res. 39(12): 1360-1367

Farhat, S.K., P.C. de Blanc, C.J. Newell, J.R. Gonzales, and J. Perez, 2004. SourceDK Remediation Timeframe Decision Support System, User's Manual, April 2004. www.gsi-net.com

Farhat, S.K., C.J. Newell, and E. Nichols, 2006. Mass Flux Toolkit - To Evaluate Groundwater Impacts, Attenuation, and Remediation Alternatives, User's Manual, March 2006. www.gsi-net.com

Ferrey, M.L., R.T. Wilkin, R.G. Ford, and J.T. Wilson, 2004. "Nonbiological Removal of cis-Dichloroethylene and 1,1-Dichloroethylene in Aquifer Sediment Containing Magnetite," Environ. Sci. Technol. 38:1746-1752.

Geomatrix, 2006. Decision Tool for Groundwater Cleanup of Chlorinated Solvent Plumes at DOE Sites. September 2006.

Gilmore, T., B. B. Looney, N. Cutshall, D. Major, T. Wiedemeier, F. H. Chapelle, M. Truex, T. Early, M. Heitkamp, J. Waugh, D. Peterson, G. Wein, C. Bagwell, M. Ankeny, K. M. Vangleas, K. M. Adams, and C. H. Sink, 2006. Characterization and Monitoring of Natural Attenuation of Chlorinated Solvents in Ground Water: A Systems Approach. WSRC-STI-2006-00084.

Hatfield, K., M.D. Annable, J.Cho, and M.R. Millings, 2006. Passive Fluxmeters: Application as a Characterization/Monitoring Tool for Monitored Natural Attenuation of Chlorinated Solvents (A Research Study of the Monitored Natural Attenuation/Enhanced Attenuation for Chlorinated Solvents Technology Alternative Project), WSRC-STI-2006-00315, In Review.

Herrera, GS, GF Pinder. 2005. Space-time optimization of groundwater quality sampling networks. Water Resources Research, Vol. 41, W12407.

Hood, E.D., D.W. Major, J.W. Quinn, W.-S. Yoon, A. Gavaskar, E.A. Edwards, 2006. Demonstration of Enhanced Bioremediation in a TCE Source Area at Cape Canaveral Air Force Station, Launch Complex 34, Environmental Science and Technology, In Review.

Hopkins, G.D., L. Semprini, and P.L. McCarty. 1993. "Microcosm and In Situ Field Studies of Enhanced Biotransformation of Trichloroethylene by Phenol-Utilizing Microorganisms." Appl. Environ. Microbiol., 59(7):2277-2285. 
WSRC-STI-2006-00377, Final

December 27, 2006

Page 47 of 68

Istok, J.D., J.A. Field, E. Reas, A.D. Peacock, M.R. Millings, K. M. Vangelas, B.B. Looney, 2006. Detecting and Quantifying Reductive Dechlorination During Monitored Natural Attenuation at the Savannah River CBRP Site (A Research Study of the Monitored Natural Attenuation/Enhanced Attenuation for Chlorinated Solvents Technology Alternative Project), WSRC-STI-2006-00XXX, In Review.

Jennings, L. K., C. Sausville-Giddings, and J.M. Gossett, 2006. EA Using Bioaugmentation with Aerobic Bacteria to Degrade cis-1,2-DCE (A Research Study of the Monitored Natural Attenuation/Enhanced Attenuation for Chlorinated Solvents Technology Alternative Project), WSRC-STI-2006-00334, In Review.

Johnson, C.D., M.J. Truex, and J.R. Spencer. 2003. "Use of Redox Zones in Modelling Natural Attenuation of a Chlorinated Solvent Plume." In: Proceedings of the Seventh In Situ and On-Site Bioremediation Symposium, Orlando, Florida; June 2-5, 2003. Battelle Press, Columbus, Ohio.

Johnson, C.D., M.J. Truex, and T.P. Clement, 2006. Developing an MNA Modeling Tool based on RT3D: 3 Reports: Natural and Enhanced Attenuation of Chlorinated Solvents Using RT3D; RT3D Reaction Modules for Natural and Enhanced Attenuation of Chloroethanes, Chloroethenes, Chloromethanes, and Daughter Products; and rtFlux: RT3D Flux Plan Utility (A Research Study of the Monitored Natural Attenuation/Enhanced Attenuation for Chlorinated Solvents Technology Alternative Project), WSRC-STI-2006-00174. U.S. Department of Energy Office of Scientific and Technical Information, www.osti.gov. October 11, 2006.

Kamath, R.K., C.J. Newell, B.B. Looney, K.M. Vangelas, and D.T. Adamson, 2006. BIOBALANCE - A Mass Balance Toolkit, User's Manual, May 2006. www.gsi-net.com

Kean, J., J. Doyon, K.M. Vangelas, G. Carey and K. Wilson, 2006. Monitored Natural Attenuation and Enhanced Attenuation National Overview: Results of an Interstate Technology Regulatory Council (ITRC) Survey, ITRC. Proceedings of the Fifth International Conference on Remediation of Chlorinated and Recalcitrant Compounds (Monterey, CA, May 22-26, 2006). Battelle Press, Columbus, OH.

Lee, M. H., S.C. Clingenpeel, O.P. Leiser, and M.E. Watwood, 2005. Molecular and Physiological Characterization of Aerobic TCE Degradation Potential. Proceedings of the Eighth International In Situ and OnSite Bioremediation Symposium. Battelle Press, Columbus, OH.

Lee, W. and Batchelor, B., 2002a, Abiotic reductive dechlorination of chlorinated ethylenes by iron-bearing soil minerals; 1 - pyrite and magnetite: Environmental Science and Technology, 36:5147-5154.

Lee, W. and Batchelor, B., 2002b, Abiotic reductive dechlorination of chlorinated ethylenes by iron-bearing soil minerals; 2 - green rust: Environmental Science and Technology, 36:5348-5354.

Looney, B.B., F.H. Chapelle, and K.Gorder, 2006a. Mass Balance for Attenuation-based Remedies: Selected Case Studies. WSRC-STI-2006-00336. Washington Savannah River Company, Aiken, SC. U.S. Department of Energy Office of Scientific and Technical Information, www.osti.gov. December, 2006, In Review.

Looney, B.B., F.H. Chapelle, T.O. Early, K. M. Vangelas, K. Adams, and C. H. Sink, 2006b. Mass Balance: A Key to Advancing Monitored and Enhanced Attenuation for Chlorinated Solvents. WSRC-STI-2006-00082. Washington Savannah River Company, Aiken, SC.

Major, D.W., M.L. McMaster, E.E. Cox, E.A. Edwards, S.M. Dworatzek, E.R. Hendrickson, M.G. Starr, J.A. Payne, and L.W. Buonamici, 2002. "Field demonstration of successful bioaugmentation to achieve dechlorination of tetrachloroethene to ethane," Environ. Sci. Technol. 36(23):5106-5116. 
WSRC-STI-2006-00377, Final

December 27, 2006

Page 48 of 68

McCarty, P.L., M.N. Goltz, G.D. Hopkins, M.E. Dolan, J.P. Allan, B.T. Kawakami, and T.J. Carrothers. 1998. "Full-Scale Evaluation of In Situ Cometabolic Degradation of Trichloroethylene in Groundwater through Toluene Injection." Env. Sci. Technol., 32(1):88-100.

McGuire, Travis M., Charles J. Newell and Brian B. Looney. 2003. Performance of MNA at Chlorinated Solvent Sites, G-2776. Savannah River Technology Center. September 26, 2003.

Millings, M.R., B.D. Riha, W.K.Hyde, 2006. Evaluating an Innovative Oxygen Sensor for Remote Subsurface Oxygen Measurements (A Research Study of the Monitored Natural Attenuation/Enhanced Attenuation for Chlorinated Solvents Technology Alternative Project), WSRC-STI-2006-00247. Washington Savannah River Company, Aiken, SC. U.S. Department of Energy Office of Scientific and Technical Information, www.osti.gov. October 12, 2006.

Minsker, B (Ed.). 2003. Long-Term Groundwater Monitoring: The State of the Art, Am. Soc. of Civ. Eng., Reston, Va.

MPCA. 2006. Guidelines - Natural Attenuation of Chlorinated Solvents in Ground Water. Minnesota Pollution Control Agency, Site Remediation Section, St. Paul, Minnesota. June, 2006.

Newell, C. J., S. S. Rifai, J. T. Wilson, J. A. Connor, J. A. Aziz and M. P. Suarez, 2002. Calculation and Use of First Order Rate Constants for Monitored Natural Attenuation Studies, EPA/540/S-02/500, U. S. Environmental Protection Agency, Subsurface Protection and Remediation Division, National Risk Management Research Laboratory, Ada OK March 2002.

NRC. 1993. In Situ Bioremediation, When Does it Work?, National Research Council Committee on Intrinsic Remediation, National Academies of Science and Engineering, National Academy Press, Washington, D.C

NRC, 2001. Natural Attenuation for Groundwater Remediation, National Research Council Committee on Intrinsic Remediation, National Academies of Science and Engineering, National Academy Press, Washington, D.C.

Parker, J.C. and E. Park, 2004. Modeling field-scale dense nonaqueous phase liquid dissolution kinetics in heterogeneous aquifers. Water Resources Res. 40(5): 12 pp.

Rafai, H. S., C. J. Newell, J. R. Gonzolez, S. Dendrou, L. Kennedy and J. T. Wilson, 1998. BIOPLUME III Natural Attenuation Decision Support System, EPA/600/R-98/010, U. S. Environmental Protection Agency Office of Research and Develoment, Washington DC.

Reinhard, M., Curtis, G.P., and Kriegman, M.R., 1990, Abiotic reductive dechlorination of carbon tetrachloride and hexachloroethane by environmental reductants: Project Summary, EPA/600/S2-90/040, September 1990.

Richardson, R., 2006. Development of mRNA-based Dehalogenation Rate Constants (A Research Study of the Monitored Natural Attenuation/Enhanced Attenuation for Chlorinated Solvents Technology Alternative Project), WSRC-STI-2006-00333, In Review.

Riley, R.G., J.E. Szecsody, D.S. Sklarew, A.V. Mitroshkov, C.F. Brown, C.J. Thompson and P.M. Gent. 2005. Carbon Tetrachloride and Chloroform Partition Coefficients Derived from Aqueous Desorption of Contaminated Hanford Sediments. PNNL-15239. 
Riley, R.G., J.E. Szecsody, AV Mitroshkov, CF Brown, 2006. Desorption Behavior of Trichloroethene and Tetrachloroethene in U.S. Department of Energy Savannah River Site Unconfined Aquifer Sediments. PNNL15884.

SERDP, 2005. SERDP and ESTCP Expert Panel Workshop on Research and Development Needs for the Environmental Remediation Application of Molecular Biological Tools, October 2005, pp. 43.

Sink, C.H., K. M. Adams, B. B. Looney, K. M. Vangelas and N. H. Cutshall. Accelerating Environmental Cleanup at DOE Sites: Monitored Natural Attenuation/ Enhanced Attenuation-A Basis for a New Paradigm. Remediation. pp 89-98. Winter 2004. (Reprinted in Federal Facilities Environmental Journal. pp 95-105. Summer 2005.)

Truex, M.J., C.J. Newell, B.B. Looney, and K.M. Vangelas, 2006. Scenarios Evaluation Tools for Chlorinated Solvent MNA (A Research Study of the Monitored Natural Attenuation/Enhanced Attenuation for Chlorinated Solvents Technology Alternative Project). WSRC-STI-2006-00096, Rev. 1. Office of Scientific and Technical Information (www.osti.gov), October 2, 2006.

Vogel, T.M., and McCarty, P.L., 1987, Abiotic and biotic transformations of 1,1,1-trichloroethane under methanogenic conditions: Environmental Science and Technology, 21(12):1208-1213.

Widdowson, M.A., E. Mendez, F.H. Chapelle, and C.C. Casey, 2005. Natural Attenuation Software (NAS), User's Manual Version 2.0, January 2006. www.nas.cee.vt.edu

Wiedemeier, T.W., H. S. Rifai, C. J. Newell, and J. W. Wilson, 1999. Natural Attenuation of Fuels and Chlorinated Solvents. John Wiley and Sons, NY.

WI-DNR, 2003. Understanding Chlorinated Solvent Behavior in Groundwater: Investigation, Assessment and Limitations of MNA, Report No. RR-699, Wisconsin Department of Natural Resources Remediation and Redevelopment Program, Madison WI.

Wood, A.L., 2003. Impacts of DNAPL source zone treatment: Experimental and modeling assessment of benefits of partial source removal. Project summary for SERDP project CU-1295, Strategic Environmental Research and Development Program.

Wymore, R.A., L.N. Peterson, L.O. Nelson, K.S. Sorenson, Jr., 2005. Lessons Learned from Implementation of Monitored Natural Attenuation for an Aerobic Trichloroethene Plume at the Idaho National Engineering and Environmental Laboratory., Proceedings of the Waste Management '05 Conference (February 27 - March 3, 2005, Tucson, AZ).

Yeager, CM., 2006. Molecular Biological Tools and Methods for Subsurface Remediation: An Evaluation of Sample Processing Decisions and Methodology, WSRC-STI-2006-00XXX, In Review. 


\section{Glossary}

abiotic - Chemical and physical processes. In some cases, such attenuation processes do not involve microorganisms or plants, while in other cases, biological and abiotic processes occur simultaneously or serve to enhance each other.

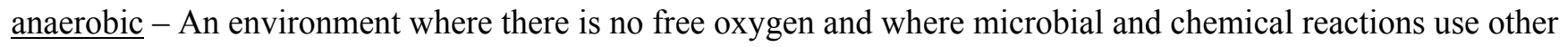
chemicals in the environment to accept electrons.

bioassessment - The general process of characterizing the biological community in terms of ecology, energy balance, and functional capabilities and rates.

bioaugmentation - Adding microorganisms to soil or groundwater to support bioremediation - this may be needed in cases where monitoring shows that chlorinated solvent-degrading microorganisms poorly distributed or at low population densities so that their activity does not provide adequate bioremediation.

bioremediation - Engineered treatment processes that rely on biological mechanisms. For MNA and EA, these processes occur in soil and groundwater.

biostimulation - Adding chemical amendments, such as nutrients or electron donors, to soil or groundwater to support bioremediation.

chlorinated ethene - Chemical substances, such as trichloroethene and tetrachloroethene, that have been used in industry as solvents.

chloromethanes - Chemical substances, such as carbon tetrachloride and chloroform, that have been used in industry as solvents.

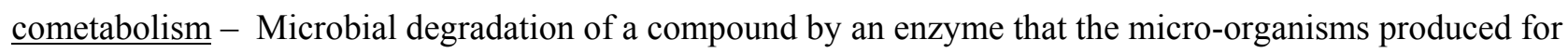
something else.

electron acceptor - Chemical substances, such as oxygen, nitrate, sulfate, and iron, that receive the electrons during microbial and chemical reactions. Micro-organisms need these compounds to obtain energy. For MNA and EA, these electron acceptors often compete with chlorinated solvents and reduce the attenuation rates.

electron donor - Chemical substances, molecular hydrogen for biological reductive dechlorination reactions, that act as energy sources to sustain life and for the degradation of other chemicals, in this case chlorinated solvents.

enhanced attenuation; enhancement - An enhancement is any type of intervention that we might implement in a source-plume system that increases the magnitude of attenuation by natural processes beyond that which occurs without our intervention. Enhanced attenuation is the result of applying an enhancement that sustainably manipulates a natural attenuation process leading to an increased reduction in mass flux of contaminants.

$\underline{\text { flux }}$ - Rate of flow of fluid, particles, or energy through a given surface.

gene expression - The process of converting a gene's DNA sequence into the structures and functions of a cell.

halorespiration, hydrogenolysis, hydrolysis, mineralization - Various chemical processes that can be involved in the degradation of chlorinated solvents. Some of these processes are microbial and others are primarily abiotic.

housekeeping activity - Expression of genes required for normal cell operation.

Integrated Mass Flux (iMF), loading, discharge - The integrated mass flux is the total quantity of a migrating substance that moves through a planar transect that is within the system of interest and oriented perpendicular to the direction of movement. If the transect is at the entry point to the system the integrated mass flux is the loading. If the transect is at the exit point from the system, the integrated mass flux is the discharge. Note that these terms have units of mass per time (e.g., $\mathrm{Kg} / \mathrm{yr}, \mathrm{g} /$ day or the like) and they represent an extension of the traditional engineering definition of flux $\left(e . g ., \mathrm{Kg} / \mathrm{yr} / \mathrm{m}^{2}\right)$ in which the transect area is accounted for to allow mass balance calculation of plume or system scale behavior. 
"irreversible" sorption - Irreversible sorption refers to a hysteresis effect in which a chemical species becomes more strongly bound over time. The term sometimes appears to be used to describe a situation where once sorbed, the contaminant is removed from the plume and remains associated with the soil.

microarray - A multifaceted tray or array of DNA material. Microarrays are expected to revolutionize medicine by helping pinpoint a very specific disease or the susceptibility to it. Sometimes called "biochips," micro arrays are commonly known as "gene chips."

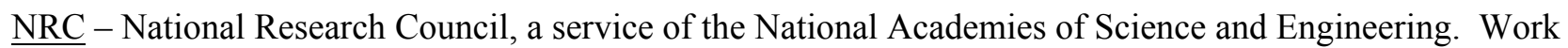
related to natural attenuation has been performed by the Committee on Intrinsic Remediation.

Office of Environmental Management - The office within the U.S. Department of Energy responsible for the department's environmental cleanup program and associated activities at its sites across the U.S.

Office of Legacy Management - The office within the U.S. Department of Energy whose mission is to manage the Department's post-closure responsibilities and ensure the future protection of human health and the environment. LM has control and custody for legacy land, structures, and facilities and is responsible for maintaining them at levels suitable for their long-term use.

Office of Science - The office within the U.S. Department of Energy supporting basic research in the physical sciences. This office's responsibilities include management of fundamental research programs in basic energy sciences, biological and environmental sciences, and computational science.

passive flux meter - Sampling device that uses the absorption and desorption properties of the sampling media to collect and measure the movement of contaminants through the device over a set period of time. These results are then used to estimate the rate at which the contaminants will move through the associated groundwater system for an extended period of time.

permeable reactive barriers - Subsurface walls composed of reactive materials that will either degrade or alter the state of a contaminant when that contaminant in a groundwater plume passes through the wall.

phytoextraction - The removal of a substance original located in the soils and groundwater surrounding the roots of a plant through that plant's vascular system.

"principal threat" waste - Those source materials considered to be highly toxic or highly mobile that generally cannot be reliably contained or would present a significant risk to human health or the environmental should exposure occur. They include liquids and other highly mobile materials (e.g., solvents) or materials having high concentrations of toxic compounds. (EPA, 1991)

Proteomics - The study of the proteins and chemicals produced by organisms, particularly their structures and functions -- what the chemicals are, the way they are distributed within the organisms and its environment.

push-pull test - A field test in which a solution is injected into one or more wells and the change in the composition of that fluid is measured over time. Depending on design, these can provide information on hydrology, chemical reactions, or biological reactions.

reductive dechlorination - Biological degradation, via sequential removal of chlorine molecules from the a chlorinated organic contaminant, that occurs in an anaerobic environment. This is one of the most common attenuation mechanisms for chlorinated solvents and this mechanism was highlighted in the EPA MNA guidance.

regulation (as related to microbiology) - The initiation, stopping and control of processes associated with gene expression.

source loading - The flux of a substance leaving the original disposal location and entering the water migrating through the soil and aquifer.

stakeholder - A person, other than regulators, owners, or technical personnel involved in the environmental activity of concern, whom has a vested interest in decisions related to those particular activities. 
sustainability - The ability of a system to maintain the important attenuation mechanisms through time. In the case of reductive dechlorination, sustainability might be limited by the amount of electron donor which might be used up before remedial goals are achieved.

sustainable enhancement - An intervention action that continues until such time that the enhancement is no longer required to reduce contaminant concentrations or fluxes.

transcription - Transfer of information in DNA sequences to produce complementary messenger RNA (mRNA) sequences. It is the beginning of the process by which the genetic information is translated to functional peptides and proteins.

transect - A cross section through which groundwater flows.

translation - The decoding of mRNA occurs after transcription to produce a specific polypeptide according to the rules specified by the genetic code. 


\section{Appendices}

\section{Appendix A}

Table of Research Projects (grouped by topic with title of project, PI, affiliation, title of research report (including document number), and major contribution to MNA/EA Project)

All research reports have an introduction written by Karen Vangelas and Brian Looney that provides the project team's perspective based on review comments of the research projects of how the research supports the objectives of the MNA/EA for Chlorinated Solvents Project. All research reports will be available from the U.S.

Department of Energy's Office of Scientific and Technical Information webpage located at www.osti.gov.

In the column identified as "Topics" either a Y (yes), M (maybe) or a blank (not relevant) is indicated for each of the three topics of Mass Balance, Enhanced Attenuation, or Characterization \& Monitoring. The MNA/EA Project's TWG reviewed and classified each research project as to how it supported these three categories. The M (Maybe) indicates the study supports the identified category is a secondary role, at best. 


\begin{tabular}{|c|c|c|c|c|c|}
\hline \multicolumn{2}{|c|}{ 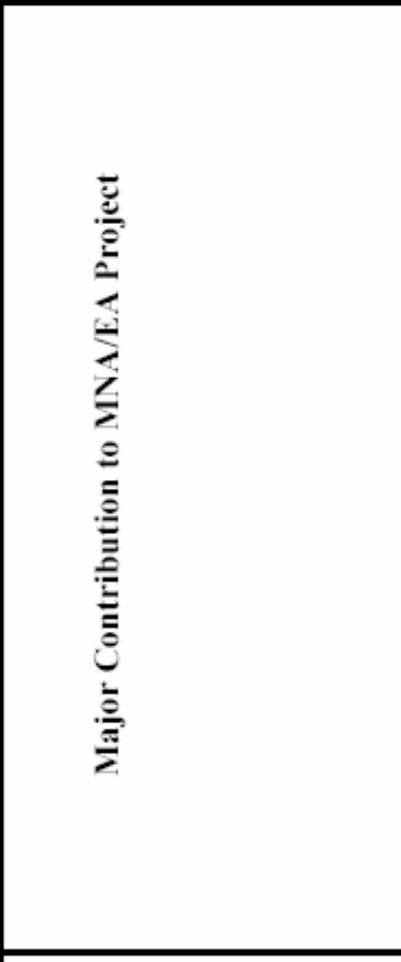 } & & 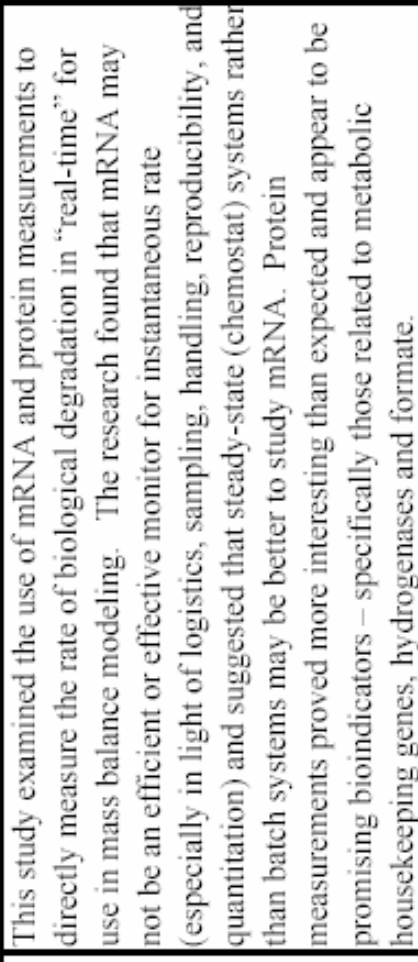 & 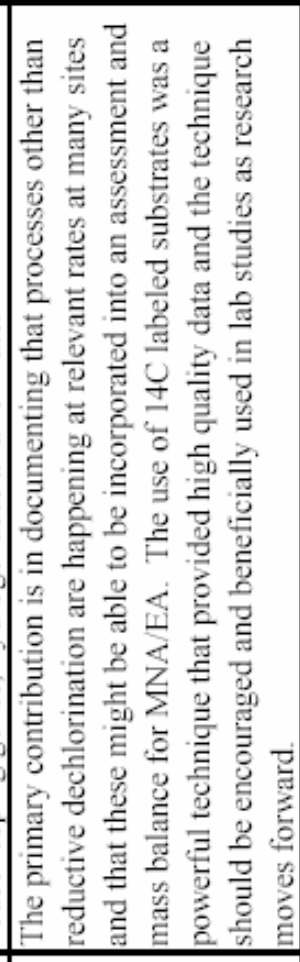 & 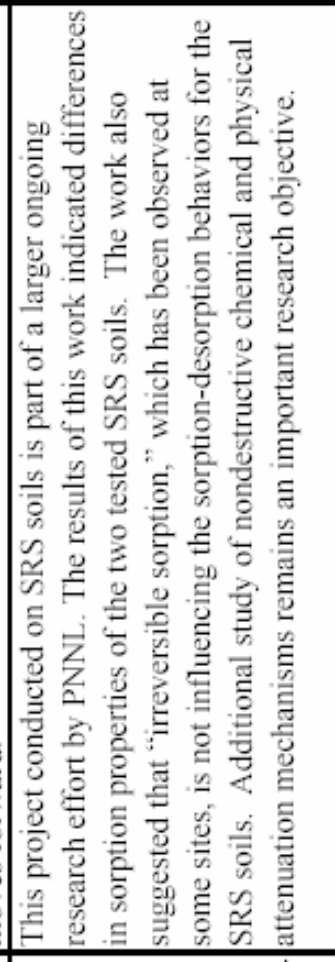 \\
\hline \multicolumn{2}{|c|}{ 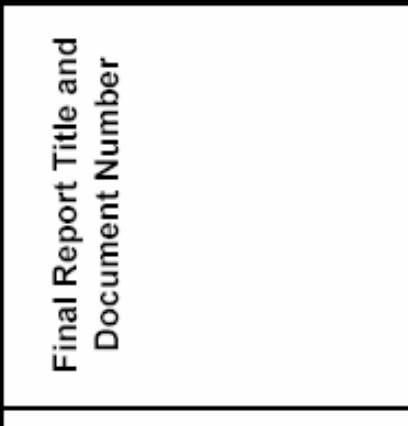 } & & 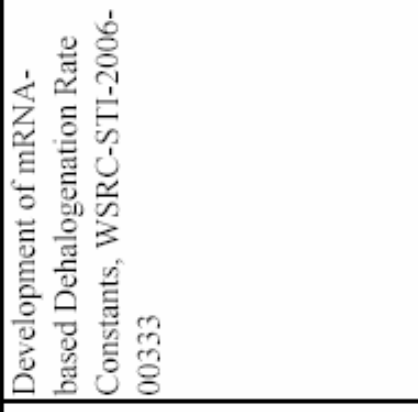 & 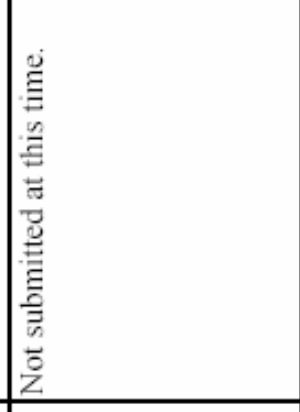 & 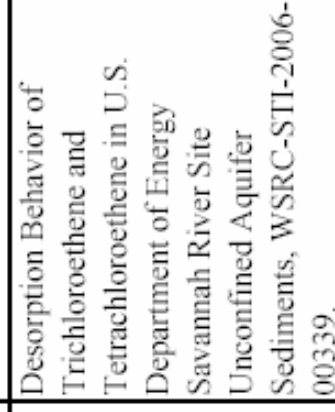 \\
\hline \multicolumn{2}{|c|}{ 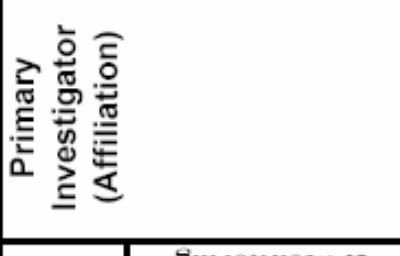 } & & 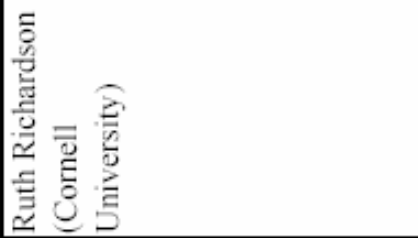 & 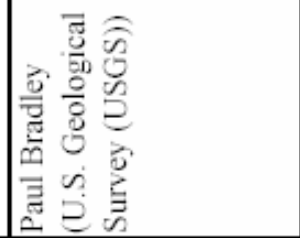 & 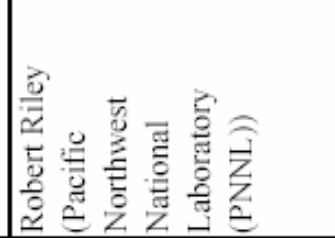 \\
\hline \multirow{3}{*}{$\begin{array}{l}\text { 음 } \\
\text { 음 }\end{array}$} & 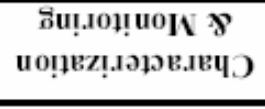 & & & & \\
\hline & 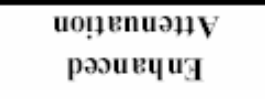 & & & & \\
\hline & әэuE|Eg SSEIN & & $\succ$ & $\succ$ & $\succ$ \\
\hline \multicolumn{2}{|c|}{$\stackrel{0}{i=}$} & 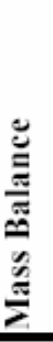 & 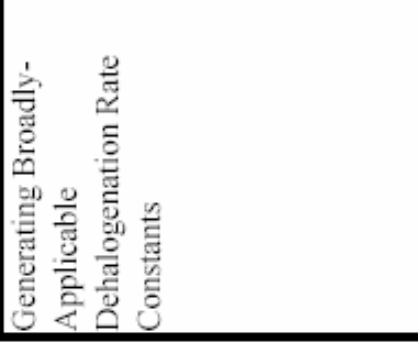 & 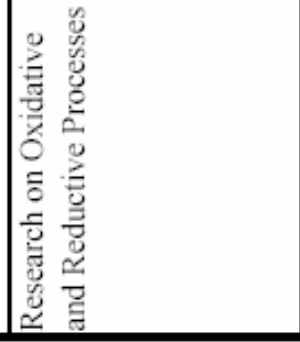 & 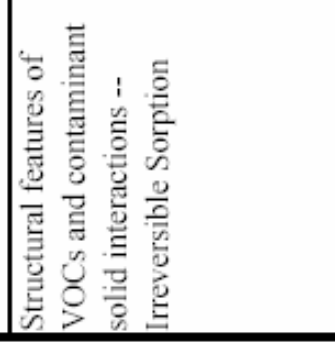 \\
\hline
\end{tabular}


WSRC-STI-2006-00377, Final

December 27, 2006

Page 55 of 68

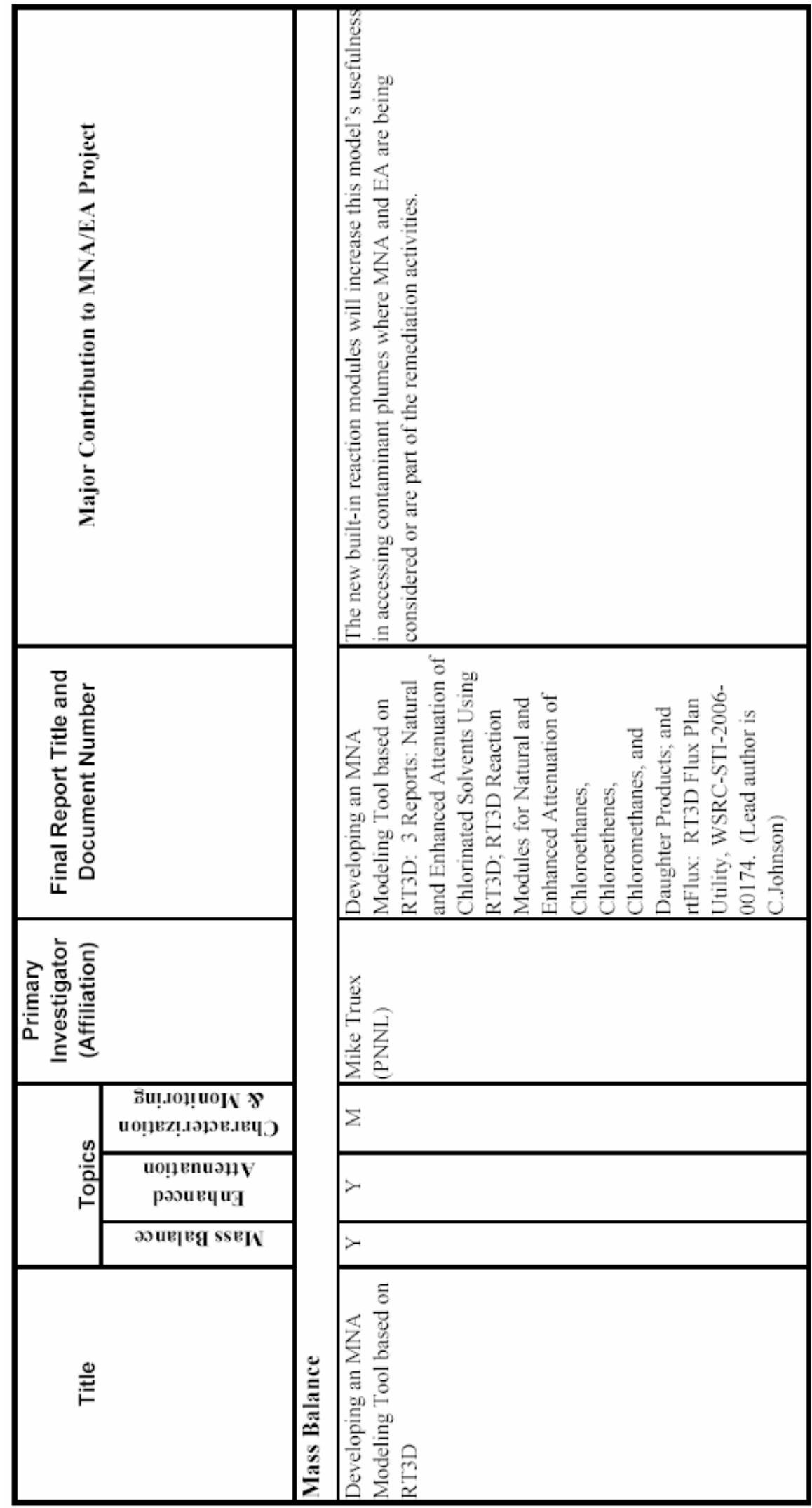




\begin{tabular}{|c|c|c|c|c|c|}
\hline 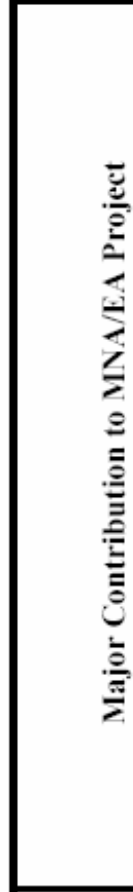 & & & 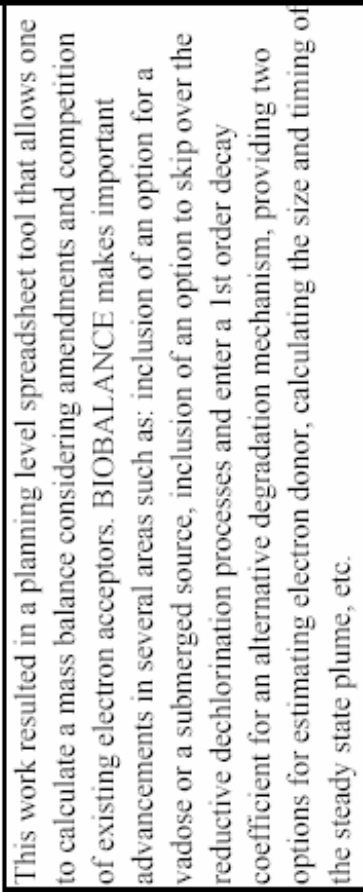 & 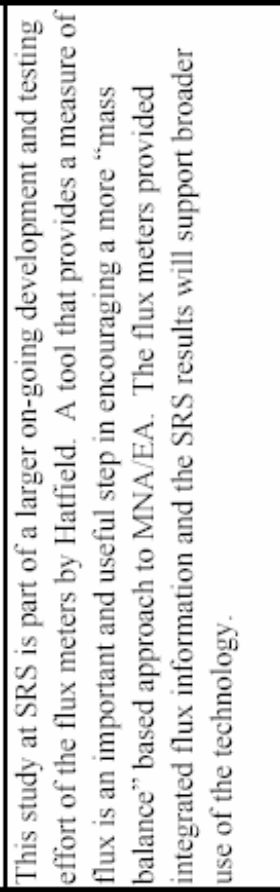 & 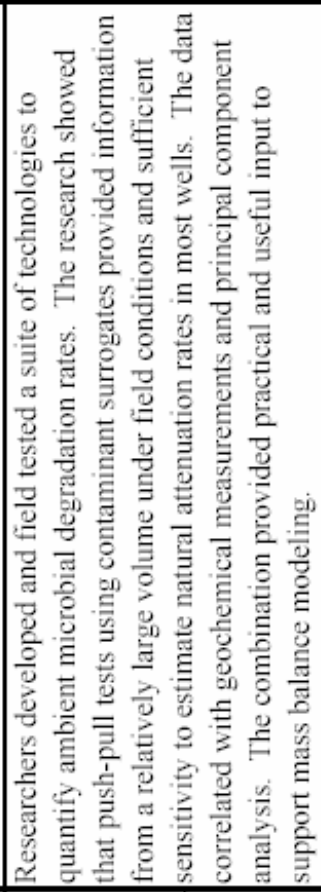 \\
\hline 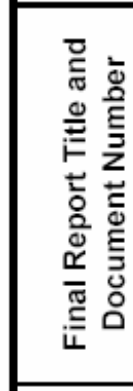 & & & 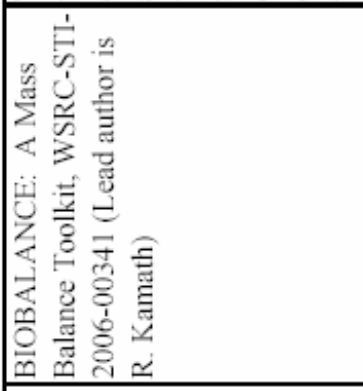 & 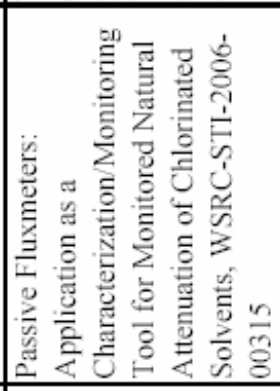 & 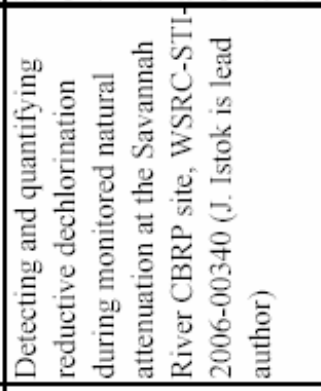 \\
\hline 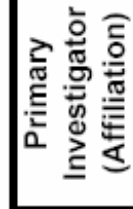 & & & 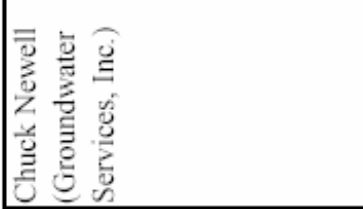 & 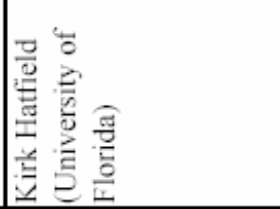 & 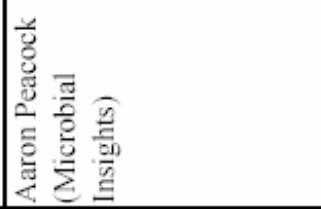 \\
\hline & 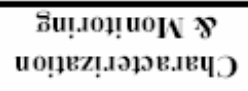 & & & $>$ & $>$ \\
\hline 음 & 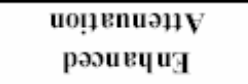 & & & & \\
\hline & әวนี|вg SSEIN & & $\succ$ & $>$ & $>$ \\
\hline$\stackrel{0}{\stackrel{D}{*}}$ & & 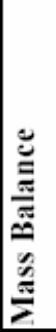 & 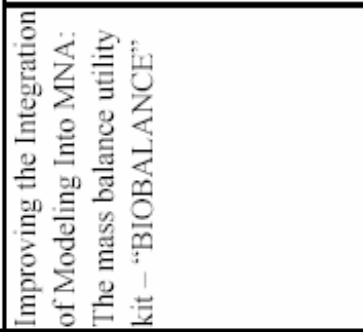 & 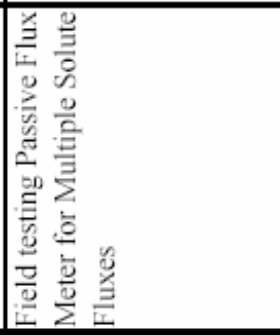 & 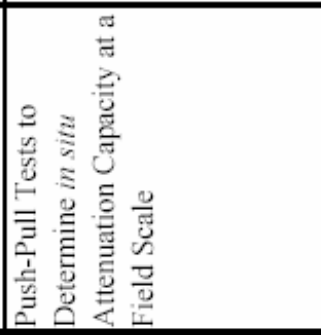 \\
\hline
\end{tabular}




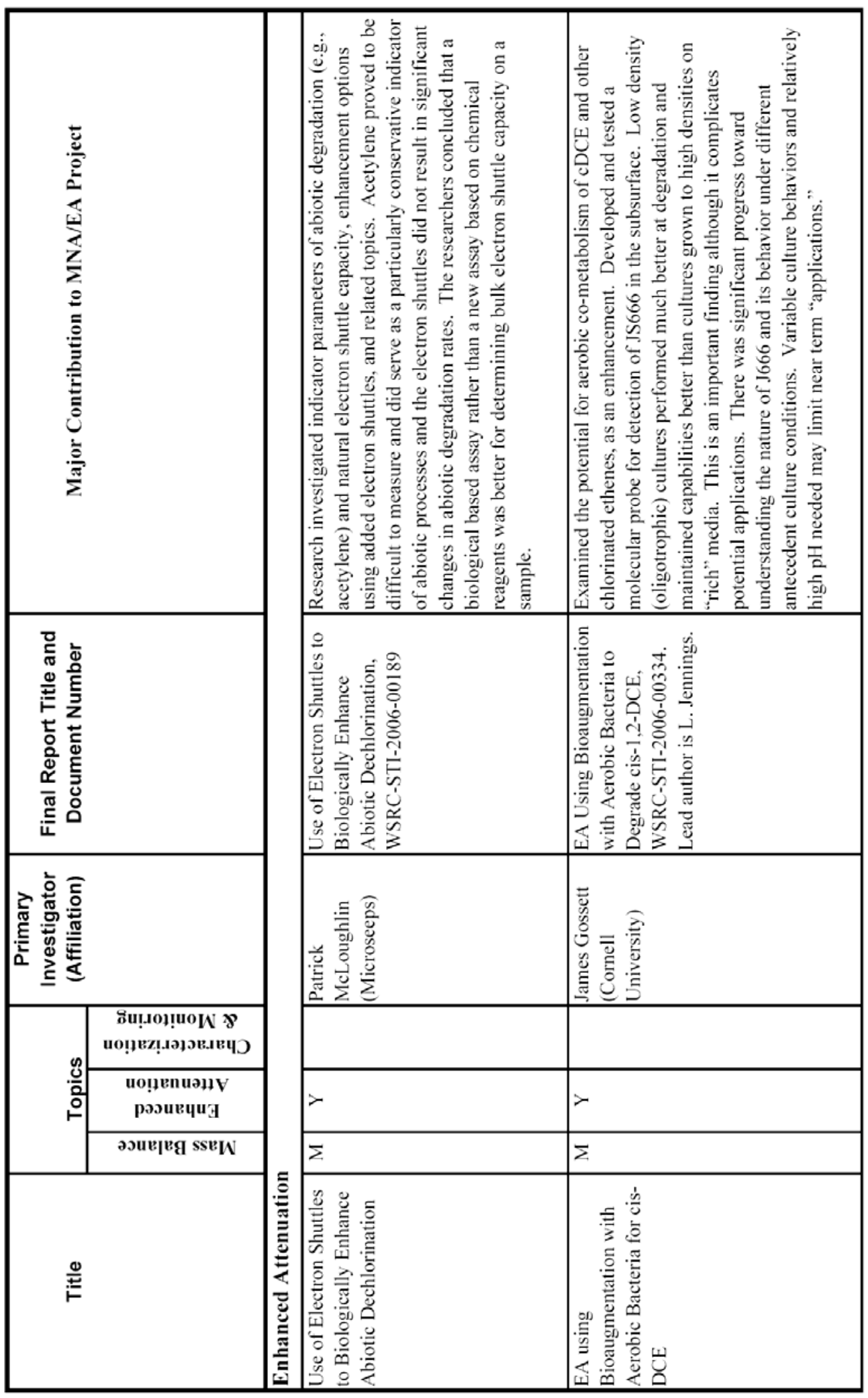




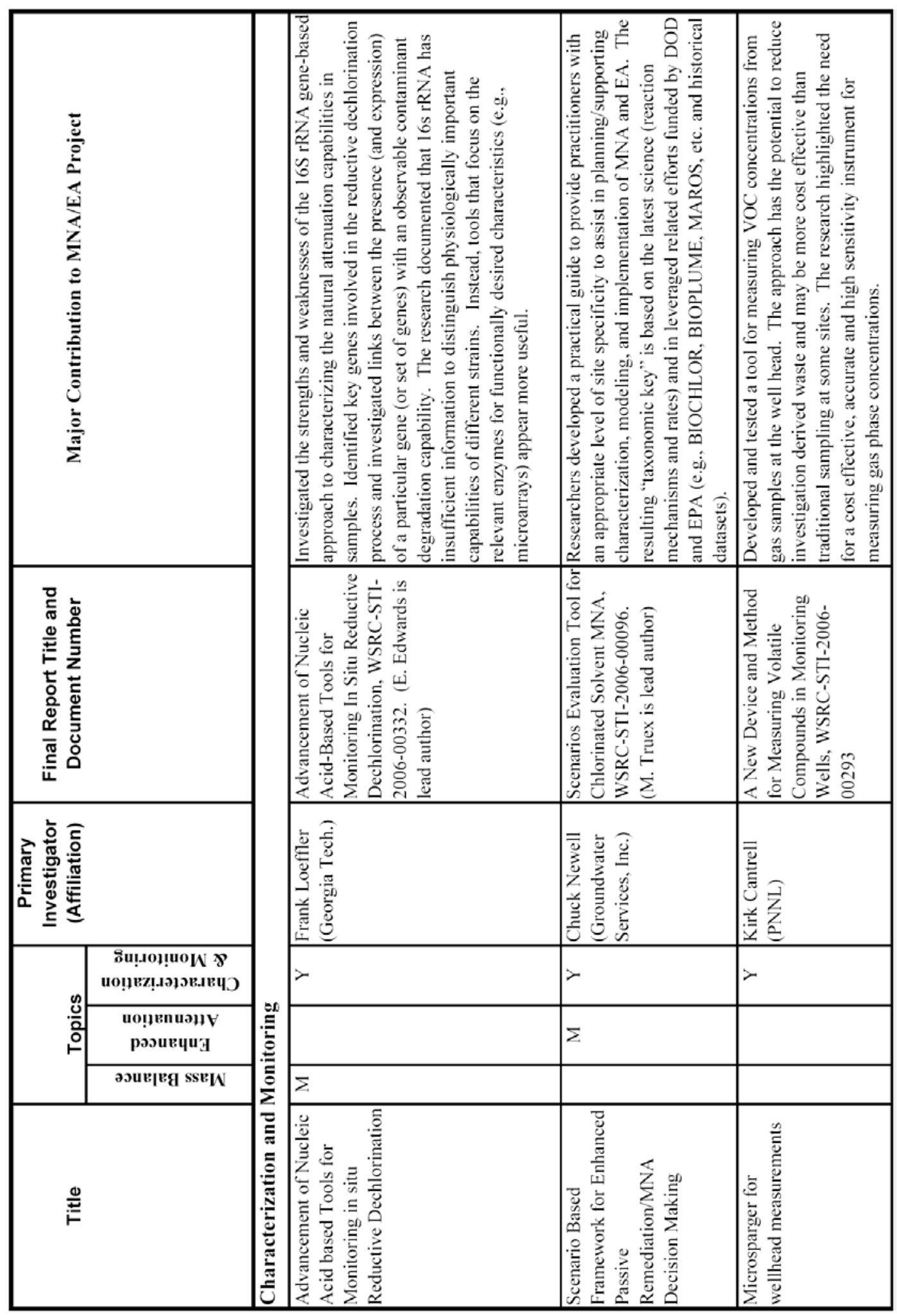




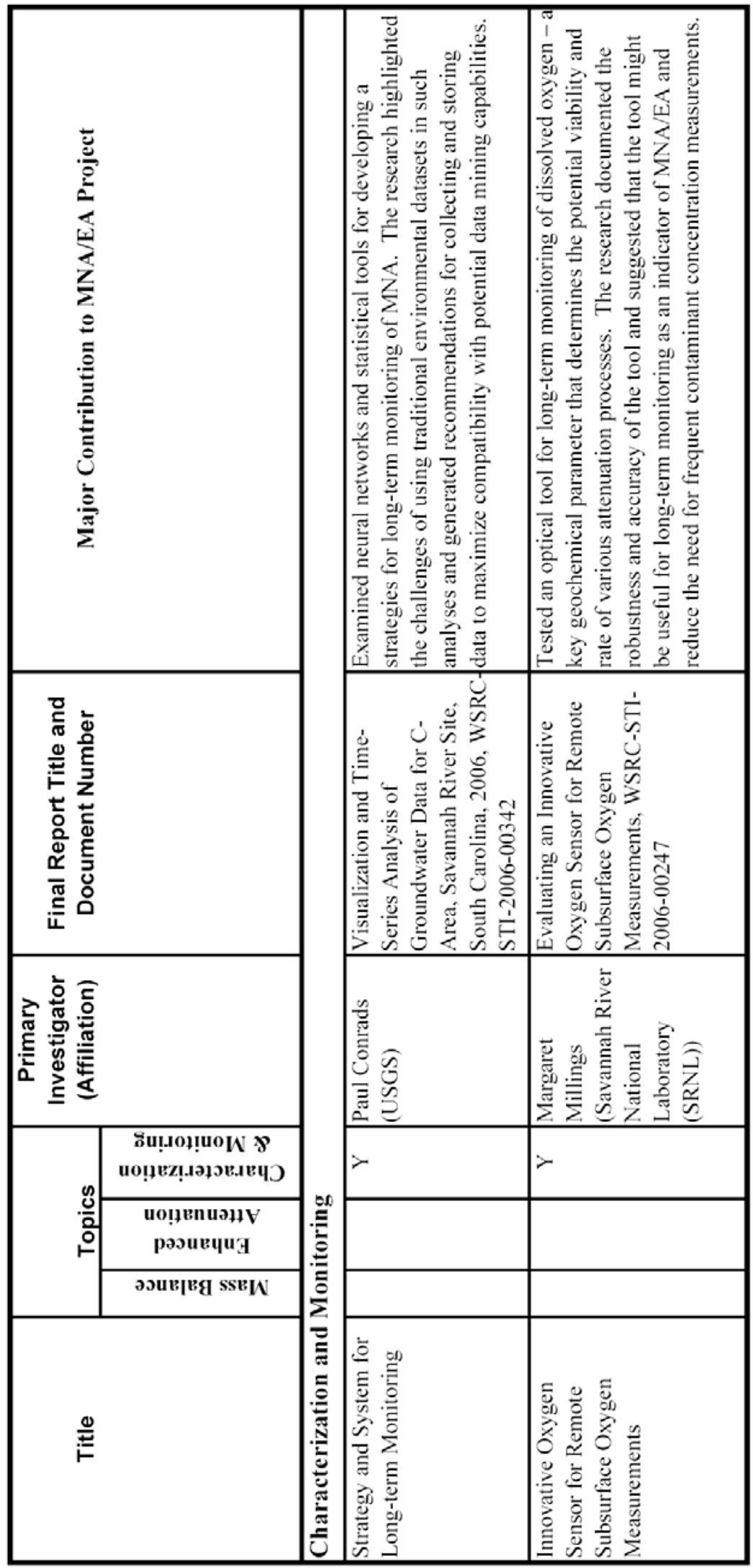




\section{Appendix B}

\section{Project Bibliography (2004-2006)}

Refereed/Peer Review Papers Published

Vangelas, Karen M., Brian B. Looney, Tom O. Early, Tyler Gilmore, Francis H. Chapelle, Karen M. Adams, Claire H. Sink. "Monitored Natural Attenuation of Chlorinated Solvents - Moving Beyond Reductive Dechlorination". Remediation, The Journal of Environmental Cleanup Costs, Technologies, and Techniques. Summer, 2006.

Vangelas, K. M. Remediation Forum Question to the Panel on the Acceptability of the term Integrated Mass Flux. Remediation, The Journal of Environmental Cleanup Costs, Technologies, and Techniques. Winter, 2005.

Sink, C. H., K. M. Adams, B. B. Looney, K. M. Vangelas, N. H. Cutshall. "Accelerating Environmental Cleanup at DOE Sites: Monitored Natural Attenuation/Enhanced Attenuation - A Basis for a New Paradigm". Federal Facilities Environmental Journal. 16(2):95-106.

McGuire, T. M., C. J. Newell, B. B. Looney, K. M. Vangelas, and C. H. Sink. "Historical Analysis of Monitored Natural Attenuation: A Survey of 191 Chlorinated Solvent Sites and 45 Solvent Plumes". Remediation, The Journal of Environmental Cleanup Costs, Technologies, and Techniques. 15(1):99-112.

Sink, C. H., K. M. Adams, B. B. Looney, K. M. Vangelas, N. H. Cutshall. "Accelerating Environmental Cleanup at DOE Sites: Monitored Natural Attenuation/Enhanced Attenuation - A Basis for a New Paradigm". Remediation, The Journal of Environmental Cleanup Costs, Technologies, and Techniques. 15(1):89-98.

\section{Conference Publications}

Platform Presentations

Looney, B. B., K. M. Vangelas, C. H. Sink. "Facilitating MNA and Enhanced Passive Remediation of Chlorinated Solvents". Remediation of Chlorinated and Recalcitrant Compounds, The Fourth International Conference. May $24-27,2004$.

Newell, C. J., T. M. McGuire, B. B. Looney, K. M. Vangelas. "Trends in Monitored natural Attenuation Application at Chlorinated Solvent Sites". Remediation of Chlorinated and Recalcitrant Compounds, The Fourth International Conference. May 24 - 27, 2004.

Chapelle, F. H., C. Journey, B. B. Looney, M. Heitkamp, R. Brigmon, D. Major, T. Early, T. H. Wiedemeier, T. Gilmore, G. Wein, C. H. Sink. “A Mass Balance Approach to Monitored Natural Attenuation”. Remediation of Chlorinated and Recalcitrant Compounds, The Fourth International Conference. May 24 - 27, 2004.

Major, D. W., M. Heitkamp, C. H. Sink. "Putting the Third Line of Evidence First - Advances in Molecular Technologies". Remediation of Chlorinated and Recalcitrant Compounds, The Fourth International Conference. May $24-27,2004$.

Gilmore, T., B. B. Looney, B. Riha, J. Waugh, C. H. Sink. "Characterization and Monitoring Strategy for Monitored Natural Attenuation". Remediation of Chlorinated and Recalcitrant Compounds, The Fourth International Conference. May 24 - 27, 2004. 
Adams, K. M., K. M. Vangelas, B.B. Looney, F. H. Chapelle, T. Early, T. Gilmore, C. H. Sink. "Monitored Natural Attenuation and Enhanced Attenuation for Chlorinated Solvent Plumes - It's All About Balance". ASCE World Water \& Environmental Resources Congress. May 15 - 19, 2005.

Raes, E.J., J. Istok, J. Jones, J. Fields, B.B. Looney, K. M. Vangelas, M. R. Millings, G. Davis, A. Peacock, J. Parker, J. Zhou. "Push-Pull Tests to Determine In Situ Site Wide Natural Attenuation Capacity and Microbial Activity at Savannah River CMP Pits and C-Area". The Eighth International In Situ and On-Site Bioremediation Symposium. June 6-9, 2005

C. J. Newell, J. A. Connor, S. K. Farhat, R. Kamath, D. Adamson, B. B. Looney, K. M.Vangelas. "Overview of Four Mass Flux Tools". National Groundwater Association Groundwater Summit. April 2005.

Chapelle, F. H., B. G. Campbell, B. B. Looney, T. H. Wiedemeier, Claire H. Sink. "Empirical and Deterministic Methods for Assessing Monitored Natural Attenuation". The Eighth International In Situ and On-Site Bioremediation Symposium. June 6 - 9, 2005

Sink, C.H. (moderator), T. Gilmore (moderator). Panel Members: B. B. Looney, F. H. Chapelle, T. H. Wiedemeier, C. J. Newell, D. W. Major, J. Kean, J. Istok, and K. Hatfield. Panel Title: Advances in Monitored Natural Attenuation for Chlorinated Solvents. The Fifth International Conference on Remediation of Chlorinated and Recalcitrant Compounds. May 22 - 25, 2006.

Kamath, R., C. J. Newell, D. Adamson, B. B. Looney, K. M. Vangelas. "Closing the Mass Balance on Sources, Donors, Competing Reactions, and Attenuation Processes at Chlorinated Solvent Sites". The Fifth International Conference on Remediation of Chlorinated and Recalcitrant Compounds. May 22 - 25, 2006.

Looney, B. B., K. M. Vangelas, C. H. Sink. "Natural Attenuation in the Balance - Evolution of a Good Idea...." The Fifth International Conference on Remediation of Chlorinated and Recalcitrant Compounds. May $22-25$, 2006.

Kean J., K. Wilson, K. M. Vangelas. "Monitored Natural Attenuation and Enhanced Attenuation: A National Overview - Results of an ITRC Survey". The Fifth International Conference on Remediation of Chlorinated and Recalcitrant Compounds. May 22 - 25, 2006.

Chapelle, F. H., B. B. Looney, T. H. Wiedemeier, C. H. Sink. "Using Mass and Energy Balance to Assess Monitored and Enhanced Natural Attenuation". The Fifth International Conference on Remediation of Chlorinated and Recalcitrant Compounds. May 22 - 25, 2006.

Early, T.O., B. B. Looney, K. M. Vangelas, M. Heitkamp, W.J. Waugh, G. Wein, D. Major, C. H. Sink. "Enhanced Attenuation: What is it and how does it fit into a remediation strategy?" National Groundwater Associations Groundwater Summit April 2006.

Kamath, R., C.J. Newell, D. Adamson, B. Looney and K. Vangelas. "Closing the Mass Balance on Sources, Donors, Competing Reactions, and Attenuation Processes at Chlorinated Solvent Sites". National Groundwater Associations Groundwater Summit April 2006.

Waugh, W.J., E. P. Glenn, R. P. Bush, and B. V. Danforth. "Enhanced Attenuation of Soil and Ground Water Using Desert Phreatophytes". National Groundwater Associations Groundwater Summit April 2006.

Wilson, K., J. Kean, K. Vangelas. "Enhanced Attenuation's Place in the Toolbox of Remedies for Chlorinated Organics: A Decision-Making Framework". National Groundwater Associations Groundwater Summit April 2006. 
Cutshall, N., T. Gilmore, T., B. B. Looney, K. M. Vangleas, K. M. Adams, and C. H. Sink, 2006.

Characterization and Monitoring of Natural Attenuation of Chlorinated Solvents in Ground Water: A Systems

Approach. 2006 Joint Assembly (American Geophysical Union). May 25, 2006. Baltimore.

Kamath, R., C. Newell, B. Looney, K.M. Vangelas, D. Adamson. "Closing the Mass Balance on Sources, Donors, Competing Reactions, and Attenuation Processes at Chlorinated Solvent Sites". National Groundwater Association 2006 Petroleum Hydrocarbons and Organic Chemicals in Ground Water®: Prevention, Assessment, and Remediation Conference. November 2006.

\section{Posters}

Vangelas, K. M., B. B. Looney, K. M. Adams, C. H. Sink. "Next Generation Monitored Natural Attenuation and Enhanced Attenuation of Chlorinated Solvents". The Eighth International In Situ and On-Site Bioremediation Symposium. June 6-9, 2005

Early, T. O., B.B. Looney, M. Keitkamp, R.D. Borden, G.R. Wien, T.H. Wiedemeier, D. W., Major, C. H. Sink. "Enhancements to Natural Attenuation Processes: New Approaches to Plume Management". The Eighth International In Situ and On-Site Bioremediation Symposium. June 6 - 9, 2005

Kean J., K. Wilson, K. M. Vangelas. "Monitored Natural Attenuation: A National Survey - Results of an ITRC Survey”. SERDP Partners in Environmental Technology, Technical Symposium \& Workshop. November $29-$ December 1, 2005.

Truex, M., C. Newell, B. B. Looney, K. M. Vangelas. "Scenarios: Tool for Monitored Natural Attenuation Evaluation". The Fifth International Conference on Remediation of Chlorinated and Recalcitrant Compounds. May $22-25,2006$.

Raes, E. J., J. Istok, J. Fields, J. Jones, M. R. Millings, K. M. Vangelas, B. B. Looney, A. Peacock, G. Davis, J. Parker, J. Zhou. "Push-Pull Tests to Distinguish Abiotic and Biotic Degradation Rates for Mass Balance Determinations of In Situ Natural Attenuation Capacity". The Fifth International Conference on Remediation of Chlorinated and Recalcitrant Compounds. May 22 - 25, 2006.

\section{Stakeholder and Regulator Communications}

2005 Annual Project Update to Tennessee Department of Environmental Control and Staff of the Oak Ridge Facility

Early, T. O., K. M. Vangelas, B. B. Looney, C. H. Sink, K. M. Adams, T. Gilmore, M. Ankeny. "MNA/EA for Chlorinated Solvents Project - Annual Update on FY05 Activities”. November 3, 2005

Semi-annual Project Update to Interstate Technology and Regulatory Council - Enhanced Attenuation Chlorinated Organics Team

Vangelas, K. M., B.B. Looney, C. H. Sink, T. O. Early. MNA/EA for Chlorinated Solvents Project - Update on Enhancements Document. Interstate Technology and Regulatory Council, Enhanced Attenuation Chlorinated Organics, Fall Meeting, October 2005.

Vangelas, K. M., B.B. Looney, C. H. Sink. MNA/EA for Chlorinated Solvents Project - FY06 Activity Summary. Interstate Technology and Regulatory Council, Enhanced Attenuation Chlorinated Organics, Fall Meeting, October 2005. 
WSRC-STI-2006-00377, Final

December 27, 2006

Page 63 of 68

Kamath, R., C. J. Newell, B. B. Looney, K. M. Vangelas. "BIOBALANCE - A Mass Balance Based Screening Tool". Interstate Technology and Regulatory Council, Enhanced Attenuation Chlorinated Organics, Fall Meeting, October 2005.

Semi-annual Project Update to Savannah River Site Citizens Advisory Board Committee

Looney, B. B., K. M. Vangelas, K. M. Adams. "Natural and Enhanced Attenuation - assuring sustainable environmental protection". Facility Disposition and Site Remediation Committee of the Savannah River Site Citizens Advisory Board. August 23, 2005.

Semi-annual Project Update to Interstate Technology and Regulatory Council - Enhanced Attenuation Chlorinated Organics Team

Sink, C. H., B. B. Looney, K. M. Vangelas. "Monitored Natural Attenuation and Enhanced Attenuation for Chlorinated Solvents Project - Overview". Interstate Technology and Regulatory Council - Enhanced Attenuation Chlorinated Organics Mtg. May 10, 2005.

Vangelas, K. M., B. B. Looney, C. H. Sink. "Overview of MNA/EA for Chlorinated Solvents Project Research Studies". Interstate Technology and Regulatory Council - Enhanced Attenuation Chlorinated Organics Mtg. May 10, 2005.

Looney, B. B., K. M. Vangelas, C. H. Sink. "MNA and EA for Chlorinated Solvents Project - Overview of 3 Key Technical Areas". Interstate Technology and Regulatory Council - Enhanced Attenuation Chlorinated Organics Mtg. May 10, 2005

Invited Presentation to Annual Meeting of the Florida Dry Cleaner Consortium

Looney, B. B., K. M. Vangelas. "Attenuation of Chlorinated Solvents: Technical Directions and Enhancements". Florida Department of Environmental Protection Hazardous Waste Cleanup Section hosted annual Hazardous Waste Cleanup Contractor Workshop for Dry Cleaner Fund Regulators and Contractors. Feb. 2005.

2004 Annual Presentation to EPA Region IV

Vangelas, K. M., B. B. Looney, K. Adams. "Alternatives for Accelerated Risk Reduction Through Natural and Enhanced Attenuation of Chlorinated Ethenes". U.S. Environmental Protection Agency, Region IV. Atlanta, GA. December 15, 2004.

Vangelas, K. M., B. B. Looney, C. H. Sink. "Overview of MNA/EA for Chlorinated Solvents Project Research Studies”. U.S. Environmental Protection Agency, Region IV. Atlanta, GA. December 15, 2004.

Invited Presentation to the Savannah River Site Citizens Advisory Board

Looney, B. B., K. M. Vangelas, K. M. Adams, C. H. Sink. Savannah River Site Citizens Advisory Board Meeting. November, 15, 2004.

Semi-annual Project Update to Interstate Technology and Regulatory Council - Enhanced Attenuation Chlorinated Organics Team

Vangelas, K. M., B. B. Looney, C. H. Sink. "Scenario Based Framework for MNA/Enhanced Attenuation Decision Making - Work in Progress". Interstate Technology and Regulatory Council - Enhanced Attenuation Chlorinated Organics Mtg. October 27, 2004.

Invited Presentation to the US EPA Robert S. Kerr Environmental Research Center

Looney, B. B., K. M. Vangelas, C. H. Sink. "Attenuation of Chlorinated Solvents: Expanding the Science Base”. EPA Robert S. Kerr Environmental Research Center - Technical Talk. October 26, 2004. 
Semi-annual Presentation to the Savannah River Site Citizens Advisory Board Committee

Looney, B.B., K. M. Vangelas, K. M . Adams, C. H. Sink. "Monitored Natural Attenuation and Enhanced Attenuation for Chlorinated Solvents Technology Alternative Project". Savannah River Site Citizens Advisory Board Meeting. September 27, 2004.

\section{Annual Presentation to Tennessee Department of Environmental Control}

Vangelas, K. M., B. B. Looney, K. Adams. "Alternatives for Accelerated Risk Reduction Through Natural and Enhanced Attenuation of Chlorinated Ethenes". Tennessee Department of Environmental Control. September 22, 2004.

Vangelas, K. M., B. B. Looney, C. H. Sink. “Overview of MNA/EA for Chlorinated Solvents Project Research Studies”. Tennessee Department of Environmental Control. September 22, 2004.

2004 Annual Presentation to South Carolina Department of Health and Environmental Control and Staff of the Oak Ridge Facility

Vangelas, K. M., B. B. Looney, K. Adams. "Alternatives for Accelerated Risk Reduction Through Natural and Enhanced Attenuation of Chlorinated Ethenes". South Carolina Department of Health and Environmental Control. Columbia, SC. September 14, 2004.

Vangelas, K. M., B. B. Looney, C. H. Sink. “Overview of MNA/EA for Chlorinated Solvents Project Research Studies". South Carolina Department of Health and Environmental Control. Columbia, SC. September 14, 2004.

2004 Annual Presentation to Savannah River Site End User Organization

Vangelas, K. M., B. B. Looney, K. M. Adams, C. H. Sink. "Monitored Natural Attenuation and Enhanced Attenuation for Chlorinated Solvents Technology Alternative Project". Presentation to Soils and Groundwater Closure Project (end user organization). August 17, 2004.

Semi-annual Presentation to the Savannah River Site Citizens Advisory Board Committee

Looney, B.B., K. M. Vangelas, K. M . Adams, C. H. Sink. "Monitored Natural Attenuation and Enhanced Attenuation for Chlorinated Solvents Technology Alternative Project - Update". Facilities Disposition and Site Remediation Committee of the Savannah River Site Citizens Advisory Board. August 17, 2004.

Initial Project Presentation to Interstate Technology and Regulatory Council - Enhanced Attenuation Chlorinated Organics Team

Sink, C. H., K. Adams, B. B. Looney, K. M. Vangelas, T. Wiedemeier, T. Early, F. Chapelle, J. Waugh, D. Major, T. Gilmore, M. Heitkamp, G. Wein. "Monitored Natural Attenuation and Enhanced Passive Remediation (MNA/EPR) for Chlorinated Solvents Technology Alternative Project". Interstate Technology and Regulatory Council - Enhanced Attenuation Chlorinated Organics. March 24, 2004.

\section{Presentation to the Hanford Advisory Board Subcommittee}

Gilmore, T. "Monitored Natural Attenuation and Enhanced Passive Remediation for Chlorinated Solvents Technology Alternative Project". Presentation to Hanford Advisory Board. MNA Subcommittee. February 2004.

\section{Project Newsletter (electronic) available at $\underline{w w w . s r s . g o v}$}

K.M. Vangelas (editor) Natural Attenuation Monitor, March 2006.

K. M. Vangelas (editor) Natural Attenuation Monitor. August 2005.

K. M. Vangelas (editor) Natural Attenuation Monitor. March 2005.

K. M. Vangelas (editor) Natural Attenuation Monitor. August 2004.

K. M. Vangelas (editor) Natural Attenuation Monitor. March 2004. 


\section{Articles in the Trade and Public Press}

"National Program Advances Knowledge of Natural Attenuation". DOE Pulse, electronic newsletter from the Office of Science, May 15, 2006.

"Cleanup Program Readying Comprehensive Look At Attenuation”. Weapons Complex Monitor. Exchange Monitor Publications, Inc. October 24, 2005.

"New Software Seeks to Guide Decisions on Subsurface Cleanup". Weapons Complex Monitor. Exchange Monitor Publications, Inc. October 3, 2005.

"Scientists let nature do its work". The Augusta Chronicle. December 4, 2004.

"Project Seeks to Enhance MNA." Materials Performance. NACE International, The Corrosion Society. February 2004.

"Waste Office Split Over Emerging Remedies for Chlorinated Solvents.” Inside EPA. Inside Washington Publishers. December 22, 2003.

"National Program Advances Knowledge of Natural Attenuation.” DOE Pulse. Office of Science, electronic publication. May 15, 2006.

\section{Project Documents available from Westinghouse Savannah River Company (contact Karen.vangelas@srnl.doe.gov)}

Looney, B.B., F.H. Chapelle, T.O. Early, K. M. Vangelas, K. Adams, and C. H. Sink, 2006. Mass Balance: A Key to Advancing Monitored and Enhanced Attenuation for Chlorinated Solvents. WSRC-STI-2006-00082.

Early. T. O., B. Borden, M. Heitkamp, B. B. Looney, D. Major, W. J. Waugh, G. Wein, T. H. Wiedemeier, K. M. Vangelas, K. M Adams and C. H. Sink, 2006. Enhanced Attenuation: A Reference Guide on Approaches to increase the Natural Attenuation Capacity of a System, WSRC-STI-2006-00083, Rev. 1.

Gilmore, T., B. B. Looney, N. Cutshall, D. Major, T. Wiedemeier, F. H. Chapelle, M. Truex, T. Early, M. Heitkamp, J. Waugh, D. Peterson, G. Wein, C. Bagwell, M. Ankeny, K. M. Vangelas, K. M. Adams, and C. H. Sink, 2006. Characterization and Monitoring of Natural Attenuation of Chlorinated Solvents in Ground Water: A Systems Approach. WSRC-STI-2006-00084, Rev. 1.

\section{Project Documents available at the Department of Energy's Office of Scientific and Technical Information Website (www.OSTI.gov)}

Chapelle, F., T. Early, T. Gilmore, M. Heitkamp, B. Looney, D. Major, G. Wein, T. Wiedemeier. 2004. "Natural and Passive Remediation of Chlorinated Solvents: Critical Evaluation of Science and Technology Targets". WSRC-TR-2003-00328. Westinghouse Savannah River Company, Aiken, SC. Report available at www.osti.gov.

Chapelle, F., R. Brigmon, T. Early, K. Finneran, T. Gilmore, M. Heitkamp, C. Journey, B. Looney, D. Major, R. Riley, G. Wein, T. Wiedemeier. 2003. "Baseline Natural Attenuation Processes: Lines of Inquiry Supporting Monitored Natural Attenuation of Chlorinated Solvents". WSRC-TR-2003-00329. Westinghouse Savannah River Company, Aiken, SC. Report available at www.osti.gov. 
WSRC-STI-2006-00377, Final

December 27, 2006

Page 66 of 68

\section{Project Website}

A project website is under development with the support of MSE and is located at www.mnaeacvocs.com. This website will house project products. 


\section{Appendix C}

\section{Monitored Natural Attenuation/Enhanced Attenuation for Chlorinated Solvents Project Team}

\section{Members of the Technical Working Group}

Brian B. Looney. Chairperson of the Technical Working Group. Brian is a senior fellow environmental engineer with the Savannah River National Laboratory. In this position for the past 23 years, he has developed and deployed a wide range of environmental characterization and clean-up methods. Successful research includes uses of environmental horizontal drilling, improved remediation tools (e.g., sparging, bioremediation, and thermal methods), and improved characterization tools (e.g., tracer testing, soil gas methods and geophysics).

Thomas $O$. Early. As well as a member of the Technical Working Group, Tom has been the project's liaison with the Department of Energy's Oak Ridge site. Tom is presently a senior scientist with GEO Consultants, LLC. In 2005, he retired after 18 years of service from Oak Ridge National Laboratory. Tom's area of emphasis is groundwater geochemistry and DNAPL source zone treatment.

Tyler Gilmore. As well as a member of the Technical Working Group, Tyler has been the project's liaison with the Department of Energy's Hanford site. He is the Technical Group Manager for the Field Hydrology and Chemistry group at the Pacific Northwest National Laboratory. He has been working on groundwater and soil remediation technology development for 18 years and has extensive experience in directing and operating laboratory and field operations in the application and development of novel and innovative methods and technologies.

Francis H. Chapelle. Frank is a research hydrologist for the U.S. Geological Survey. His research over the years has focused on how microbial processes affect the chemical quality of groundwater in both pristine and contaminated ground-water systems. Frank has been the lead contributor to the mass balance concepts.

Jeff Ross. Jeff is a senior scientist and technical lead for the Soil and Groundwater Closure Project at the Savannah River Site. He has worked for 19 years in the characterization and remediation of soil and groundwater contamination.

Mark Ankeny. Mark has fifteen years leading and conducting research and development and laboratory management; laboratory and field research concerning soil physical and hydraulic properties; synthesis of physical, chemical, and biological processes in environmental applications; and design of field and laboratory instrumentation. He holds eight patents related to measurement, monitoring, and control of environmental processes. Mark is currently working at the Idaho National Laboratory.

Michael Heitkamp. Michael is a Research Manager for the Environmental Biotechnology Section of the Savannah River National Laboratory. He has over 26 years of experience in environmental microbiology and biotechnology. His training and experience span microbial ecology, microbial physiology, molecular biology, chemical biodegradation and laboratory, pilot-scale and field testing of novel microbial technologies for biotreatment of water, air and soils.

David W. Major. David is a principal of GeoSyntec Consultants, Inc. He is a recognized expert on the in situ biodegradation of chlorinated solvents in natural or engineered environments.

W. Jody Waugh. Jody is a principal scientist with S. M. Stoller Corporation at the DOE's Environmental Sciences Laboratory in Grand Junction, Colorado. He has more than 20 years of research and application experience 
monitoring the performance of existing engineered covers in arid environments and developing phytoremediation technologies for air-land applications. Jody is currently working on long-term stewardship issues of the DOE Office of Legacy Management.

Gary Wein. Gary is currently the Executive Director for the Highlands-Cashiers Land Trust in Highlands, NC. $\mathrm{He}$ is also affiliated with the University of Georgia's Savannah River Ecology Laboratory where he has nearly 20 years experience with the Savannah River Site's ecosystems dealing with basic ecology and remediation of contaminated sites. As a former employee for Bechtel Savannah River Inc., Gary represented the SRS's endusers.

Todd H. Wiedemeier is president of T.H. Wiedemeier and Associates. He has over 14 years experience in remediation and has conducted natural attenuation and bioremediation feasibility studies at more than 100 sites contaminated with fuel hydrocarbons, MTBE, and chlorinated solvents.

\section{Ex Officio Project Members}

Karen M. Vangelas. Operations Lead for the MNA/EA Project. Karen is a fellow engineer with the Savannah River National Laboratory. She has led various characterization projects for chlorinated solvents and tritium and technology demonstrations associated with chlorinated solvent contamination.

Karen M. Adams. Savannah River Site Manager for the MNA/EA Project. Karen has project management responsibilities for remediation of soil and groundwater for the Savannah River Site Operations Office, U.S. Department of Energy.

Claire H. Sink. Project Manager for the MNA/EA Project. Claire is recently retired from the DOE Office of Groundwater and Soil Remediation. Within the DOE, she held research program management, oversight of research laboratories, and technology policy positions. Prior to joining the federal government, she was affiliated with the private sector and academia.

Norman H. Cutshall. Norm is a consultant, retired from the Oak Ridge National Laboratory. He has 35 years' experience in the application of environmental science principles to environmental management.

Ken Lovelace. Ken is with the U.S. Environmental Protection Agency Office of Solid Waste and Emergency Response - Office of Superfund Remediation and Technology Information in Washington, DC. Ken is recognized for his experience in developing MNA policy and in providing broad-based technical and policy support within EPA. He was instrumental in providing guidance to the DOE MNA/EA project to help assure that the developments were consistent with current and emerging EPA guidance. 